Florida International University FIU Digital Commons

$11-10-2010$

\title{
An Analysis of Efficiency and Melt Curve Effects on Quantitative Polymerase Chain Reaction (qPCR) Inhibition
}

Robyn E. Thompson

Florida International University, rthom007@fiu.edu

DOI: $10.25148 /$ etd.FI10122001

Follow this and additional works at: https://digitalcommons.fiu.edu/etd

\section{Recommended Citation}

Thompson, Robyn E., "An Analysis of Efficiency and Melt Curve Effects on Quantitative Polymerase Chain Reaction (qPCR) Inhibition" (2010). FIU Electronic Theses and Dissertations. 329.

https://digitalcommons.fiu.edu/etd/329 


\section{FLORIDA INTERNATIONAL UNIVERSITY \\ Miami, Florida}

AN ANALYSIS OF EFFICIENCY AND MELT CURVE EFFECTS ON QUANTITATIVE POLYMERASE CHAIN REACTION (QPCR) INHIBITION

A thesis submitted in partial fulfillment of the

requirements for the degree of

MASTER OF SCIENCE

in

FORENSIC SCIENCE

by

Robyn E. Thompson 
To: Dean Kenneth G. Furton

College of Arts and Sciences

This thesis, written by Robyn E. Thompson, and entitled An Analysis of Efficiency and Melt Curve Effects on Quantitative Polymerase Chain Reaction (qPCR) Inhibition, having been approved in respect to style and intellectual content, is referred to you for judgment.

We have read this thesis and recommend that it be approved.

DeEtta Mills

George Duncan

Bruce McCord, Major Professor

Date of Defense: November 10, 2010

The thesis of Robyn E. Thompson is approved.

\begin{tabular}{r}
$\begin{array}{r}\text { Dean Kenneth G. Furton } \\
\text { College of Arts and Sciences }\end{array}$ \\
\hline Interim Dean Kevin O'Shea \\
University Graduate School
\end{tabular}

Florida International University, 2010 


\section{DEDICATION}

I dedicate this thesis to my parents Stacey and Karen Thompson have given me utmost encouragement and support and strength to complete another chapter of my life. I thank you for the sacrifices you have made to make this possible. I am truly blessed. 


\section{ACKNOWLEDGMENTS}

I would first like to thank God, through whom all things are possible. My deepest gratitude to my research advisor, Dr. Bruce McCord, for providing me the opportunity to be a part of his research group, believing in me and making my dream a reality. This thesis would not have been possible without your guidance, optimism and dedication to this project. To the members of my committee, Dr. George Duncan and Dr. DeEtta Mills, I thank you for taking an interest in my research and for your professional inputs. I would also like to thank Dr. McCord's former doctoral students, Dr. John Butler, for setting the foundation and giving insight to forensic applications, and Kerry Opel, whose previous studies in this area of research has been a tremendous help. I would like to thank the National institute of Justice (NIJ) for funding this project and to the members of Promega

Corporation and Qiagen for their technical support. To my fellow lab mates, I thank you for your constant assistance. 


\begin{abstract}
OF THE THESIS
AN ANALYSIS OF EFFICIENCY AND MELT CURVE EFFECTS ON QUANTITATIVE POLYMERASE CHAIN REACTION (QPCR) INHIBITION
\end{abstract}

by

Robyn E. Thompson

Florida International University, 2010

Miami, Florida

\title{
Professor Bruce McCord, Major Professor
}

Real-time or quantitative PCR (qPCR) is an innovative method used to determine the amount of amplifiable DNA in a biological sample. Typically, a fluorescent dye is introduced during thermal cycling, causing a change in fluorescent output as the doublestranded DNA (dsDNA) product accumulates. Both TaqMan ${ }^{\circledR}$ and Plexor HY System methods detect PCR inhibition through the monitoring of internal control sequences. Alternatively, SYBR ${ }^{\circledR}$ Green and Plexor detect inhibition through melt curve effects.

Previous work using $\mathrm{SYBR}^{\circledR}$ Green intercalation has demonstrated that inhibitors can affect melt curves differently depending on their structure and mode of action. Inhibitors that bind DNA can cause melt curve shifts while those primarily affecting Taq polymerase do not. Unlike $\mathrm{SYBR}^{\circledR}$ Green, Plexor dyes are fluorescently linked to a modified base, 5'-methylisocytosine (iso-dC), adjacent to the $5^{\prime}$ end of the dsDNA. This produces minimal interference in dsDNA structure making it an ideal procedure for measuring these effects. In this study, inhibition of qPCR was evaluated by observing the effects of various inhibitor concentrations and amplicon lengths on DNA amplification. 


\section{TABLE OF CONTENTS}

CHAPTER

PAGE

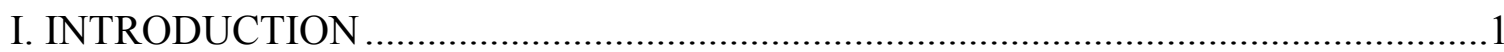

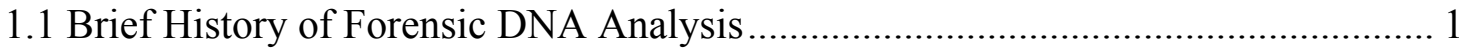

II. QUANTITATIVE POLYMERASE CHAIN REACTION (qPCR) .......................... 10

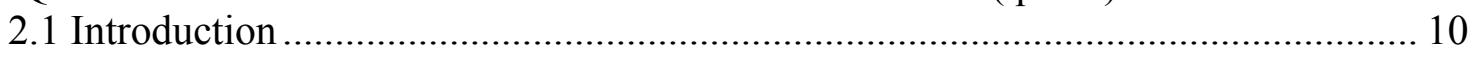

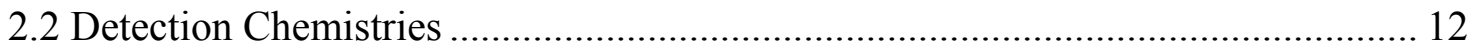

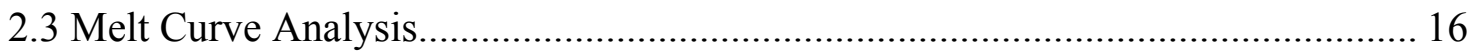

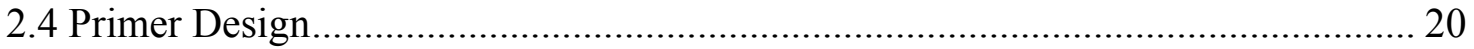

III. POLYMERASE CHAIN REACTION (PCR) INHIBITION ...................................22

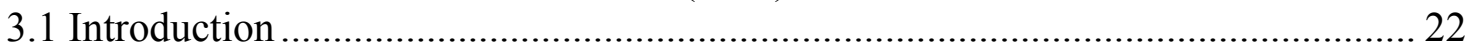

3.2 Common Polymerase Chain Reaction (PCR) Inhibitors.................................... 23

3.3 Mechanisms of Polymerase Chain Reaction (PCR) Inhibition............................. 29

3.4 Methods to Overcome Inhibition .................................................................... 30

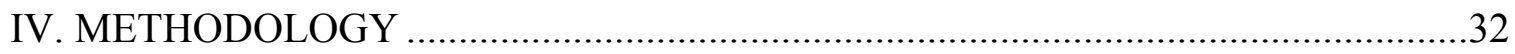

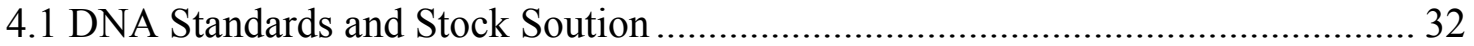

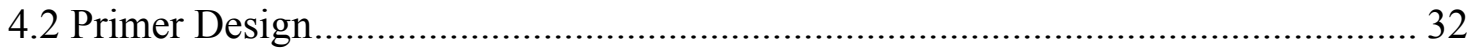

4.3 Real-Time Polymerase Chain Reaction (PCR) Analysis .................................... 33

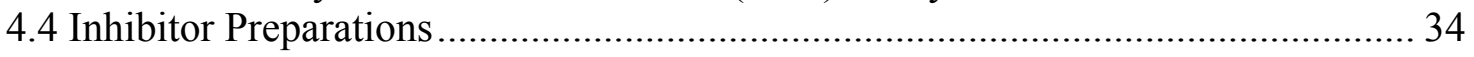

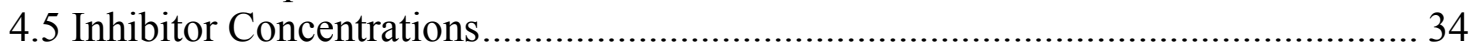

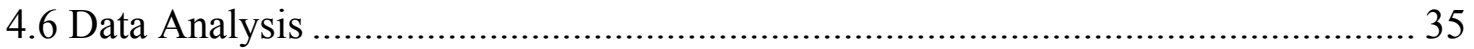

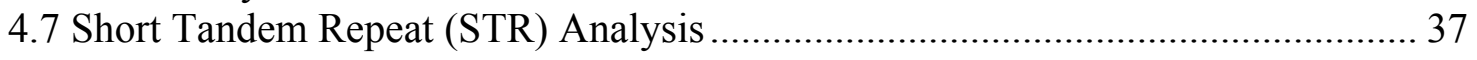

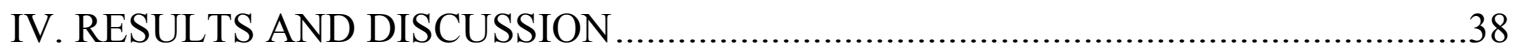

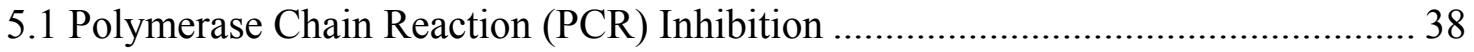

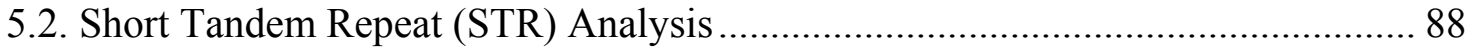

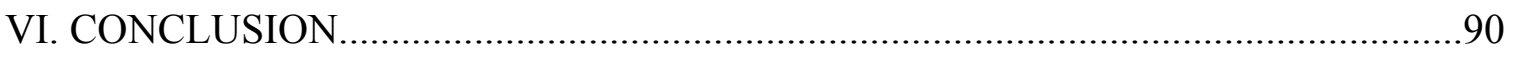

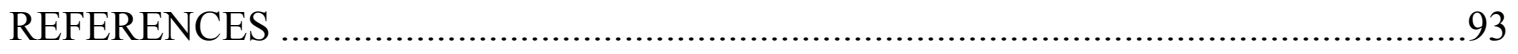

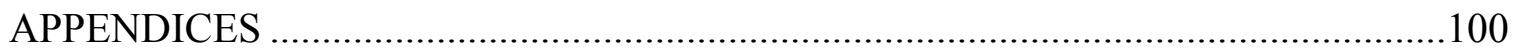




\section{LIST OF FIGURES}

FIGURE

PAGE

Figure 1-1: Schematic of a capillary electrophoresis instrument.................................6

Figure 1-2: Electropherogram of the genetic information of an individual using the Powerplex 16 allelic ladder...............................................................................

Figure 2-1: The PCR amplification curve can be broken into three different phases showing the accumulation of fluorescent signal at each cycle .11

Figure 2-2: Comparison of SYBR Green (and also applies to TaqMan) (green/top) and Plexor HY (blue/bottom) amplification curves

Figure 2-3: Plexor novel basespair .15

Figure 2-4: Overview of the Plexor HY Technology for qPCR

Figure 2-5: Plexor melt curves generated from human DNA for Plexor RNU2 sequence (blue) and newly designed RNU2 primer (red) DNA

Figure 5-1a: Plexor HY amplification curves plotting RFU versus cycle number for increasing calcium concentrations

Figure 5-1b: Plexor HY melt curves plotting the rate of change of the RFU with time versus temperature for increasing calcium concentrations....

Figure 5-1c: $\mathrm{C}_{\mathrm{T}}$ versus increasing concentrations of calcium inhibitor.....

Figure 5-1d: $\mathrm{T}_{\mathrm{m}}\left({ }^{\circ} \mathrm{C}\right)$ versus increasing concentrations of calcium inhibitor

Figure 5-1e: Efficiency versus increasing concentrations of calcium inhibitor

Figure 5-2a: Plexor HY amplification curves plotting RFU versus cycle number for increasing humic acid concentrations ....

Figure 5-2b: Plexor HY melt curves plotting the rate of change of the RFU with time versus temperature for increasing humic acid concentrations

Figure 5-2c: $\mathrm{C}_{\mathrm{T}}$ versus increasing concentrations of humic acid inhibitor

Figure 5-2d: $\mathrm{T}_{\mathrm{m}}\left({ }^{\circ} \mathrm{C}\right)$ versus increasing concentrations of humic acid inhibitor 46

Figure 5-2e: Efficiency versus increasing concentrations of humic acid inhibitor .46 
Figure 5-2f: Plexor HY amplification and melt curves plotting RFU versus cycle number

for increasing humic acid concentrations for modified RNU2 sequence 47

Figure 5-2g: Plexor HY amplification curves plotting RFU versus cycle number for increasing humic acid concentrations without BSA

Figure 5-2h: Plexor HY melt curves plotting the rate of change of the RFU with time versus temperature for increasing humic acid concentrations without BSA

Figure 5-3a: Plexor HY amplification curves plotting RFU versus cycle number for increasing collagen concentrations

Figure 5-3b: Plexor HY melt curves plotting the rate of change of the RFU with time versus temperature for increasing collagen concentrations

Figure 5-3c: $\mathrm{C}_{\mathrm{T}}$ versus increasing concentrations of collagen inhibitor .53

Figure 5-3d: $\mathrm{T}_{\mathrm{m}}\left({ }^{\circ} \mathrm{C}\right)$ versus increasing concentrations of collagen inhibitor .53

Figure 5-3e: Efficiency versus increasing concentrations of collagen inhibitor. .53

Figure 5-4a: Plexor HY amplification curves plotting RFU versus cycle number for increasing phenol concentrations.

Figure 5-4b: Plexor HY melt curves plotting the rate of change of the RFU with time versus temperature for increasing phenol concentrations. .56

Figure 5-4c: $\mathrm{C}_{\mathrm{T}}$ versus increasing concentrations of phenol inhibitor...........................57

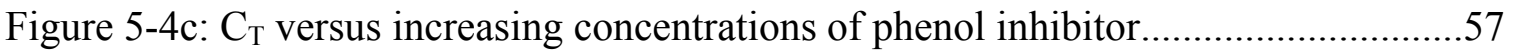

Figure 5-4e: Efficiency versus increasing concentrations of phenol inhibitor

Figure 5-5a: Plexor HY amplification curves plotting RFU versus cycle number for increasing tannic acid concentrations

Figure 5-5b: Plexor HY melt curves plotting the rate of change of the RFU with time versus temperature for increasing tannic acid concentrations

Figure 5-5c: $\mathrm{C}_{\mathrm{T}}$ versus increasing concentrations of tannic acid inhibitor .61

Figure 5-5d: $\mathrm{T}_{\mathrm{m}}\left({ }^{\circ} \mathrm{C}\right)$ versus increasing concentrations of tannic acid inhibitor 61

Figure 5-5e: Efficiency versus increasing concentrations of tannic acid inhibitor. 
Figure 5-5f: Plexor HY amplification curves plotting RFU versus cycle number for increasing tannic acid concentrations without BSA

Figure 5-53g: Plexor HY melt curves plotting the rate of change of the RFU with time versus temperature for increasing tannic acid concentrations without BSA

Figure 5-6a: Plexor HY amplification curves plotting RFU versus cycle number for increasing hematin concentrations.

Figure 5-6b: Plexor HY melt curves plotting the rate of change of the RFU with time versus temperature for increasing hematin concentrations .66

Figure 5-6c: $\mathrm{C}_{\mathrm{T}}$ versus increasing concentrations of hematin inhibitor.

Figure 5-6d: $\mathrm{T}_{\mathrm{m}}\left({ }^{\circ} \mathrm{C}\right)$ versus increasing concentrations of hematin inhibitor

Figure 5-6e: Efficiency versus increasing concentrations of hematin inhibitor

Figure 5-7a: Plexor HY amplification curves plotting RFU versus cycle number for increasing melanin concentrations.

Figure 5-7b: Plexor HY melt curves plotting the rate of change of the RFU with time versus temperature for increasing melanin concentrations. .70

Figure 5-7c: $\mathrm{C}_{\mathrm{T}}$ versus increasing concentrations of melanin inhibitor. .71

Figure 5-7d: $\mathrm{T}_{\mathrm{m}}\left({ }^{\circ} \mathrm{C}\right)$ versus increasing concentrations of melanin inhibitor . .71

Figure 5-7e: Efficiency versus increasing concentrations of melanin inhibitor .71

Figure 5-8a: Plexor HY amplification curves plotting RFU versus cycle number for increasing bile salts concentrations.

Figure 5-8b: Plexor HY melt curves plotting the rate of change of the RFU with time versus temperature for increasing bile salts concentrations.

Figure 5-8c: $\mathrm{C}_{\mathrm{T}}$ versus increasing concentrations of bile salts inhibitor ..........................75

Figure 5-8d: $\mathrm{T}_{\mathrm{m}}\left({ }^{\circ} \mathrm{C}\right)$ versus increasing concentrations of bile salts inhibitor ...................75

Figure 5-8e: Efficiency versus increasing concentrations of bile salts inhibitor ................75

Figure 5-9a: Plexor HY amplification curves plotting RFU versus cycle number for increasing urea concentrations..... 
Figure 5-9b: Plexor HY melt curves plotting the rate of change of the RFU with time versus temperature for increasing urea concentrations ......................................................78

Figure 5-9c: $\mathrm{C}_{\mathrm{T}}$ versus increasing concentrations of urea inhibitor.................................79

Figure 5-9d: $\mathrm{T}_{\mathrm{m}}\left({ }^{\circ} \mathrm{C}\right)$ versus increasing concentrations of urea inhibitor .........................79

Figure 5-9e: Efficiency versus increasing concentrations of urea inhibitor ......................79

Figure 5-10a: Plexor HY amplification curves plotting RFU versus cycle number for

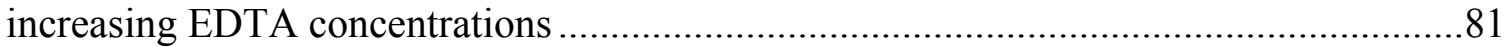

Figure 5-10b: Plexor HY melt curves plotting the rate of change of the RFU with time

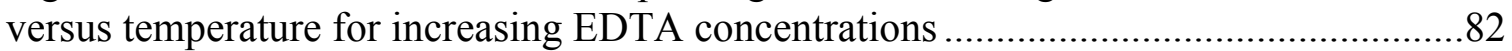

Figure 5-10c: $\mathrm{C}_{\mathrm{T}}$ versus increasing concentrations of EDTA inhibitor.............................83

Figure 5-10d: $\mathrm{T}_{\mathrm{m}}\left({ }^{\circ} \mathrm{C}\right)$ versus increasing concentrations of EDTA inhibitor ....................83

Figure 5-10e: Efficiency versus increasing concentrations of EDTA inhibitor .................83

Figure 5-11a: Plexor HY amplification curves plotting RFU versus cycle number for

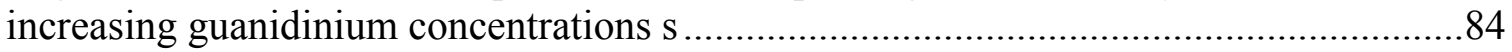

Figure 5-11b: Plexor HY melt curves plotting the rate of change of the RFU with time versus temperature for increasing guanidinium concentrations..........................................86

Figure 5-11c: $\mathrm{C}_{\mathrm{T}}$ versus increasing concentrations of guanidinium inhibitor ...................87

Figure 5-11d: $\mathrm{T}_{\mathrm{m}}\left({ }^{\circ} \mathrm{C}\right)$ versus increasing concentrations of guanidinium inhibitor...........87

Figure 5-11e: Efficiency versus increasing concentrations of guanidinium inhibitor........87 


\section{ABBREVIATIONS}

ASO

BLAST

BSA

$\mathrm{bp}$

CCD

CODIS

DTT

dNTP

DMSO

DNA

EDTA

FBI

M

$\mathrm{mM}$

mtDNA

ng

NCBI

PCIA

PCR

pg

qPCR

RFLP
Allele-specific Oligonucleotide

Basic Local Alignment Search Tool

Bovine Serum Albumen

Basepair

Charge-Coupled Device

Combined DNA Index System

Dithiolthreitol

Dideoxy Nucleotide Tri Phosphate

Dimethyl sulfoxide

Deoxyribonucleic Acid

Ehtylenediaminetetraacetic Acid

Federal Bureau of Investigation

Molar

Millimolar

Mitochondrial DNA

Nanogram

National Center for Biotechnology Information

Pghenol Chloroform Isoamyl Alcohol

Polymerase Chain Reaction

Picogram

Quantitative (real-time) PCR

Restriction Fragment Length Polymorphism 


$\begin{array}{ll}\text { RFU } & \text { Relative Florescence Unit } \\ \text { SEB } & \text { Stain Extraction Buffer } \\ \text { STR } & \text { Short Tandem Repeats } \\ \text { Taq } & \text { Thermus Aquaticus } \\ \text { TE } & \text { Tris-EDTA } \\ \mathrm{T}_{\mathrm{m}} & \text { Melting temperature } \\ \text { ug } & \text { Microgram } \\ \text { ul } & \text { Microliter } \\ \text { VNTR } & \text { Variable Number of Tandem Repeats }\end{array}$




\section{INTRODUCTION}

\subsection{Brief History of Forensic DNA Analysis}

Deoxyribonucleic acid (DNA) analysis is a powerful tool for human identity testing and is well established in the forensic community. It is used to aid in the identification of perpetrators of violent crimes such as murder and rape, in paternity cases and in identification of the remains of missing persons. More recently, technological advances such as capillary array electrophoresis and real-time polymerase chain reaction have become routine in forensic laboratories around the world and standardized protocols have been validated for presumptive and confirmatory testing, DNA extraction, DNA quantitation and analysis of short tandem repeats (STRs) (Butler, 2005).

Although the existence of variable loci in human DNA has been recognized for a long period of time, it was not until the late 1970s and early 1980s that use of polymorphisms for large-scale mapping of human genes was proposed. Arlene Wyman and Ray White established the foundation for this concept, which used a polymorphic DNA locus characterized by a variable-length restriction fragments called restriction fragment length polymorphisms or RFLP (Wyman et al., 1980). David Botstein et.al later initiated the use of RFLP in mapping genes of the human genome to indicate genetic differences among individuals (Botstein et al., 1980). However, it was Sir Alec Jeffreys who became the first to describe the scientific jargon known today as "DNA fingerprinting" or "DNA typing." Jeffreys, an English geneticist, discovered a set of genetic markers called minisatellites or variable number of tandem repeats (VNTRs), which are highly specific to an individual (Jeffreys et al., 1985). These VNTRs have 
highly variable regions of DNA and are composed of targeted tandem sequences repeated a number of times within the DNA that could be used to differentiate DNA among members of a population. The length of VNTRs ranges from 10-100 base pairs (bp) in length, making it highly polymorphic and resulting in a highly discriminating tool for human identification.

The technique used by Jeffreys to examine VNTRs was RFLP. In RFLP analysis, restriction enzymes are used to cut extracted DNA into smaller pieces of 4 to $6 \mathrm{bp}$ sequences. The fragments are separated by size using gel electrophoresis and then transferred to a nylon membrane by the Southern blot technique. A radioactive probe containing a VNTR sequence is hybridized to the single-stranded DNA (ssDNA) attached to the nylon membrane for detection (Butler, 2005). The probed DNA is exposed to x-ray film, producing a "DNA fingerprint." Jeffreys proposed the use of HinfI or HaeIII restriction enzyme digests with multi-locus (oligonucleotide) probes to detect multiple DNA fragments in the human DNA (Jeffreys et al., 1985). The band patterns obtained, which are unique to an individual, were difficult to interpret; therefore subsequent methods with single locus probes that hybridize to only a specific region of the genome were later used.

The first court cases in which Jeffreys' DNA fingerprint methodology was successfully used occurred in England during the mid 1980s. These cases involved an immigration dispute of a British boy whose parents were originally from Ghana and a double rape/homicide of teenage girls in 1985 and 1986, respectively (Jeffreys et al., 1985; Aronson, 2005). 
Another important development was later applied to forensic DNA typing. The technology was termed Polymerase Chain Reaction (PCR). The development of PCR in 1985 by Kary Mullis has lead a great deal of scientific progress in DNA analysis, especially in the forensic community. Using the Sanger method, PCR was originally developed for DNA sequencing; however, it was later applied to what biologists refer to as "Molecular Xeroxing." This application produces multiple "copies" of a nucleic acid sequence in vitro (Mullis, 1990).

During the PCR reaction, the double-stranded DNA (dsDNA) undergoes a threestep process: denaturation, annealing and extension. The strands in each target DNA are denatured by heating at high temperatures $\left(\sim 95^{\circ} \mathrm{C}\right)$ then cooled to a lower temperature $\left(\sim 55^{\circ} \mathrm{C}\right)$, allowing the primers (short oligonucleotide sequences) to anneal to the single strands. The temperature is then raised $\left(\sim 72^{\circ} \mathrm{C}\right)$ and a DNA polymerase enzyme extends the primers through incorporation of dinucleotide triphosphates (dNTPs). By doing this, synthesis of the dsDNA target is produced in a rapid cyclic process. For every cycle, PCR generates a 2 -fold increase in the target DNA (the amount of DNA theoretically doubles).

Polymerase chain reaction requires a mixture of reaction components and amplification parameters, which must be optimized to produce sufficient amplification products. The major components, included in the "master mix" to be aliquoted into each PCR tube are as follows: buffer, dNTPs, polymerase, primers, and magnesium. Thermus aquaticus (Taq), a species of bacterium found in hot springs, is the source of the thermal stable polymerase used for PCR. The later development of a "hot-start" formulation of Taq polymerase, which is inactive until heated $\left(95^{\circ} \mathrm{C}\right)$, is another improvement for 
amplifying samples minimizing the possibility of mispriming and misextension (Butler, 2005). A modified form of Taq polymerase has been developed named Amplitaq Gold ${ }^{\mathrm{TM}}$ DNA polymerase (Applied Biosystems, Foster City, CA). Other PCR components that may be included are non-acetylated bovine serum albumin (BSA) and dimethylsulfoxide, both of which improve the efficiency of the reaction and reduce inhibition.

Polymerase chain reaction became an important analytical method for forensic samples because of its sensitivity, specificity, rapid analysis, and ease of automation. The PCR amplification technology provides the analysis of forensic samples with low quantities $(<1 \mathrm{ng})$ of extracted DNA, unlike RFLP methods that require at least 50ng (Butler, 2005). Additionally, many degraded DNA samples can be amplified and subsequently typed because the alleles are much smaller in size compared to the alleles detected by RFLP analysis (Mullis et al., 1994; Butler 2003). It provides a valid and reliable approach for the analysis of biological evidence found at crime scenes. Historically, the first PCR-related approach used for forensic purposes was the detection of sequence polymorphisms through the use of allele-specific oligonucleotide (ASO) hybridization probes. Approaches involving the detection of PCR amplified length polymorphisms known as minisatellites were also explored. For example the locus D1S80 consisted of a 16 base sequence that repeated up to 41 times yielding allele sizes 400 to greater than $800 \mathrm{bp}$ in length (Duncan et al., 1997).

In the late $1980 \mathrm{~s}$, during the same time minisatellites were discovered, microsatellites - better known as short tandem repeats (STRs) - were being described. The STR technology differs from VNTRs by having a shorter repeat sequence (2 to $7 \mathrm{bp}$ ) and is the primary method presently used in forensic laboratories. Tetramer repeats have 
become more widely used than loci consisting of di-, tri-, and even penta-nucleotides and have been multiplexed with up to sixteen loci co-amplified in a single PCR reaction. When compared to other PCR-based methods, STR analysis is faster, more sensitive and can be multiplexed, permitting multiple loci to be analyzed in a single run. The STR regions are also highly polymorphic, providing an extremely high power of discrimination (Butler, 2005).

In 1997, the Federal Bureau of Investigation (FBI) Laboratory launched a nationwide effort to establish core STR loci for use within a national DNA database known as CODIS (Combined DNA Index System) (Budowle, 1999). The thirteen CODIS loci are CSF1PO, FGA, TH01, TPOX, VWA, D3S1358, D5S818, D7S820, D8S1179, D13S317, D16S539, D18S51 and D21S11. A DNA profile obtained using the thirteen autosomal STR loci yields an average random match probability of about one in a trillion among randomly chosen individuals (Butler, 2005). These loci are nationally recognized as the standard for human identification. Applied Biosystems Foster City, California and Promega Corporation in Madison, Wisconsin are the two vendors of multiplex kits that include the thirteen core loci for CODIS, AmpFISTR ${ }^{\circledR}$ Identifiler and PowerPlex ${ }^{\circledR} 16$ respectively. These manufacturers provide allelic ladders in their multiplex kits as standards for accurate genotyping. The kits also contain several additional non-CODIS loci as well as a sequence in the Amelogenin gene that contains a 6 bp deletion in the $\mathrm{X}$ chromosome, permitting its use in sex typing (Sullivan et al., 1993). Overall, this set of STR loci is more than adequate for addressing most problems of human identification. Due to their high level of polymorphism and discrete allele sizes, the kits are particularly useful in resolving DNA mixtures (Parson et al., 2008). 
Genetic analyzers, using the capillary gel electrophoresis based technology, are the most popular system for separating STR alleles. The foundation of a basic capillary electrophoresis device includes a narrow capillary, two vials filed with buffer, and two electrodes connected to high voltage power supply (Figure 1-1). For DNA separation, a PCR product is injected into a polymer filled capillary. The polymer acts as a sieve to separate DNA fragments by charge to size ratio as they move down the capillary under the influence of an electric field (Altria, 1995). The smaller negatively charged amplicons interact less with the sieving polymers and are therefore detected earlier by a laserinduced fluorescence detector. Capillary electrophoresis involves a laser that excites the fluorescently labeled primers incorporated in the DNA strand, which can be distinguished by an emission spectrum with the use of a charged coupled device (CCD) camera (Butler, 2005). Modern instruments can simultaneously detect up to five dyes. The emission

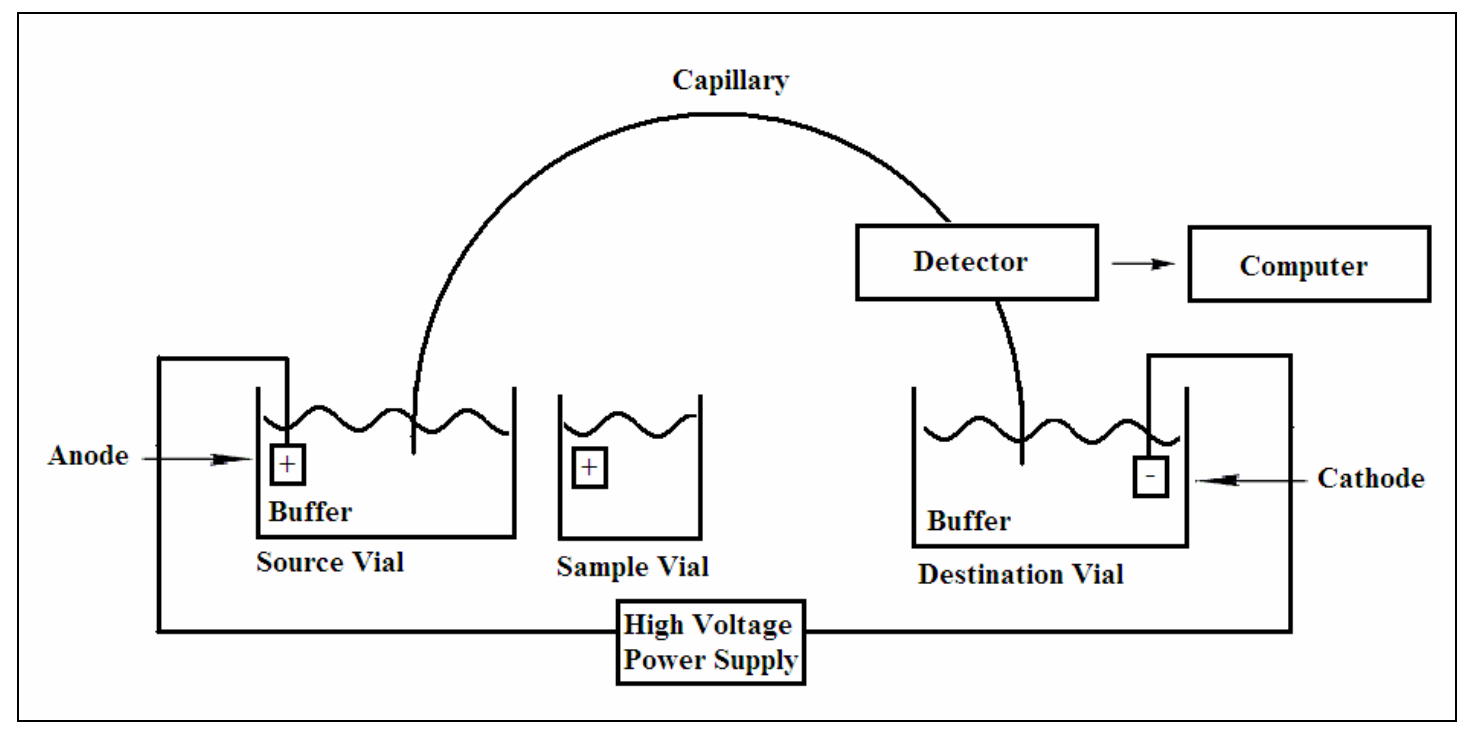

Figure 1-1: Schematic of a capillary electrophoresis instrument. The capillary ends and electrodes (connected to a high-voltage power supply) are placed in vials of buffer solution. The sample replaces one of the buffers and is introduced into the capillary. When an electric current is passed across the capillary, analytes are separated based on mass to charge ratio and detected by a UV or fluorometric detector. 


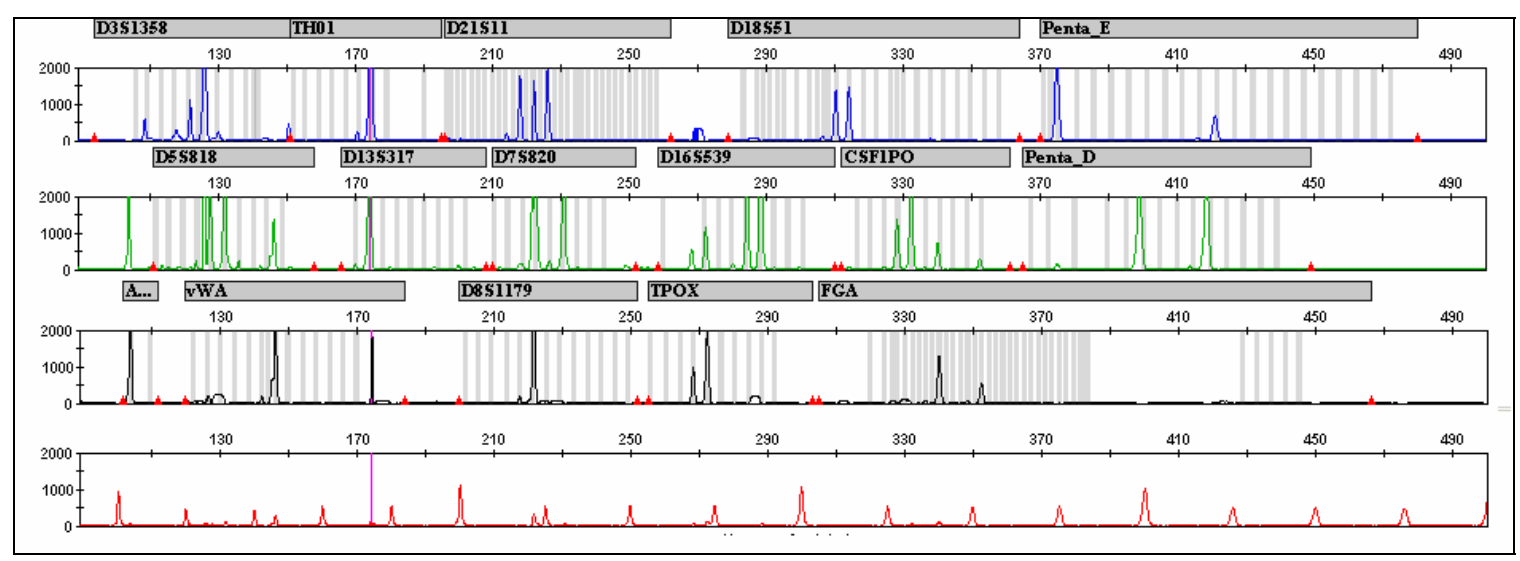

Figure 1-2: Electropherogram of the genetic information of an individual using the Powerplex 16 allelic ladder. The colors represent the different fluorescent dyes for each particular locus: Fluorescein (blue), JOE (green), TMR (black but represents yellow). CXR (red) shows fragments of the Internal Lane Standard (ILS) 600. The boxed numbers represent the allele calls for each locus. The scales at the top of the peaks represent the number of basepairs and the scale to the right represent the intensity of the fluorescent signal in relative fluorescent units (RFUs).

spectra of these dyes permit multiplexing with allele identification based on size and fluorescent wavelength. The data are represented in the form of an electropherogram, where each peaks represent the different alleles at a particular locus (Figure 1-2).

Commercial multiplex STR kits include allelic ladders, which contain the most commonly known alleles for a particular locus, internal sizing standards that are added to each sample and a calibrated curve that is established using the known sizes of the internal size standard. The amplified alleles are then called and compared to the allelic ladder in order to determine the genotype. This is done through the use of software programs that are compatible with the modern genetic analyzers. The two programs Genescan $^{\circledR}$ and Genotyper ${ }^{\circledR}$ software (Applied Biosystems, Foster City, CA) are used to size the PCR products and assign the allele calls respectively. A new software was later developed by Applied Biosystems, which merged the two programs known as 
Genemapper ${ }^{\circledR}$ ID (Butler, 2005).

In spite of the advantages associated with STR analysis, there are several drawbacks. Short tandem repeats have a lower discrimination power per locus than VNTRs because there are a smaller number of alleles and less heterozygosity per locus. Interpretation of results may be difficult due to "stutter," an artifact of the PCR process that produces "false" alleles one repeat shorter than the main allele. Another issue occurs when alleles contain incomplete repeat units, known as microvariant alleles, resulting in small variations in allele size. Similarly, mutations in the flanking regions of template DNA can result in poor binding of the primer to the DNA. These situations in which an allele may amplify poorly or not at all produces poor peak balance or allele dropout at heterozygous loci.

Currently the manufacturers continue to upgrade their already validated and highly discriminatory STR systems to tolerate samples that have been highly degraded and inhibited in order to generate profiles that could not be previously amplified. Such systems include PowerPlex 16 Hot-Start (HS) (Promega Corporation, Madison WI) (Promega, 2009 (b)), which is more robust and sensitive, generating profiles from as low as $100 \mathrm{pg}$ of DNA.

A relatively recent technological development in forensic DNA typing is quantitative PCR (qPCR), also known as real-time PCR. This process involves instrumentation that measures the concentration of DNA during PCR as the template is amplified. Quantitative PCR uses the same steps as traditional PCR (denaturation, annealing, and extension); however a fluorescent marker or probe is introduced in the reaction that is sensitive to the formation of dsDNA permitting the measurement of 
accumulation of amplified products. The primary advantages of DNA quantification by qPCR include a wide dynamic range, high-throughput capabilities, high sensitivity and target-specific quantitation (Butler, 2005). It is now widely used in forensics, predominantly using $\operatorname{TaqMan}^{\circledR}, \mathrm{SYBR}^{\circledR}$ Green and Plexor HY System real-time chemistries (a detailed discussion of this will be presented in Chapter 2).

Quantitative PCR and STRs are state-of-the art technologies and are currently the methods of choice for quantifying and genotyping forensic samples. However, there are issues such as sample degradation and inhibition due to environmental insults and postmortem aging that can prevent successful analysis of samples. 


\section{QUANTITATIVE POLYMERASE CHAIN REACTION (qPCR)}

\subsection{Introduction}

Quantitative PCR was first developed in 1993 by constructing a system that detects PCR products as they accumulate (Higuchi et al., 1993). Initially, this "real-time" system included an ethidium bromide intercalating dye incorporated into the DNA during amplification, a modified thermal cycler with ultraviolet (UV) light source to illuminate the samples, and detection of raw fluorescence output from a CCD-camera. Amplification produces increasing amounts of dsDNA that bind ethidium bromide, therefore increasing the intensity of the fluorescent signal as more copies of DNA are produced. The system then plots the relative fluorescence units (RFU) on the y-axis versus cycle number on the $\mathrm{x}$-axis.

Quantitative PCR can be divided into three distinct phases: exponential (geometric) amplification, linear amplification and the plateau region (Bloch et al., 1991) (Figure 21). During the exponential phase of the PCR process, the reaction results in a theoretical doubling of amplicons with each cycle. While the ideal efficiency is not achieved, the doubling is close to $100 \%$, yielding a consistent relationship of input DNA to the amount of product. At the beginning of the exponential phase, the baseline establishes the threshold and occurs when the fluorescence signal is consistent with the normal background levels. During the amplification process of a sample, the point at which the level of fluorescence exceeds the threshold is referred to as the cycle threshold $\left(\mathrm{C}_{\mathrm{T}}\right)$. The $\mathrm{C}_{\mathrm{T}}$ value is inversely related to the template concentration at the beginning of the $\mathrm{qPCR}$ process, therefore it is lower for a sample with a higher initial concentration and is higher 
for a lower concentration sample (Wilhelm et al., 2000). The $\mathrm{C}_{\mathrm{T}}$ values of the samples are then compared to the standard curve in order to determine the starting concentration. The $\mathrm{C}_{\mathrm{T}}$ values are determined by a linear relationship between the $\log$ of the concentration of DNA template and the number of PCR cycles (Butler, 2005). During the linear phase, the consumption of some of the PCR reagents, such as dNTPs, primers and Taq polymerase, will impede the efficiency because they are consumed at different rates. For this reason, this phase is not useful for data comparison. As product increases, there is a depletion of critical reagents, resulting in the gradual decline in the rate of formation of new product. Eventually, PCR enters the plateau phase and the product concentration remains constant.

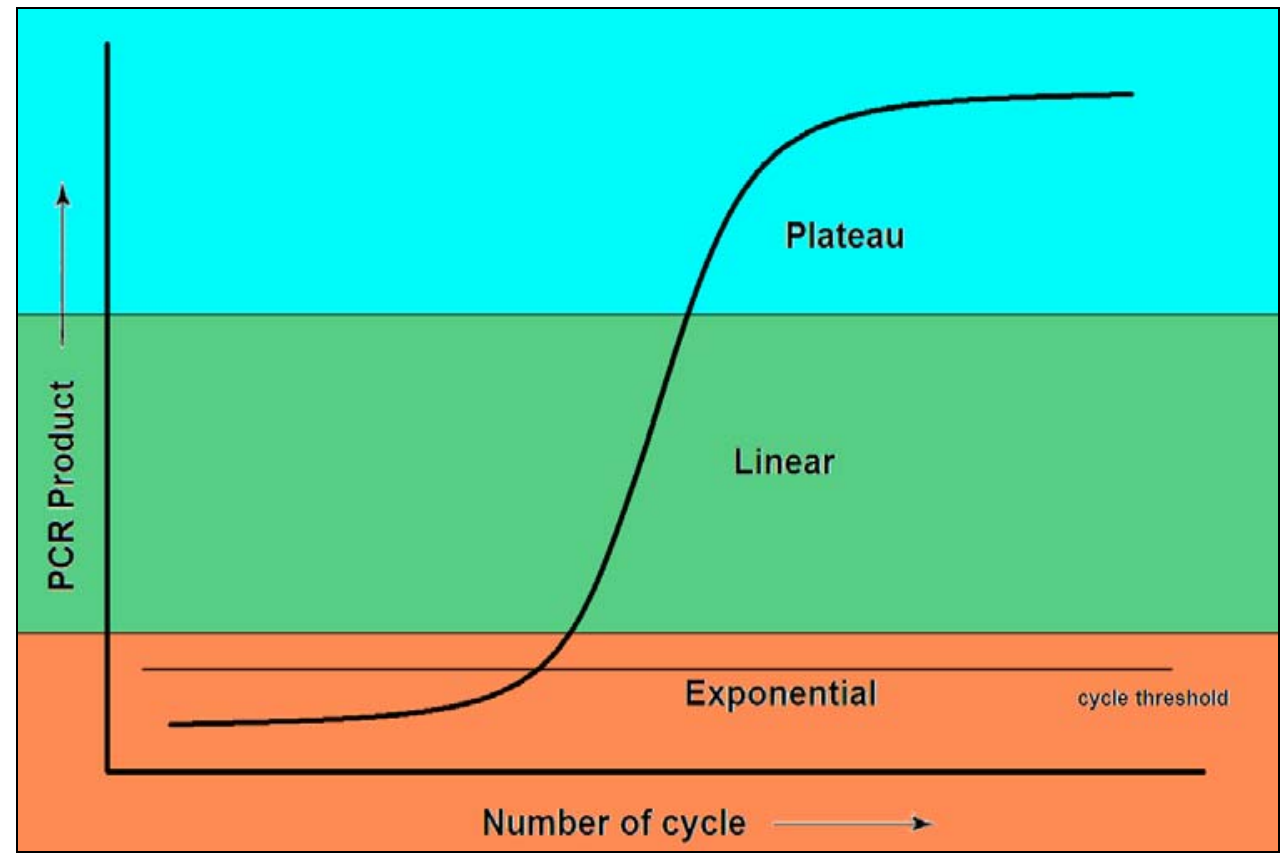

Figure 2-1: The PCR amplification curve can be broken into three different phases showing the accumulation of fluorescent signal at each cycle. Exponential amplification results when there is a 2-fold increase in DNA at every cycle. Linear amplification occurs as the reaction components are being consumed and eventually become limited. A plateau is reached and the reaction has stopped once no more product is made. The graph plots intensity of fluorescence as PCR product accumulates versus the number of cycles. 


\subsection{Detection Chemistries}

There are different approaches that can be used for fluorescence-based detection assays including fluorogenic probes, DNA binding dyes, scorpion probes, and molecular beacon technology (Bustin, 2000). The two most common methods used are the fluorogenic 5'nuclease assay - more familiarly known as TaqMan - and SYBR Green intercalation. The result of these assays is an increase in fluorescence intensity proportional to the amount of amplicon produced.

The TaqMan technology is based upon measuring a change in fluorescence due to the displacement of a dual dye labeled probe within a target region. The two dyes consist of a fluorescence reporter with a quencher dye in close proximity to prevent fluorescence. During primer annealing, the probe binds to the sequence and as the Taq extends, its 5' exonuclease activity results in degradation of the probe, releasing both of the dyes, thus removing the quenching effect and producing fluorescence (Bustin, 2000). Non-specific amplification as a result of mis-priming or primer dimerization (primer dimers) does not generate fluorescent signal because specific hybridization between the probe and target DNA is required.

The SYBR Green assay detects formation of all PCR products by dye intercalation. Since the dye binds specifically to dsDNA molecules, the real-time fluorescence detector can monitor product accumulation during annealing and extension steps. For forensic DNA analysis, the most common SYBR Green assay targets human specific Alu sequences, which is highly repetitive, has a high degree of sensitivity as well as a wide dynamic range, generally $1 \mathrm{pg} / \mathrm{ul}$ to 10ng/ul DNA standards (Nicklas et al., 2003). Careful optimization of the PCR reaction is necessary for specificity since these types of dyes 
bind to all dsDNA (Morrison et al., 1998). High concentrations of SYBR Green can inhibit amplification, therefore limited amounts should be used.

Recently, a new technique has been developed known as the Plexor HY System, which involves the incorporation of a fluorescence quencher into the product during amplification. Plexor primers are labeled with a fluorescent dye that is quenched upon binding to the previously labeled product. The quenching process (Figure 2-2) can be used to measure product accumulation during PCR amplification of dsDNA. The Plexor technology permits multiplexing of qPCR as a series of dye labels and quenchers can be used. Standard curves are generated using DNA standards in the range of $3.2 \mathrm{pg} / \mathrm{ul}$ to 50ng/ul. Table 1-1 displays a comparison of Plexor HY, TaqMan and SYBR Green chemistries.

The Plexor HY System uses the interaction between two manufactured nucleotides, isoguanine (iso-dG) and 5'-methylisocytosine (iso-dC), for qPCR analysis. They form a unique base pair when incorporated into the dsDNA and pair only with each other (Johnson et al., 2004) (Figure 2-3). The reaction only uses two primers, one containing the fluorescent label on the $5^{\prime}$ end, adjacent to the modified base, 5'-methylisocytosine (iso-dC), and the other unlabelled. The fluorescent quencher (dabcyl) and the modified nucleotide, iso-deoxyguanine triphosphate (iso-dGTP), are included in the reaction mix. During amplification, the incorporation of dabcyl and iso-dGTP is preferentially at a position complimentary only to iso-dC. After subsequent rounds of PCR, the quencher and the fluorescent label are sufficiently close together, causing a reduction in the fluorescent signal (Frackman et al., 2005) (Figure 2-4). 


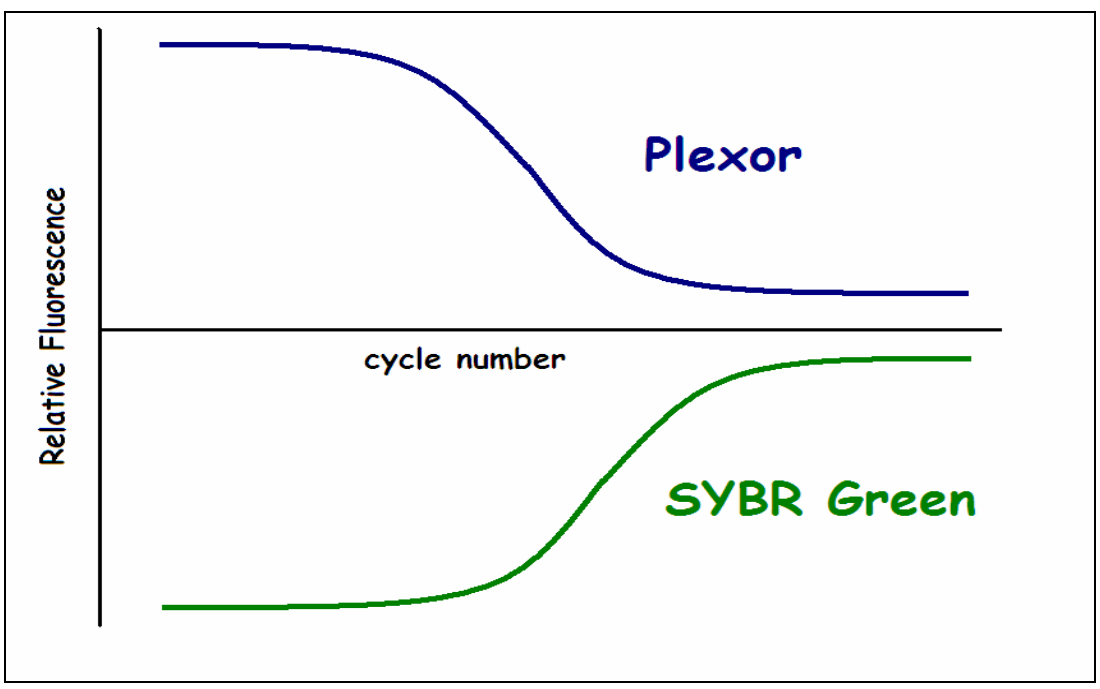

Figure 2-2: Comparison of SYBR Green (and also applies to TaqMan) (green/top) and Plexor HY (blue/bottom) amplification curves. For SYBR Green and TaqMan, fluorescence increase in proportion to the amount of amplified product, whereas for Plexor, fluorescence decreases as amplification increases.

Commercial qPCR kits such as the Quantifiler Duo DNA Quantification Kit (Applied Biosystems, Foster City CA) and Plexor HY System (Promega Corporation, Madison WI) are currently being used and validated to produce robust, reliable and reproducible results (LaSalle, 2009). These advantages are important for providing an efficient approach to DNA typing. The commercial kits include an internal PCR control (IPC) that verifies the amplification process and permits discrimination between low template levels and PCR inhibition (Bessetti, 2007). 


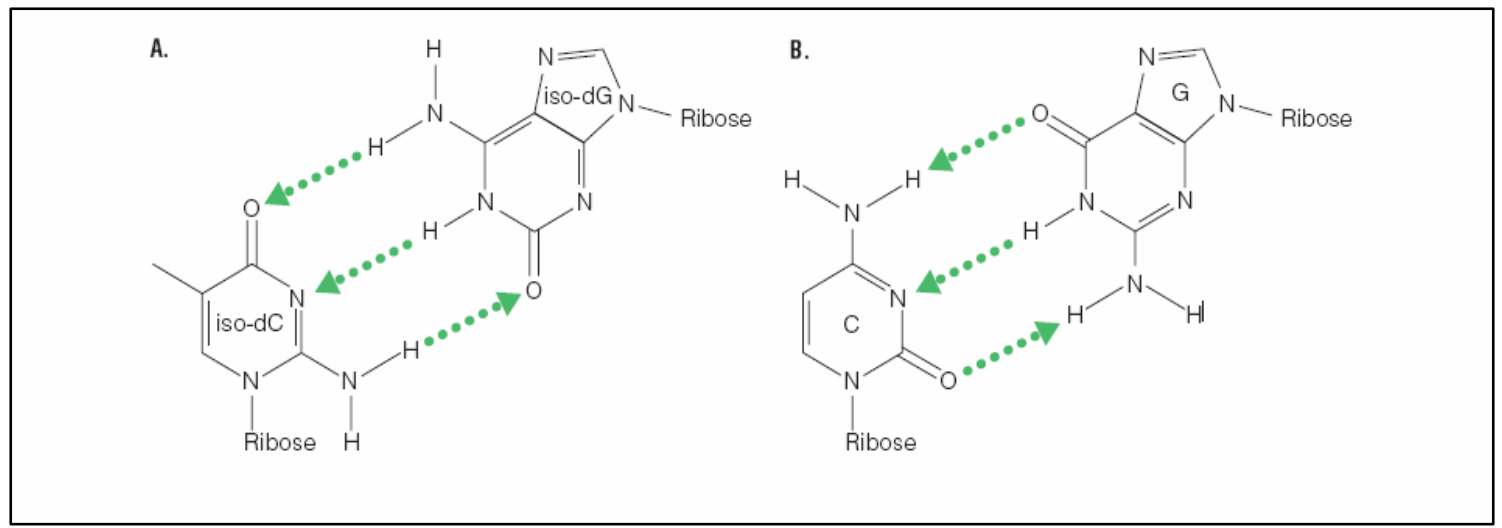

Figure 2-3: Plexor novel basepair. Isoguanine (iso-dG) paired with 5'-methylisocytosine (iso-dC) on left and deoxyguanosine paired with deoxycytidine on right (Frackman et al., 2005).

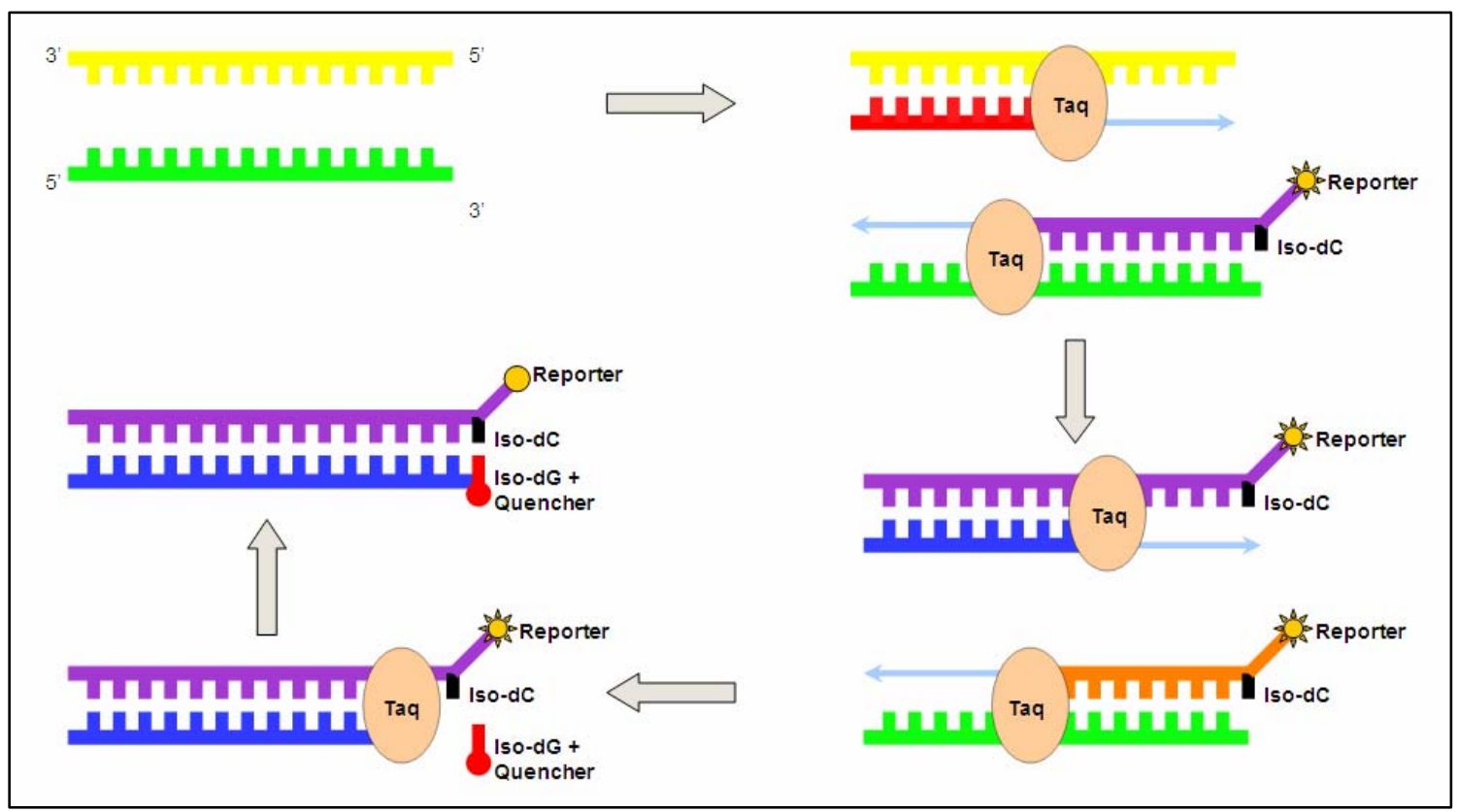

Figure 2-4: Overview of the Plexor HY Technology for qPCR. The procedure is based upon the incorporation of the iso-dC and a fluorescent dye (reporter) during thermal cycling. Throughout the PCR process iso-dGTP, bound to a quencher molecule, is incorporated into the new DNA strand opposite the iso-dC. In close proximity, the quencher and the reporter cause quenching of fluorescence as DNA product accumulates. 


\subsection{Melt Curve Analysis}

The Watson and Crick double helix structure of a DNA molecule consists of two anti-parallel strands that are linked together through a process known as hybridization, where nucleotides pair up through the formation of hydrogen bonding between complementary bases (Butler, 2005). In Chargaff's base pairing rule, it states that adenine (A) forms a basepair with thymine (T) and guanine $(\mathrm{G})$ forms a basepair with cytosine (C), which therefore means that the percentage of bases in DNA should be equal for A and $\mathrm{T}$ as well as $\mathrm{G}$ and $\mathrm{C}$ (Chargaff, 1951). Two hydrogen bonds are formed between AT basepairs and three hydrogen bonds between GC basepairs. Therefore more energy is required to break GC bonds and they have a higher thermal stability than AT bonds (Butler, 2005). A DNA molecule may be rich in AT content at one region and rich in GC content at other regions. The molecule would therefore be melted in segments since the AT pairs would separate before the GC pairs as the temperature is gradually increased.

The hydrogen bonds linking the DNA strands together can be broken (denatured) under various conditions. Denaturation occurs at elevated temperatures or through the process of chemical treatment with acidic, alkali, oxidizing, reducing, chelating or denaturing agents. The DNA molecule can also be denatured by placing it in a salt solution of low ionic strength (Butler 2005).

The process of denaturation is reversible. Once a fragment of DNA is exposed to high temperatures it will separate into its two strands. However, when the temperature is reduced the ssDNA will adhere to its complementary sequence and anneal to each other. The process in which the complementary strands re-form to their original conformation is known a renaturation (or reannealing). 
The melt curve analysis is generally used in conjunction with qPCR. It is generated after PCR amplification and indicates a change in fluorescence as temperature is raised by a fraction of a degree, from $60^{\circ} \mathrm{C}$ and slowly increasing to $90^{\circ} \mathrm{C}$. Quenched amplicons produce a significant change in fluorescent signal as they are denatured. The difference in fluorescence is used to determine the melting temperature $\left(\mathrm{T}_{\mathrm{m}}\right)$, the temperature at which amplicon dissociation occurs. The melt curve software plots the rate of change of the relative fluorescence units $(R F U)$ with time $(\mathrm{T})(-\mathrm{d}(\mathrm{RFU}) / \mathrm{dT})$ on the Y-axis versus the temperature on the $\mathrm{X}$-axis. The result is a DNA melt curve with a peak signal occurring at the $T_{m}$. Systems using TaqMan chemistries such as Quantifiler ${ }^{\circledR}$ cannot perform melt curve analysis as the formation of dsDNA is monitored in these systems through the use of external probes. The $T_{m}$ of a giver sample is obtained by product length, sequence, GC content and strand complementarity (Ririe et al., 1997). Therefore, nonspecific amplification products such as primer-dimer artifacts, mis-priming, and inhibitor binding will result in alterations to the melting temperature and curve. The precise shape of the curve is also a function of the DNA sequence being melted. This allows amplicons containing different length and sequence variants to be discriminated on the basis of melt curve shape, irrespective of whether they share the same $T_{m}$.

Figure 2-5 is a representation of Plexor autosomal melt curves of human DNA for different primers generated from the RNU2 sequence (Krenke et al., 2008). The curves within the highlighted $\pm 5^{\circ} \mathrm{C}$ window indicate the same target DNA, whereas the curves outside the window indicate nonspecific amplification. For the Plexor HY System, the $\mathrm{T}_{\mathrm{m}}$ of autosomal and IPC amplicons range between $79-81^{\circ} \mathrm{C}$ and for $\mathrm{Y}$ chromosomal amplicons, range between $81-83^{\circ} \mathrm{C}$ (Promega, 2009). 
Melt curve analysis can also be used to study high throughput genotyping and epigenetic changes in DNA. A technique currently and rapidly being adopted for these purposes is high resolution melting (HRM) analysis, which is a relatively new, post-PCR analysis method used to identify variations in nucleic acid sequences. Like melt curve analysis, HRM is used to characterize samples according to their dissociation behavior as they transition from dsDNA to ssDNA with increasing temperature and fluorescence detection. Samples can also be discriminated according to their sequence, length, GC content or strand complementarity. However, HRM goes beyond the power of traditional melt curve analysis by allowing the study of thermal denaturation of dsDNA in much more detail, permitting the detection of subtle changes in sequence, GC content or structure.

Fluorescence intercalating dyes are commonly used in real time PCR melt curve analysis. Dyes like SYBR Green are commonly used. These compounds exhibit little it binds nonspecifically to the dsDNA. However in the Plexor HY System, the primer that

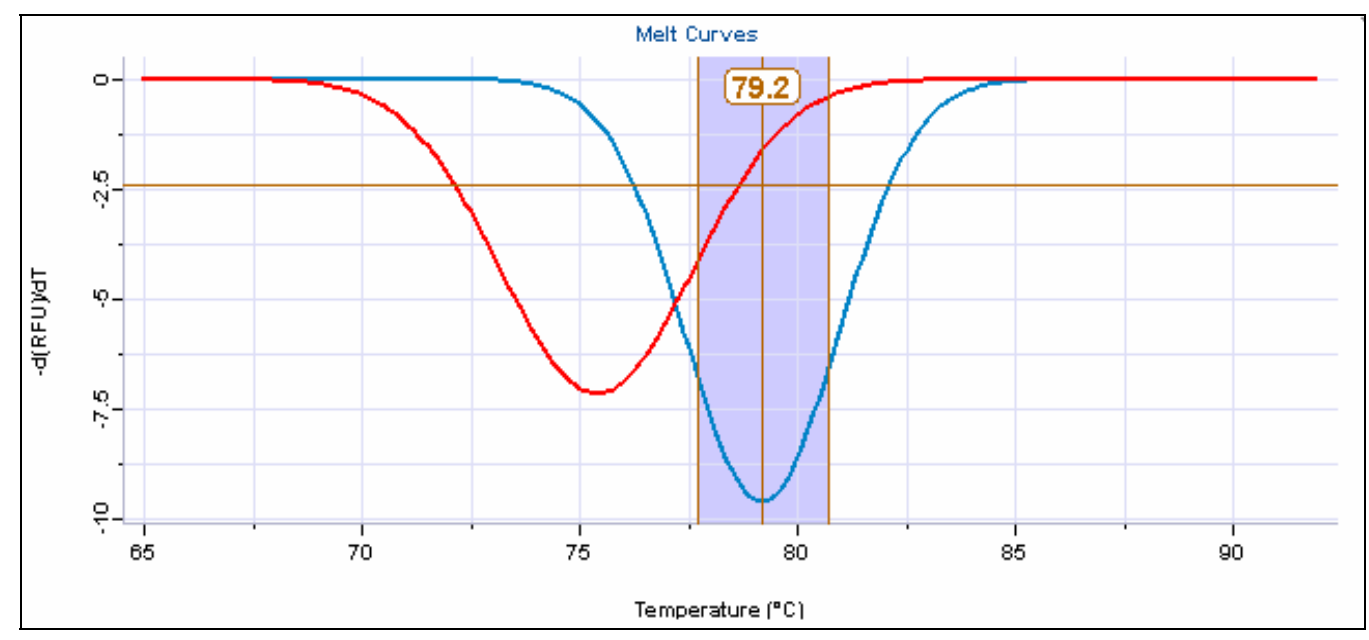

Figure 2-5: Plexor melt curves generated from human DNA for Plexor RNU2 sequence (blue) and newly designed RNU2 primer (red) DNA. Differences are due to the presence of nucleotide base content. 
fluorescence when it is free in solution, but its fluorescence increases significantly when contains both the fluorescent label and modified base binds specifically to the $5^{\prime}$ end of the DNA molecule. Since Plexor HY involves minimal interference in the dsDNA structure, it is therefore an ideal procedure for measuring inhibitory effects.

Table 2-1: Comparison of qPCR Detection Chemistries

\begin{tabular}{|c|c|c|c|}
\hline & PLEXOR & TAQMAN & SYBR GREEN \\
\hline Mode & $\begin{array}{l}\text { Fluorescence } \\
\text { quenching }\end{array}$ & Fluorescence gain & Fluorescence gain \\
\hline Mechanism & $\begin{array}{l}\text { Fluorescent labeled } \\
\text { primer opposite a } \\
\text { dabcyl quencher as } \\
\text { dsDNA forms }\end{array}$ & $\begin{array}{l}5((3 \text { ( exonuclease } \\
\text { base degradation of a } \\
\text { probe quencher pair, } \\
\text { emitting fluorescence } \\
\text { when separate }\end{array}$ & $\begin{array}{l}\text { Fluorescent dye } \\
\text { increases signal } \\
\text { when intercalated in } \\
\text { dsDNA }\end{array}$ \\
\hline Specificity & $\begin{array}{l}\text { Detects specific } \\
\text { amplification } \\
\text { products only }\end{array}$ & $\begin{array}{l}\text { Detects specific } \\
\text { amplification } \\
\text { products only }\end{array}$ & $\begin{array}{l}\text { Detects all } \\
\text { amplified dsDNA, } \\
\text { including non- } \\
\text { specific reaction } \\
\text { products }\end{array}$ \\
\hline Oligonucleotides & $\begin{array}{l}\text { One labeled and one } \\
\text { unlabeled primer }\end{array}$ & $\begin{array}{l}\text { Two unlabeled } \\
\text { primers and one } \\
\text { dual-labeled probe }\end{array}$ & $\begin{array}{l}\text { Two unlabeled } \\
\text { primers }\end{array}$ \\
\hline $\begin{array}{l}\text { Melt Curve } \\
\text { Analysis }\end{array}$ & Yes & No & Yes \\
\hline $\begin{array}{l}\text { Multiplex } \\
\text { Capability }\end{array}$ & Yes & Yes & No \\
\hline IPC & Yes & Yes & No \\
\hline Sensitivity & Medium & Low & High \\
\hline
\end{tabular}




\subsection{Primer Design}

Primers are an essential component of the PCR reaction. They contain sequences that are the reverse compliment of a specific DNA target. If the primer does not bind successfully to the DNA then amplification cannot occur; therefore successful PCR entails careful primer design. There are a number of parameters that should be considered when designing primers: primer length, melting temperature $\left(T_{m}\right)$, GC content, secondary structures, and product position.

The primer length (and annealing temperature) controls the specificity of binding. Specificity is defined as the frequency that a mispriming event occurs (Dieffenbach et al., 1993). The longer the primer sequence, the lower the probability of obtaining another sequence other than its target. Primer sequences with long runs of a single base are not recommended (Abd-Elsalam, 2003). Generally, primers of 17-25 bp in length work best (Robertson et al., 1998).

The stability of the primer annealing is measured by its $T_{m}$, which is the temperature at which $50 \%$ of the dsDNA will dissociate and become ssDNA. Optimal $\mathrm{T}_{\mathrm{m}}$ for primers generally range from $56-62^{\circ} \mathrm{C}$ (Dieffenbach et al., 1993). Primers with $\mathrm{T}_{\mathrm{m}}$ above $65^{\circ} \mathrm{C}$ should also be avoided due to possible secondary annealing (Abd-Elsalam, 2003). The $T_{m}$ of the forward and reverse primers should be similar so optimal annealing temperatures are close (Robertson et al., 1998).

The $\mathrm{GC}$ content $(\mathrm{GC} \%)$ is the percentage of guanidine and cytosine bases in the primer and provides information about the strength of annealing. Primers should have a GC $\%$ between 40-60\% (Robertson et al., 1998). The GC content, $\mathrm{T}_{\mathrm{m}}$ and annealing temperatures are all dependent on one another. For primers with a GC content below 
$50 \%$, the primer length should be extended so that the $\mathrm{T}_{\mathrm{m}}$ remains above the minimum temperature recommended (Abd-Elsalam, 2003). The GC content for primer pairs should also be similar. The difference in GC content can be compensated by altering the length of the primer pairs (Robertson et al., 1998).

Secondary structures such as hairpins, primer-dimers and self-dimers are formed by inter- or intra-molecular forces. The primer can either fold back upon itself or bind to its primer pair, which may cause misleading results. Secondary structures are likely to form with longer primer lengths (Abd-Elsalam, 2003).

The primer can be positioned near the $5^{\prime}$ or $3^{\prime}$ end of the DNA marker that is to be amplified. Usually, sequences close to the $3^{\prime}$ end of the marker are preferred for the control of mis-priming (Abd-Elsalam, 2003). 


\section{POLYMERASE CHAIN REACTION (PCR) INHIBITION}

\subsection{Introduction}

In addition to the DNA samples being affected due to template degradation, contaminants deposited on biological evidence at a crime scene often present a challenge in the analysis of DNA in cases of forensic human identification. These source contaminants, generally referred to as PCR inhibitors, commingle with DNA samples upon exposure to clothing, soils, and other environmental contaminante. Inhibitors can be endogenous or exogenous to a PCR reaction (Butler, 2005). Endogenous contaminants are process-introduced materials and reagents that are co-extracted with the target DNA during the stages of the sample preparation process such as extraction or purification. On the other hand, exogenous contaminants originate from improperly controlled hygienic or laboratory conditions. Whatever the source, once present in a biological sample, they can co-extract with the DNA and prevent or reduce the sensitivity of PCR amplification.

The most common effect of an inhibitor is a decrease in reaction efficiency, resulting in either no STR profiles or partial profiles that are difficult to interpret. Therefore, it is important for an analyst to know if an inhibitor is present in a DNA extract and to take additional steps to remove it prior to PCR amplification. It is also important to understand the mechanisms of inhibition so that the analyst can properly determine best practices to deal with inhibited samples and interpret results obtained from inhibited samples. 


\subsection{Common Polymerase Chain Reaction (PCR) Inhibitors}

Inhibitors are often present in forensic DNA samples. For casework samples such as blood on leaf litter, semen on jeans, or saliva on food items, the inhibitor may sometimes be avoided using a transfer method rather than processing a piece of the stained material. However, other inhibitors are inherent to biological samples. Common inhibitors found in forensic samples are included in various components of bodily fluids and tissues (hematin, heparin, collagen, melanin, bile salts, urea), environmental compounds (humic, fulvic and tannic acids, phenolic compounds, heavy metals) and food constituents (glycogen, fats, calcium ions) (Wilson, 1997). Inhibitors, such as indigo, the dye present in denim, may also be extracted with biological material found on clothing. Some other examples of endogenous inhibitors include phenol, ethanol, isopropanol, ethylenediaminetetraacetic acid (EDTA), potassium chloride $(\mathrm{KCl})$, sodium chloride $(\mathrm{NaCl})$ and other salts, guanidinium thiocyanate, and ionic detergents such as sodium deoxycholate (SD), and sodium dodecyl sulfate (SDS) (Demeke et al., 2010; Bessetti, 2007). Exogenous sources include glove powder, bacteria and dust (de Lomas et al., 1992; Wilson, 1997). Although several inhibitors have been widely reported, eleven of these are known to affect forensic samples and were chosen for this particular study (in research order):

\section{$\underline{\text { Calcium }}$}

Extracted DNA from bone is known to cohere high levels of PCR inhibitors, primarily calcium. Calcium is the main inorganic component of bone, which is two-thirds of the composition. The other one-third is comprised of organic material. Food samples 
(Powell et al., 1994; Bickley et al., 1996) and swabs used for DNA isolation (Wadowsky et al., 1994) have also been reported as sources of calcium ions for PCR inhibition. Calcium is known to be a competitor of magnesium in the PCR reaction as a result of their similarity in configuration. This therefore affects the polymerase activity. Very high calcium levels can be found in cells, such as 3 to $7 \mathrm{mM}$ in the nucleus of hyperplastic prostate epithelial cells (Dobi et al., 1998). Up to $2 \mathrm{mM}$ of calcium may also inhibit samples up without the presence of additives of removal procedures (Opel et al., 2010).

\section{$\underline{\text { Humic Acid }}$}

Humic acid is one of the major constituents of soil organic matter and consists of a mixture of decomposed plant and animal residue (Zipper et al., 2003). It is commonly found in aquatic, soil, and sediment environments and is usually encountered in samples that have been buried, particularly in those of bone and teeth. Characteristic features include its ability to interact with a variety of organic compounds and bind with metal ions by complex formation (Zipper et al., 2003; Sutlovic et al., 2008). The macromolecular structure of humic acid is primarily aromatic quinonic and heterocyclic rings with side chains consisting of polysaccharides, peptide, aliphates, and carboxylic acid, carbonyl, alcohol hydroxyl and phenolic active functional groups (Figure 3-1) (Sutlovic et al., 2008). Although the chemical composition of humic acid is complex, it is easily co-extracted and co-purified with DNA. Concentrations between 0.7 and $0.33 \mathrm{ug} / \mathrm{ul}$ can be extracted from soil (Tebbe et al., 1993). It has been reported that trace amounts of humic substances can inhibit the PCR and cause false-negative results at final concentrations of up to $80 \mathrm{ng} / \mathrm{ul}$ (Tsai et al., 1992; Opel et al., 2010). 


\section{$\underline{\text { Collagen }}$}

Collagen is a protein that constitutes the bulk of the organic portion of bone and is a major component in connective tissue (Sholz et al., 1998). The presence of collagen may be encountered in DNA extracted from skeletal and food samples. Different collagen types have been identified throughout the body, however, the most abundant is type I (Zhou et al., 2006). All forms of collagen share the same basic structure: three polypeptide strands, alpha chains, coiled together to form a triple helix or "super helix," a cooperative quaternary structure stabilized by numerous hydrogen bonds (Mrevlishvili et al., 2005). These triple helices are then coiled together and the resulting protein, often called tropocollagen, is the basic building block of collagen. Collagen is known to inhibit PCR at concentrations ranging from 15 to $100 \mathrm{ng} / \mathrm{ul}$ (Opel et al., 2010; Kim et al., 2000).

\section{$\underline{\text { Phenol }}$}

Phenol is a highly reactive organic compound commonly used in the manufacturing of plastic, as well as a precursor to pharmaceuticals and herbicides (Wiedbrauk et al., 1995). Phenol is a known process-introduced inhibitor most commonly in the Phenol Chloroform Isoamyl Alcohol (PCIA) DNA extraction step. The addition of phenol helps to remove proteins and lipids, leaving the nucleic acid in the aqueuous layer. However, traces of phenol can sometimes remain in the aqueous layer as a result of poor pipetting techniques and therefore inhibit the sample. The structure of phenol is a simple six-membered aromatic ring, bonded to a hydroxyl group. It has been reported that small traces of phenol is known to inactivate Taq polymerase yet functions normally in the presence of Tth DNA polymerase (Katcher et al., 1994). 


\section{$\underline{\text { Tannic acid }}$}

Tannic acid is a natural component of some types of wood and other plant material as well as a color agent found in leather (Wilson, 1997). It may be encountered in samples that have been exposed to leaf litter (Opel et al., 2010). Tannic acid is a hydrolysable plant polyphenol with anti-inflammation effects. Its complex structure consists of gallic acid molecules linked by glucose ester bonds. Tannic acids are distinguished from other plant phenolics, such as humic and fulvic acids, in terms of their chemical and biological properties including their ability to precipitate alkaloids, gelatin, and other proteins (Thoss et al., 2002). Tannic acid can inhibit a PCR reaction starting at a concentration of $30 \mathrm{ng} / \mathrm{ul}$ (Kontanis et al., 2006; Opel et al., 2010).

\section{$\underline{\text { Hematin }}$}

Hematin, the hydroxide of heme, is a metal chelating molecule found in red blood cells (Akane et al., 1994). It is the main oxygen carrier in blood. This heme compound, usually obtained from bloodstains, has been reported to sometimes co-purify with DNA by PCIA treatment and ethanol precipitation (Akane et al., 1994). The fundamental structure of hematin is a porphyrin containing a ferric ion (known as protoporphyrin IX) with a hydroxide ligand (Figure 3-2). Hematin is regarded as a major inhibitor of PCR

reactions by chelating the divalent cation $\mathrm{Mg}^{2+}$, which is a required cofactor for Taq polymerase activity. Hematin is inhibitory to PCR at a final concentration of $0.8 \mathrm{uM}$ or higher (Erlich, 1989; Opel et al., 2010). 


\section{$\underline{\text { Melanin }}$}

Melanin is a pigment found in human hair and skin, and is a possible inhibitor for telogen hair samples (Yoshii et al., 1993). Melanin is a complex and highly heterogeneous polymer consisting of monomeric units of dihydroxyphenylalanine (DOPA) and/or cysteinyl-DOPA. Its main biological function is thought to be the protection of epidermal cells from damage by ultraviolet irradiation. Two of the main melanins in the human body are eumelanin and pheomelanin. Melanin can bind to metal ions and a variety of small molecules. Melanin potently blocks PCR at final concentrations below $200 \mathrm{ug} / \mathrm{ul}$ (Eckhart et al., 2000).

\section{$\underline{\text { Bile Salts }}$}

One group of PCR inhibitors present in feces is bile salts (Kreader et al., 1996; Wilson, 1997). Bile salt is a chemical that is produced in the liver and stored in the gallbladder. They aid in the digestion of lipids in the small intestines and help in the elimination of toxins from the body. The two major bile salts in humans, cholate and chenodeoxycholate, are normally conjugated with either glycine or taurine (Bisschop et al., 2004). All bile salts consist of a steroid structure with four rings, short aliphatic sidechain (usually four or eight carbons) terminating in a carboxylic acid, and the presence and orientation of different numbers of hydroxyl groups. It has been reported that more than $25 \mu \mathrm{g} / \mathrm{ul}$ of bile salts (sodium glycocholate and sodium taurocholate) can inhibit PCR reactions. Normal adults excrete 200 to $650 \mathrm{mg}$ bile salts per day, which is enough to reach PCR-inhibitory concentrations (Lantz et al., 1997). Concentrations between 1-10 ug/ul inhibit the PCR reaction without the presence of additives (Kreader et al., 1996). 


\section{Urea}

Urea, also called carbamide, is an organic chemical compound, which essentially is the waste product of the metabolism of protein in mammals. It is commonly found in fertilizers and is an essential raw material in the chemical industry. The molecule has two amine residues joined by a carbonyl functional group. Urea is the predominant inhibitory component of urine and was found to inhibit PCR reactions from neonatal urine samples, which generally contain less urea than an adolescent. It is known to inhibit at a final concentration of more than $50 \mathrm{mM}$ (Khan et al., 1991).

\section{$\underline{E D T A}$}

Ehtylenediaminetetraacetic acid is a novel molecule for complexing metal ions. It is a chelating agent widely used to sequester di- and trivalent metal ions. It forms strong complexes with $\mathrm{Mg}^{2+}, \mathrm{Ca}^{2+}$ and $\mathrm{Fe}^{3+}$. Ehtylenediaminetetraacetic acid is a known inhibitor of metal dependent enzymatic reactions, and can be removed from reaction mixtures by ultrafiltration or alcohol precipitation of DNA. It is used in chelation therapy in medicine and as an additive to detergents for industrial cleaning. This common PCR inhibitor is a preservative and anticoagulant added to blood (Rossen et al., 1992; Al-Soud et al., 2000; Al-Soud et al., 2001). Inhibition by EDTA is caused by the removal of divalent cations from the PCR system (Seto et al., 1974). In previous PCR inhibitory studies, the addition of final concentrations of $0.25 \mathrm{mM}$ and $1 \mathrm{mM}$ EDTA inhibited the PCR reaction by approximately $46 \%$ without any additives present and in the presence of BSA or T4 gene 32 protein (gp32) respectively (Al-Soud et al., 2001; Kreader et al., 1996). 


\section{Guanidine}

Guanidine is a basic crystalline compound that is formed by the oxidation of guanine. It is commonly found in laboratories in the form of guanidinium salts including guanidinium thiocyanate (guanidinium is the conjugate acid of guanidine). Guanidinium thiocyanate is used primarily for the isolation of nucleic acids (Makowski et al., 1997). It is also used to deactivate viruses and is a general protein denaturant. It has also been noted that both the guanidinium cation and the thiocyanate anion have chaotropic properties, which means they disrupt the sturcture of macromolecules including DNA.

\subsection{Mechanisms of Polymerase Chain Reaction (PCR) Inhibition}

The mechanisms associated with PCR inhibition can be hypothesized by one or more of three essential modes of action: Inhibitors can interfere with cell lysis during DNA extraction, degrade or capture nucleic acids, or inhibit DNA polymerase activity (Wilson, 1997). Inadequate lysing of cells can result in reduction of or failure to expose the target DNA, which will therefore prevent PCR amplification. Inhibitors can also degrade or capture nucleic acids by specific binding to either the nucleases or the DNA itself, depending on configuration and composition (Butler, 2005). Inhibitors act by binding to the active sites of the polymerase and deactivating it. The most widely used polymerase in PCR as previously mentioned is Taq DNA polymerase. Thermus aquaticus can be degraded by proteinases, denatured by phenol or detergents such as EDTA and inhibited by binding to the $\mathrm{Mg}^{2+}$ necessary for polymerase activity through the formation of chelate complexes or competing with other divalent cations. 
Other research studies have identified various factors affect inhibitor binding (Opel et al., 2010; Chung 2004). The three potential mechanisms proposed are: binding of the inhibitor to the DNA template, binding of the inhibitor to the polymerase, and blocking of primer binding. If the inhibitor binds to DNA, there should be a reduction in the amount of available template and therefore changes in the $C_{T}$ value. If the inhibitor binds to the Taq polymerase, the amplicon efficiency is affected due to limiting reagent and results in the amplification curve not reaching its plateau. Amplicons should also be inhibited at roughly the same rate despite template size, primer melting temperature, and sequence, which would produce minimal changes in the $\mathrm{C}_{\mathrm{T}}$ value. If the inhibitor interacts with the primer, Taq extension is affected and there is a possibility of no available product. During primer extension, the inhibitor may bind to the polymerase or DNA and longer amplicons should be inhibited at lower concentrations than shorter amplicons.

\subsection{Methods to Overcome Inhibition}

Experimentally, there are several approaches to overcome the effects of inhibitors. Common techniques including sample dilution, DNA purification via spin column filtration using Microcon ${ }^{\circledR}$ or Centricon ${ }^{\circledR}$ columns (Millipore Corporation, Bedford MA) and QIAQuick ${ }^{\circledR}$ and QIAamp ${ }^{\circledR}$ columns (Qiagen Inc., Valencia CA), magnetic bead separation using the DNA IQ ${ }^{\mathrm{TM}}$ (Promega Corporation, Madison WI), and destruction of inhibitors that are known intercalators using sodium hydroxide $(\mathrm{NaOH})$ (Yang et al., 1998; Bourke et al., 1999). 
However there are other treatment methods that do not eliminate inhibition during DNA isolation and purification, such addition of DNA polymerase and magnesium. Increasing the amount of Taq polymerase and magnesium as well as the choice of DNA polymerase can also have a huge impact on resistance to inhibition (Butler, 2005). Previous research in this area has identified inhibitors that have no effect on the addition of Taq or magnesium - humic acid, collagen, and melanin (Opel et al., 2010).

Unfortunately, previous research has concluded that inhibitors still may cause complications for DNA samples that are highly degraded or of low template. This is because isolation methods for inhibitors, such as dilution, filtration or treatment with base, will affect recovery of these samples. For example, by diluting the inhibited sample, the low quantity of genomic DNA is also diluted. Inhibitors are particularly problematic in degraded and low copy samples, because the normal methods of removal, such as dilution of the sample to reduce the concentration of the inhibitor, are not applicable for these samples.

An alternate procedure to avoid PCR inhibition is to add a chaperon molecule such as bovine serum albumen (BSA). Bovine serum albumin is a protein used to stabilize the enzyme during PCR and prevents adhesion of the enzyme to reaction tubes. It is commonly used as pretreatment of the extracted DNA because of its stability, lack of effect in many biochemical reactions, and low cost (Butler, 2005). However, BSA may also bind to some substances, which can inhibit the PCR reaction (Satoh et al., 1998). 


\section{METHODOLOGY}

\subsection{DNA Standards and Stock Soution}

The Plexor HY Male Genomic DNA Standard, provided with the Plexor HY System, was used to generate standard curves ranging from $50 \mathrm{ng} / \mathrm{ul}$ to $3.2 \mathrm{pg} / \mathrm{ul}$. The DNA Standard was also used for primer optimization. For the inhibition tests, multiple buccal swabs were collected from a human male individual. The swabs were extracted using the PCIA with ethanol precipitation protocol (see Appendix A). The extracts were combined into one stock solution, quantified using the protocol in the Plexor HY Systems Technical Manual (Promega, 2009 (a)), and diluted to approximately $2 \mathrm{ng} / \mu \mathrm{L}$ concentration.

\subsection{Primer Design}

Primers for the human RNU2 locus that amplify autosomal DNA for the Plexor HY System was designed using the GenBank sequence accession number K02227 (see Appendix B) obtained by performing a BLAST from National Center for Biotechnology Information (NCBI) and the online primer design programs Primer3 (http://frodo.wi.mit.edu/primer3/input.htm) and Plexor ${ }^{\mathrm{TM}}$ Primer design Software (www.promega.com/plexorresources/). A primer length of $20 \mathrm{bp}$ was used as a default and the target amplicon size range was: 150-200 bp; and target melting temperature range was: $58-61^{\circ} \mathrm{C}$. Five sets of oligonucleotide primer pairs were designed and ordered by Integrated DNA Technologies (Coralville, IA). Amplification of the K562 standard DNA was performed for each of the five primer sets with 2ng of template DNA using the Alu- 
based qPCR protocol (see Appendix C). The primer pair with the most suitable parameters and amplification results was selected. The forward primer, synthesized with an iso-dC residue and a fluorescent label (FAM) at the $5^{\prime}$ end, was manufactured by Biosearch Technologies (Novato, CA) at an amplicon size of $180 \mathrm{bp}$.

\subsection{Real-Time Polymerase Chain Reaction (PCR) Analysis}

Testing of the Plexor HY System on extracted samples was performed on the Corbett Rotorgene 6000 Real-Time PCR System (Qiagen Inc., Valencia CA). The reaction components were based on the Plexor HY Systems Technical Manual (Promega, 2009 (a)) with $1 \mathrm{uL}$ of nuclease-free water substituted with inhibitor. DNA (2ng/ul) was added to the reaction mixture before separating the mixture into aliquots and adding the inhibitor. The final reaction volume was $20 \mu \mathrm{L}$. Cycling parameters for the reactions were as follows: hold for 2 minutes at $95^{\circ} \mathrm{C} ; 40$ cycles of $95^{\circ} \mathrm{C}$ for $10 \mathrm{~s}$, then $60^{\circ} \mathrm{C}$ for $20 \mathrm{~s}$ with data collection during the elongation/extension step. The melt cycle was: ramp from $65^{\circ} \mathrm{C}$ to $92^{\circ} \mathrm{C}, 0.5$ degree for each step, with a 90 second pre-melt and 5 seconds for each step thereafter, with the melt data acquired to Melt A on green, orange, red, and yellow. All reactions were performed in triplicate. For the modified RNU2 primers, the cycling parameters for the reactions were as follows: hold for 3 minutes at $95^{\circ} \mathrm{C} ; 45$ cycles of $95^{\circ} \mathrm{C}$ for $10 \mathrm{~s}, 60^{\circ} \mathrm{C}$ for $20 \mathrm{~s}, 72^{\circ} \mathrm{C}$ for $20 \mathrm{~s}$ with data collection during the extension step. The melt cycle was: ramp from $65^{\circ} \mathrm{C}$ to $92^{\circ} \mathrm{C}, 0.5$ degree for each step, with a 90 second pre-melt and 5 seconds for each step thereafter, with the melt data acquired to Melt A on green. 


\subsection{Inhibitor Preparations}

The inhibitor stock solutions were prepared as follows: calcium hydrogen phosphate (Aldrich, Milwaukee, WI), $100 \mathrm{mM}$ in $0.5 \mathrm{~N}$ hydrochloric acid (FisherScientific); humic acid (Alfa Aesar, Ward Hill, MA), $1 \mathrm{mg} / \mathrm{mL}$ in water; collagen (from calf skin) (Sigma), $1 \mathrm{mg} / \mathrm{mL}$ in $0.1 \mathrm{~N}$ acetic acid (Fisher); phenol solution (Sigma), $100 \mathrm{mM}$ in water; tannic acid (Sigma), $1 \mathrm{mg} / \mathrm{mL}$ in water; hematin (ICN Biomedicals, Aurora, $\mathrm{OH}$ ), $100 \mathrm{mM}$ in $0.1 \mathrm{~N}$ sodium hydroxide (Fisher Scientific); melanin (Sigma), $1 \mathrm{mg} / \mathrm{mL}$ in $0.5 \mathrm{~N}$ ammonium hydroxide (Fisher Scientific); Urea (FisherScientific), $10 \mathrm{M}$ in water; Bile salts (sodium cholate plus deoxycholate) (Fluka), $100 \mathrm{mg} / \mathrm{ml}$ in water; EDTA (Fluka), $0.5 \mathrm{M}$ in water; Guanidinium thiocyanate (Sigma), $100 \mathrm{mg} / \mathrm{ml}$ in water. All subsequent dilutions were prepared with water. These inhibitors were added to samples prior to quantification and STR analyses.

\subsection{Inhibitor Concentrations}

A range of concentrations was tested to determine at which inhibitor concentration a change in the signal output would be observed. The starting concentrations were based on previous work with these inhibitors (Opel et al., 2010) and information on their chemical properties. The qPCR tests were conducted using Plexor HY multiplex primers (Promega, 2009 (a)) and designed RNU2 primer. The ranges of concentrations for each inhibitor are presented in Table 4-1. 


\subsection{Data Analysis}

Following data collection on the real-time instrument, raw data were exported from the instrument software and imported into the Plexor Analysis Software version 1.5.4.18 (Promega Corporation, Madison WI). The software generated the amplification and melt curves, cycle threshold $\left(\mathrm{C}_{\mathrm{T}}\right)$, product melt temperature $\left(\mathrm{T}_{\mathrm{m}}\right)$, standard curve and unknown sample quantification data. The PCR inhibitory effects on qPCR amplification were identified by amplification efficiency, $\mathrm{C}_{\mathrm{T}}$ values, and changes in the melt curves.

Table 4-1: Final inhibitor concentrations for the $20 \mu \mathrm{L}$ reaction mix.

\begin{tabular}{||l|l|l||}
\hline \multicolumn{1}{|c|}{ INHIBITOR } & \multicolumn{1}{|c|}{ SOURCE } & \multicolumn{1}{c|}{ CONCENTRATIONS } \\
\hline Calcium & Milk, bone & $0,0.5,1.1 .5,2,2.5 \mathrm{mM}$ \\
\hline Humic acid & Soils & $0,5,10,15,20,25,30 \mathrm{ng} / \mathrm{uL}$ \\
\hline Humic acid* & Soils & $0,1,2,3,4,5 \mathrm{ng} / \mathrm{ul}$ \\
\hline Collagen & Bone & $0,25,37.5,50,62.5,75,87.5,100 \mathrm{ng} / \mathrm{uL}$ \\
\hline Phenol & Organic extraction & $0,33,66,83,100,116,133 \mathrm{ug} / \mathrm{uL}$ \\
\hline Tannic acid & Plant material, leather & $0,3.75,7.5,11.25,15,18.75,22.5 \mathrm{ng} / \mathrm{uL}$ \\
\hline Tannic acid* & Plant material, leather & $0,1,2,3,4,5,6,7 \mathrm{ng} / \mathrm{ul}$ \\
\hline Hematin & Blood & $0,15,30,45,60,75,90,105 \mathrm{uM}$ \\
\hline Melanin & Hair, tissue & $0,10,20,30,40,50,60 \mathrm{ug} / \mathrm{uL}$ \\
\hline Bile Salts & Feces & $0,0.25,0.5,0.75,1,1.25,1.5 \mathrm{ug} / \mathrm{uL}$ \\
\hline Urea & Urine & $0,200,400,600,800,1000,1200 \mathrm{mM}$ \\
\hline EDTA & Blood thinner & $0,0.4,0.8,1.2,1.6,2,2.4 \mathrm{mM}$ \\
\hline Guanidinium & Guanidinium salts & $0,1.5,3,4.5,6,7.59 \mathrm{ug} / \mathrm{uL}$ \\
\hline Concentrations without BSA & \\
\hline
\end{tabular}




\section{Amplification Efficiency}

The efficiency reveals the dynamics of the PCR reaction for each sample, which includes reaction components, potential presence of inhibitors and cycling parameters. A more efficient amplification will generate more products with fewer cycles. The individual PCR efficiency is expressed as a numerical value (between 1 and 2) and is calculated from slope of the amplification curve in the exponential phase $\left(\mathrm{E}=10^{\text {slope }}\right)$ (Ruijter et al., 2009). An ideal PCR efficiency is $100 \%$ or $E=2$, which means that the amount of amplicon has doubled; therefore $\mathrm{E}=1$ means that there is no amplification. For this study, low efficiency values suggested that inhibition had reduced the amplification. Efficiency values close to 1 showed no amplification. Efficiencies were obtained by exporting the raw Excel data from the Real-Time PCR System and importing into LinRegPCR (Ruijter et al., 2009), a program that enables more reliable identification of efficiency over comparable approaches (Kontanis et al., 2006).

\section{$\underline{\text { Cycle threshold }\left(\mathrm{C}_{\mathrm{T}}\right) \text { values }}$}

Cycle threshold $\left(\mathrm{C}_{\mathrm{T}}\right)$ values are inversely proportional to the $\log$ of the initial template DNA concentration. As a result, a higher $\mathrm{C}_{\mathrm{T}}$ value usually corresponds to a lower amount of template DNA. For this purpose, increasing $\mathrm{C}_{\mathrm{T}}$ values were identified as the inhibitor binding to the DNA, as such binding will reduce the amount of template available for amplification. Wider ranges in $\mathrm{C}_{\mathrm{T}}$ values indicated more binding likewise, smaller ranges corresponded to less interaction between DNA and inhibitor. The Plexor Analysis Software amplification threshold accounts for noise levels and by default is set at 10 standard deviations below the mean baseline fluorescence (Promega, 2009 (a)). 


\section{Melt Curve Changes}

The shape and shift in the melt curve is as a result of varying $\mathrm{T}_{\mathrm{m}}$, the reduction in DNA concentration, nonspecific amplification products and other effects such as inhibitor binding. For the purpose of this inhibition study, changes in the melt curves indicated that the DNA is melting at different temperature due to the structure and mode of action of the inhibitor as it interferes with the DNA. As a result, inhibitors that bind DNA should produce shifts in the melt curves while those affecting the Taq primarily do not.

\subsection{Short Tandem Repeat (STR) Analysis}

DNA (0.5ng) was added to a $25 \mathrm{uL}$ reaction and amplified as described in the Powerplex16 System (Promega, 2008) and Powerplex 16 HS System (Promega, 2009 (b)) Technical Manuals. After amplification, samples were prepared by combining $1 \mathrm{ul}$ of sample, $9.5 \mathrm{ul}$ of $\mathrm{Hi}-\mathrm{Di}^{\mathrm{TM}}$ formamide and $0.5 \mathrm{ul}$ of Internal Lane Standard 600 (ILS600) per reaction. Separation and detection of STR amplification products were performed on an ABI Prism ${ }^{\circledR} 310$ Genetic Analyzer (Applied Biosystems, Foster City CA) using the GS STR POP4 (1ml) A module. Samples were injected at $5 \mathrm{kV}$ for 3 seconds with $15 \mathrm{kV}$ separation at $60^{\circ} \mathrm{C}$ and a run time of 35 minutes. Data analysis was performed using the

GeneMapper ID Software version 4.0. Electropherograms were interpreted based on peak height and allele drop-out at particular loci when compared to the control with a minimum detection threshold of 50 RFUs. 


\section{RESULTS AND DISCUSSION}

\subsection{Polymerase Chain Reaction (PCR) Inhibition}

\section{$\underline{\text { Calcium }}$}

Results obtained by introducing increasing amounts of calcium into different PCR reaction mixtures show a decrease in the reaction efficiency, increase in $\mathrm{C}_{\mathrm{T}}$, and no changes in the $\mathrm{T}_{\mathrm{m}}$ for autosomal $\mathrm{Y}$, and IPC (Figures 5-1a and $\mathrm{b}$ ). For calcium, the $\mathrm{C}_{\mathrm{T}}$ values increased by a factor of 12 cycles over the concentration range, potentially indicating a loss of template (Figure 5-1c). However, closer examination of the amplification curves demonstrates that this increase in $\mathrm{C}_{\mathrm{T}}$ is mainly due to a loss in overall reaction efficiency, not template. The $\mathrm{T}_{\mathrm{m}}$ of calcium at different concentrations did not change and was consistent at $80.4{ }^{\circ} \mathrm{C}$ (Figure 5-1d). These results are consistent with the analysis that the major effect of calcium is on the Taq polymerase. Error bars are indistinguishable as the results did not deviate across the three replicates. Potential loss of template concentration and reduced availability of Taq throughout the runs resulted in relatively low efficiencies at concentrations of $1.5 \mathrm{mM}$ and higher (Figure 5-1e). These results indicate that calcium is a possible Taq inhibitor and appears to interfere with the interaction between the polymerase enzyme and magnesium, which acts as a cofactor for the enzyme. Calcium and magnesium are both divalent cations and therefore similar in structure and properties, so they may compete with one another throughout the PCR run. Limited Taq in the PCR reaction would reduce the amplification therefore generating less available product and low amplification efficiencies. 
Previous SYBR Green results involving calcium inhibition without BSA concluded that the addition of Taq and magnesium to the reaction produced a slight increase in amplification efficiency, indicating a higher affinity for the calcium ions in PCR (Opel et al., 2010). Gel electrophoresis studies using lower concentrations of calcium confirm a significant reduction in PCR inhibition occurs if the level of magnesium in the reaction is increased (Bickley et al., 1996). These studies demonstrate that calcium is inhibits PCR through interference with the magnesium cofactor of the Taq enzyme.

\section{$\underline{\text { Humic Acid }}$}

Humic acid reduced the efficiency of the amplification at higher concentrations of inhibitor but did not produce a change in the melt curve for all three amplicons (Figures 5-2a and $\mathrm{b})$. An increase in $\mathrm{C}_{\mathrm{T}}$ of approximately 10 cycles occurred over the range of humic acid concentration (Figure 5-2c). However, unlike calcium, this was due to a change in apparent template concentration, as the slope of the amplification curves was more constant. The change in $\mathrm{T}_{\mathrm{m}}$ that occurred with increasing concentration of humic acid was $0.3{ }^{\circ} \mathrm{C}$, which is not strong evidence of DNA binding (Figure 5-2d). However, high efficiencies of up to $20 \mathrm{ng} / \mathrm{ul}$ of inhibitor, does support this (Figure 5-2e).

Effects of inhibition were also measured at an amplicon length larger than Plexor primers, which amplify up to $150 \mathrm{bp}$. These modified primers, based on the RNU2 sequence of $188 \mathrm{bp}$, did not produce changes in the melt curve when the reaction was optimized (Figure 5-2f). However, there were significant effects on the amplification efficiency. It becomes clear that the effect on $\mathrm{C}_{\mathrm{T}}$ with the longer amplicons (Figure 5-2f) involves effective loss of template, unlike the earlier result with calcium (Figure 5-1a) or 


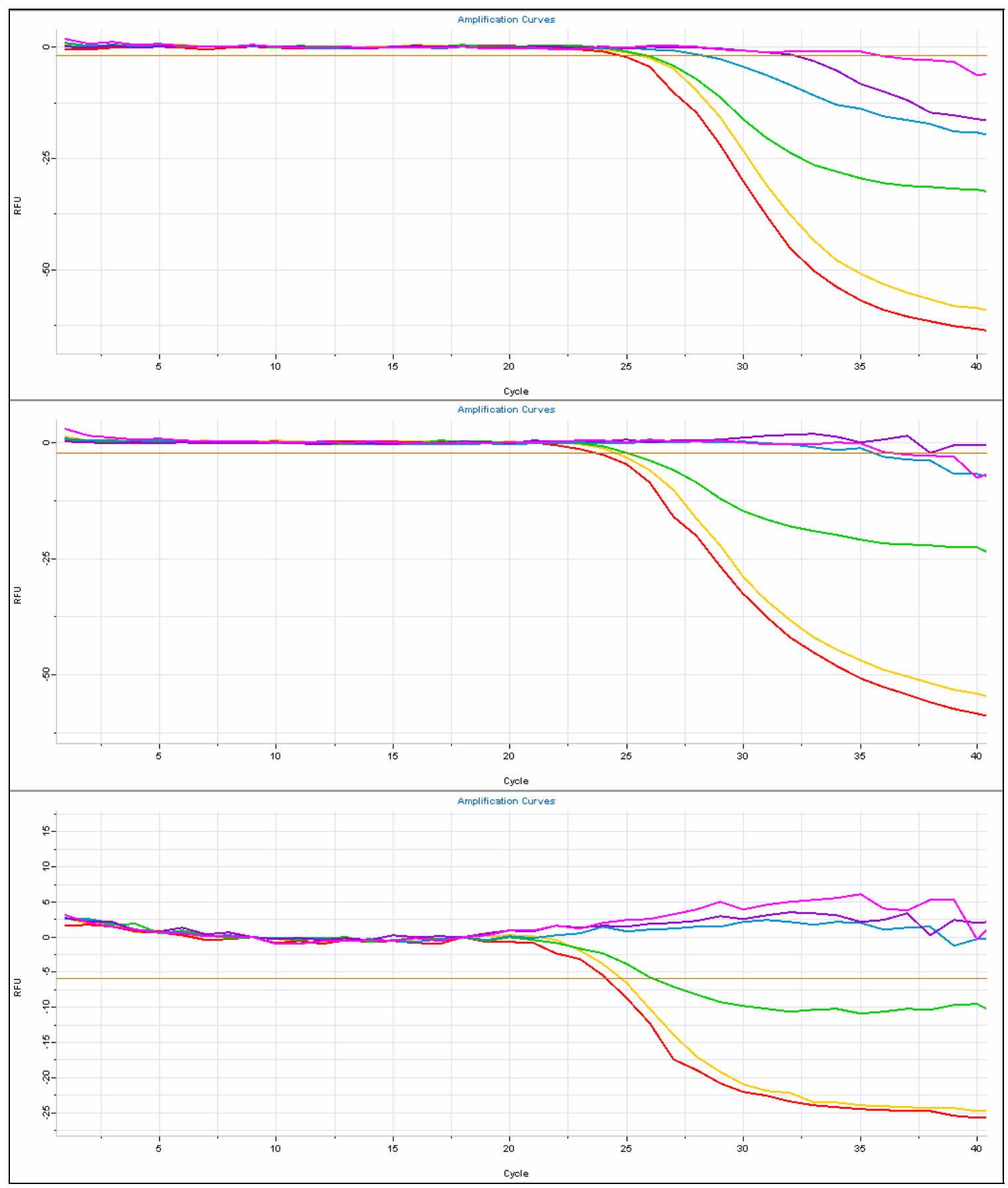

Figure 5-1a: Plexor HY amplification curves plotting RFU versus cycle number for increasing calcium concentrations. Changes in Autosomal (top), Y Chromosomal (middle) and IPC (bottom) curves at the following concentrations of calcium: $0 \mathrm{mM}$ (red), $0.5 \mathrm{mM}$ (yellow), $1 \mathrm{mM}$ (green), $1.5 \mathrm{mM}$ (blue), $2 \mathrm{mM}$ (purple), $2.5 \mathrm{mM}$ (pink). 


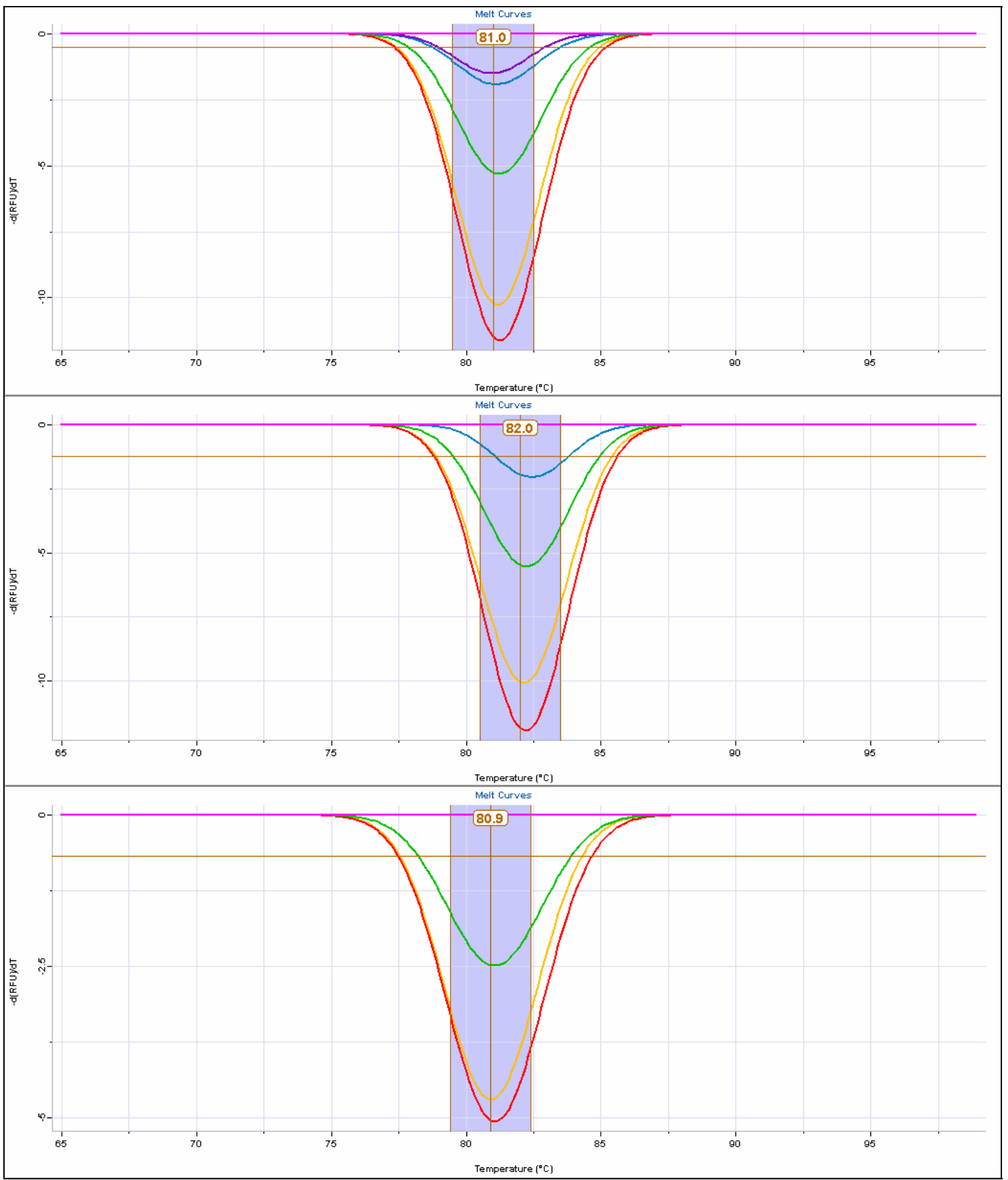

Figure 5-1b: Plexor HY melt curves plotting the rate of change of the RFU with time versus temperature for increasing calcium concentrations. Changes in Autosomal (top), Y Chromosomal (middle) and IPC (bottom) curves at the following concentrations of calcium: $0 \mathrm{mM}$ (red), $0.5 \mathrm{mM}$ (yellow), $1 \mathrm{mM}$ (green), $1.5 \mathrm{mM}$ (blue), $2 \mathrm{mM}$ (purple), $2.5 \mathrm{mM}$ (pink). 


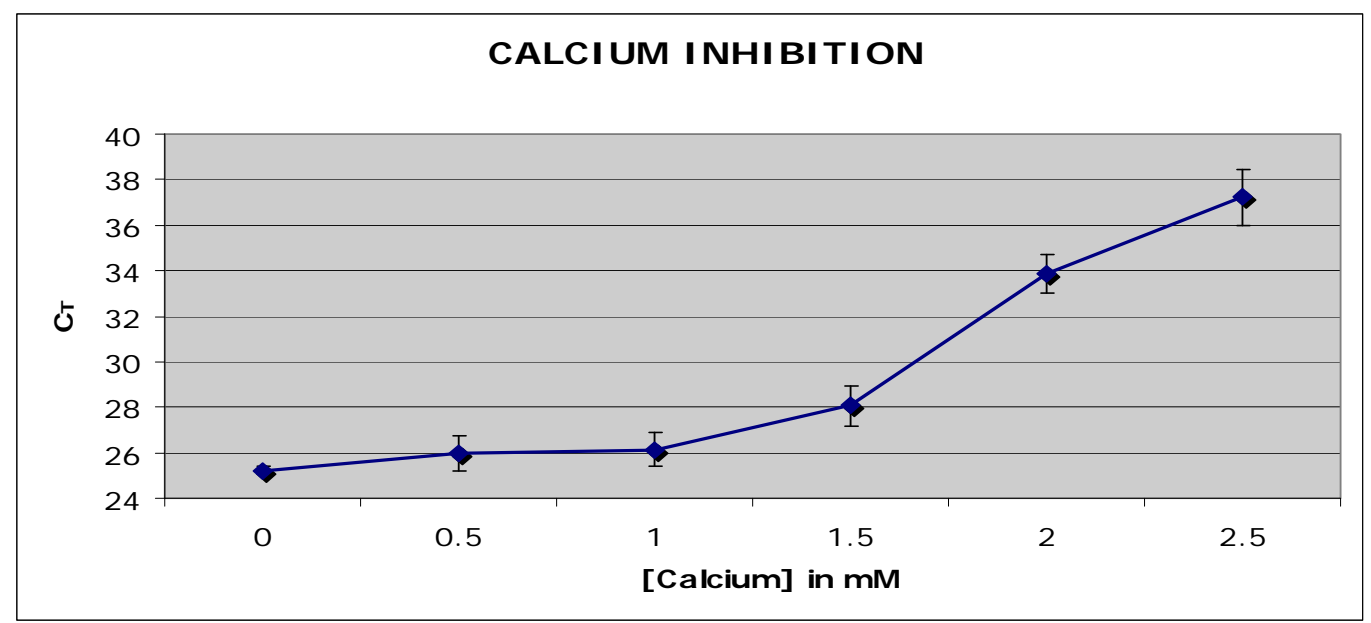

Figure 5-1c: $C_{\mathrm{T}}$ versus increasing concentrations of calcium inhibitor

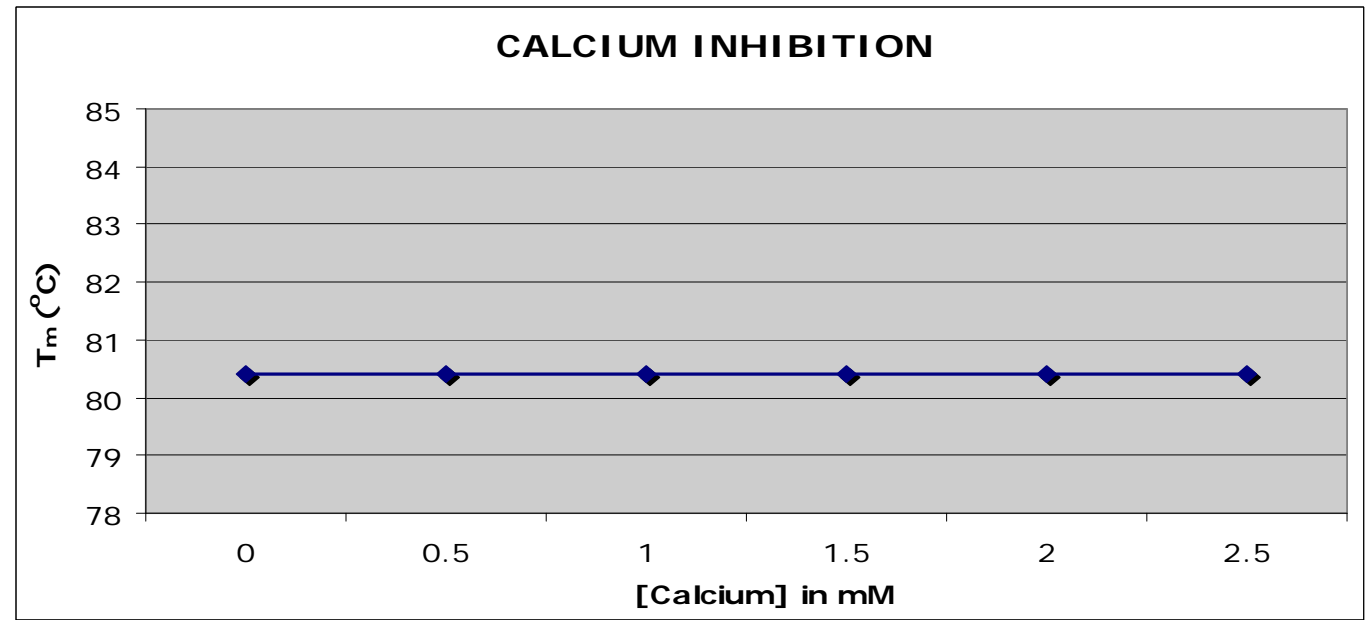

Figure 5-1d: $\mathrm{T}_{\mathrm{m}}\left({ }^{\circ} \mathrm{C}\right)$ versus increasing concentrations of calcium inhibitor

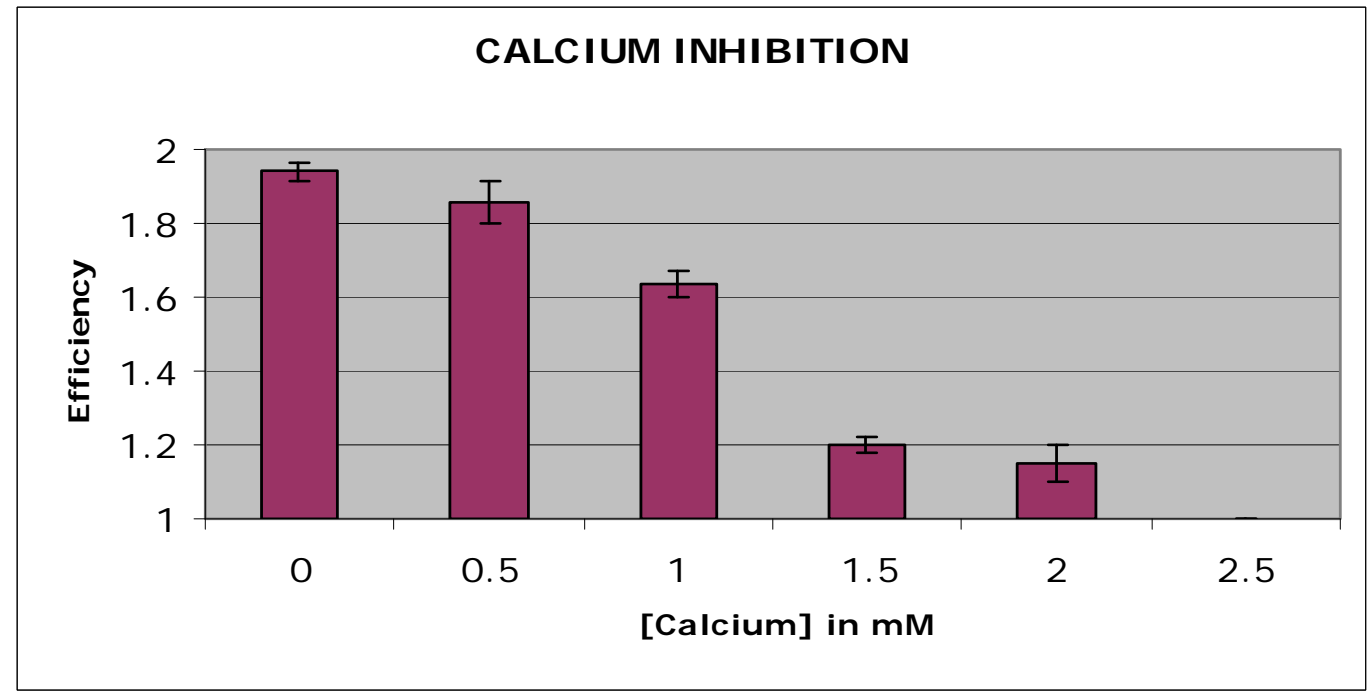

Figure 5-1e: Efficiency versus increasing concentrations of calcium inhibitor 
humic acid (Figure 5-2a). The slope of the exponential curve in Figure 5-2f remains high over the larger range of concentrations and the increase in $\mathrm{C}_{\mathrm{T}}$ is not the result of major changes in slope. Previous research using SYBR Green showed a consistent increase in $\mathrm{C}_{\mathrm{T}}$ with increasing concentrations of humic acid and little to no changes in efficiency (Opel et al., 2010). Large changes in the melt curves with primer sets of 200 and $300 \mathrm{bp}$ were also seen. When BSA was eliminated from the Plexor reaction, the major change was in the quality of the amplification curve. However no significant changes occurred in $\mathrm{T}_{\mathrm{m}}$ (Figures $5-2 \mathrm{~g}$ and $\mathrm{h}$ ). Humic acid is a relatively large inhibitor and could be a possible DNA intercalator or groove binder due to its flat planar system throughout the molecule as well as its size, which accommodates wrapping around the DNA (Zipper et al., 2003). An inhibitor of that size may not bind to very short amplicon lengths ( $<200 \mathrm{bp})$, which explains the relative lack of melt curve effects.

For the SYBR Green results, humic acid may be competing with the dye as an intercalator, which produced those distinct changes in the melt curve (Opel et al., 2010). It was verified as a DNA inhibitor when additional Taq or magnesium did not improve amplification. Additional SYBR Green and TaqMan studies confirm humic acid binding to DNA (Tebbe et al., 1993; Sutlovic et al., 2008). The lack of major effects on the melt curve with Plexor may be more a function of the different checmistries in the two qPCRassays. SYBR green binds throughout the entire length of the double helix while Plexor is only measured at the distal end of the molecule. Unlike other qPCR assays, Plexor did not interfere or bind the dsDNA, which could be a possible reason why there were no effects observed. Another SYBR Green study using crude soil samples identified Taq as a typical inhibitor in the presence of 1 ng or less (Kermekchiev et al., 2009). 


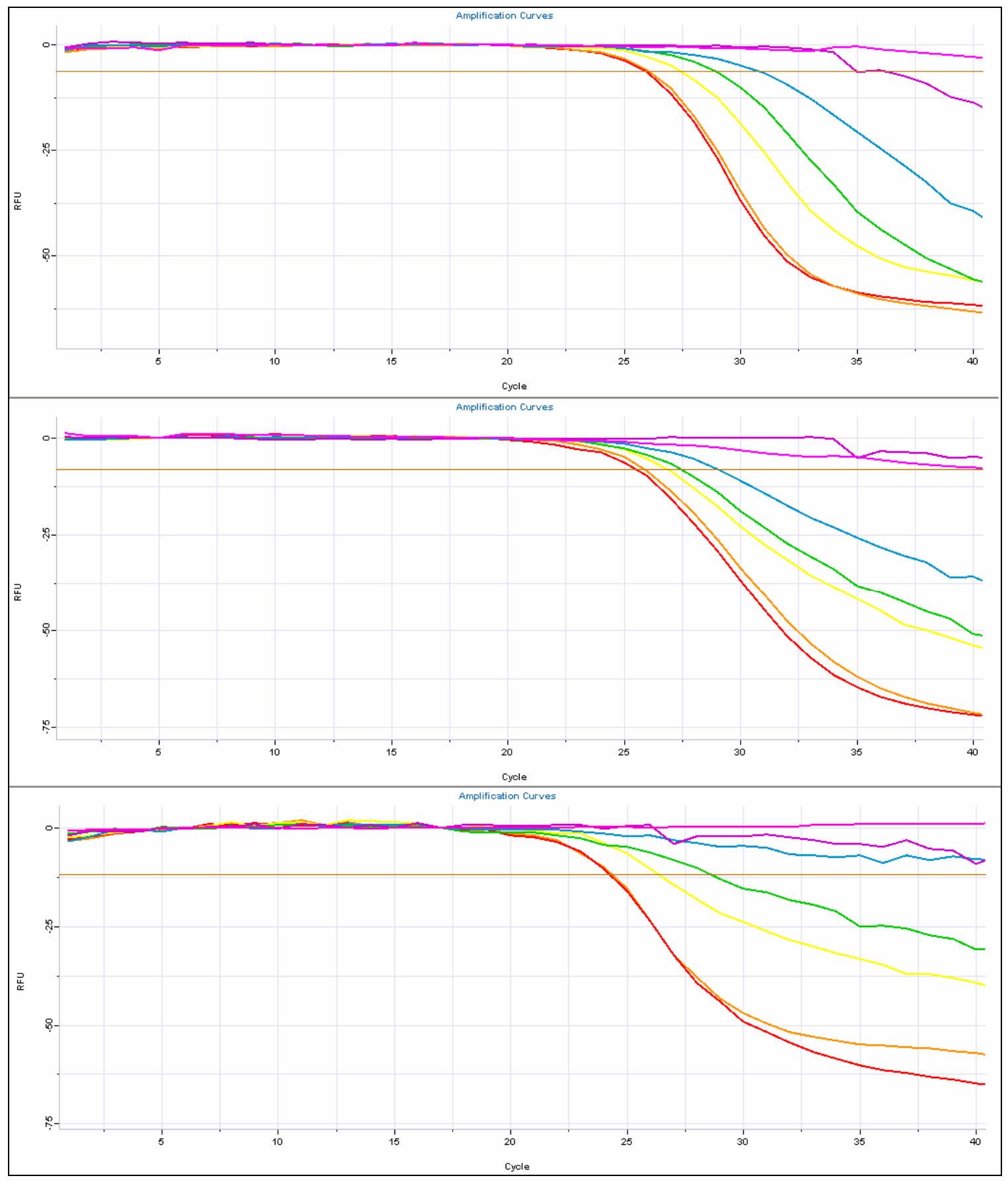

Figure 5-2a: Plexor HY amplification curves plotting RFU versus cycle number for increasing humic acid concentrations. Changes in Autosomal (top), Y Chromosomal (middle) and IPC (bottom) curves at the following concentrations of humic acid: $0 \mathrm{ng} / \mathrm{uL}$ (red), 5ng/uL (orange), 100ng/uL (yellow), 15ng/uL (green), 20ng/uL (blue), 25ng/uL (purple), 30ng/uL (pink). 


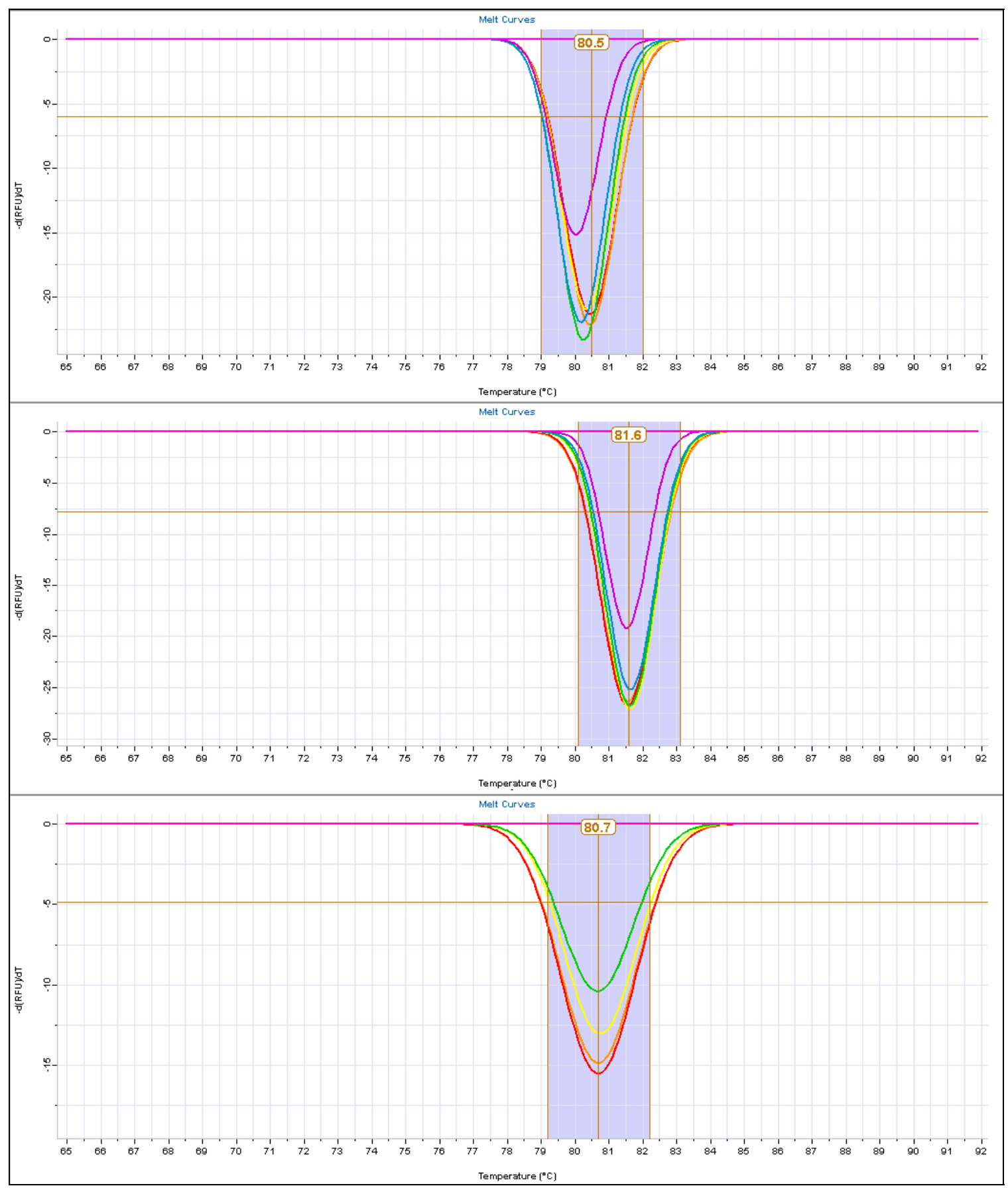

Figure 5-2b: Plexor HY melt curves plotting the rate of change of the RFU with time versus temperature for increasing humic acid concentrations. Changes in Autosomal (top), Y Chromosomal (middle) and IPC (bottom) curves at the following concentrations of humic acid: $0 \mathrm{ng} / \mathrm{uL}$ (red), $5 \mathrm{ng} / \mathrm{uL}$ (orange), 100ng/uL (yellow), 15ng/uL (green), 20ng/uL (blue), 25ng/uL (purple), 30ng/uL (pink). 


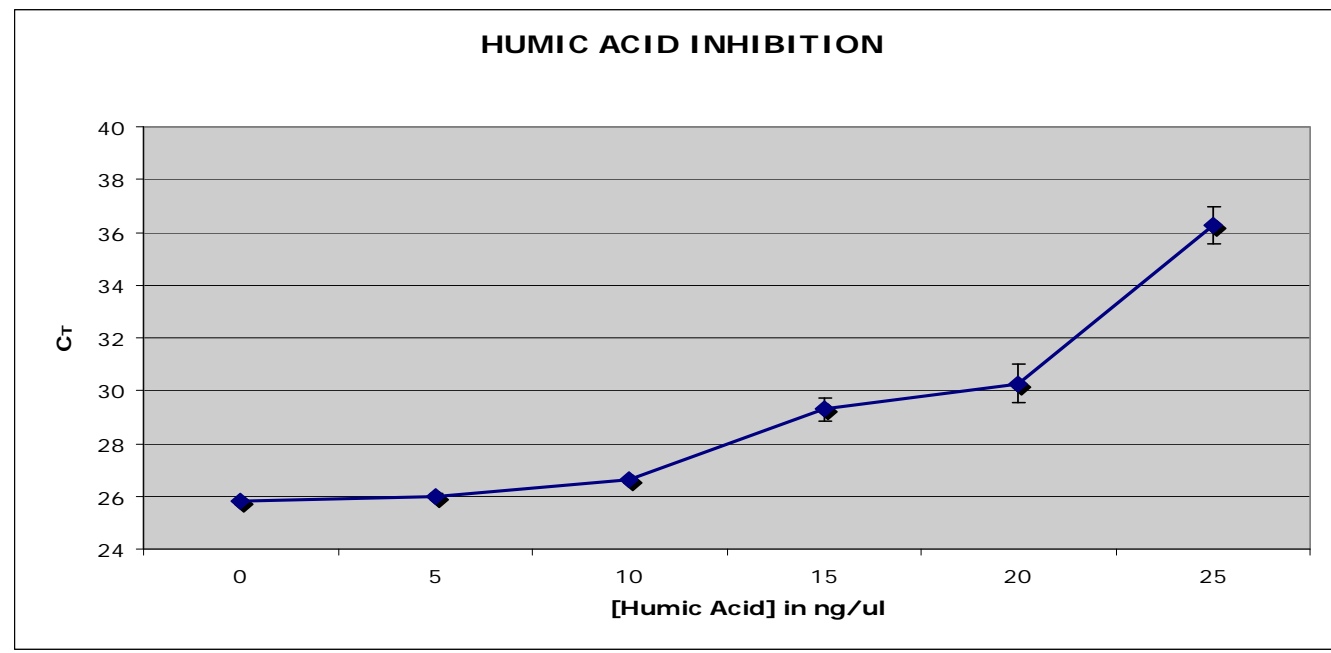

Figure 5-2c: $\mathrm{C}_{\mathrm{T}}$ versus increasing concentrations of humic acid inhibitor

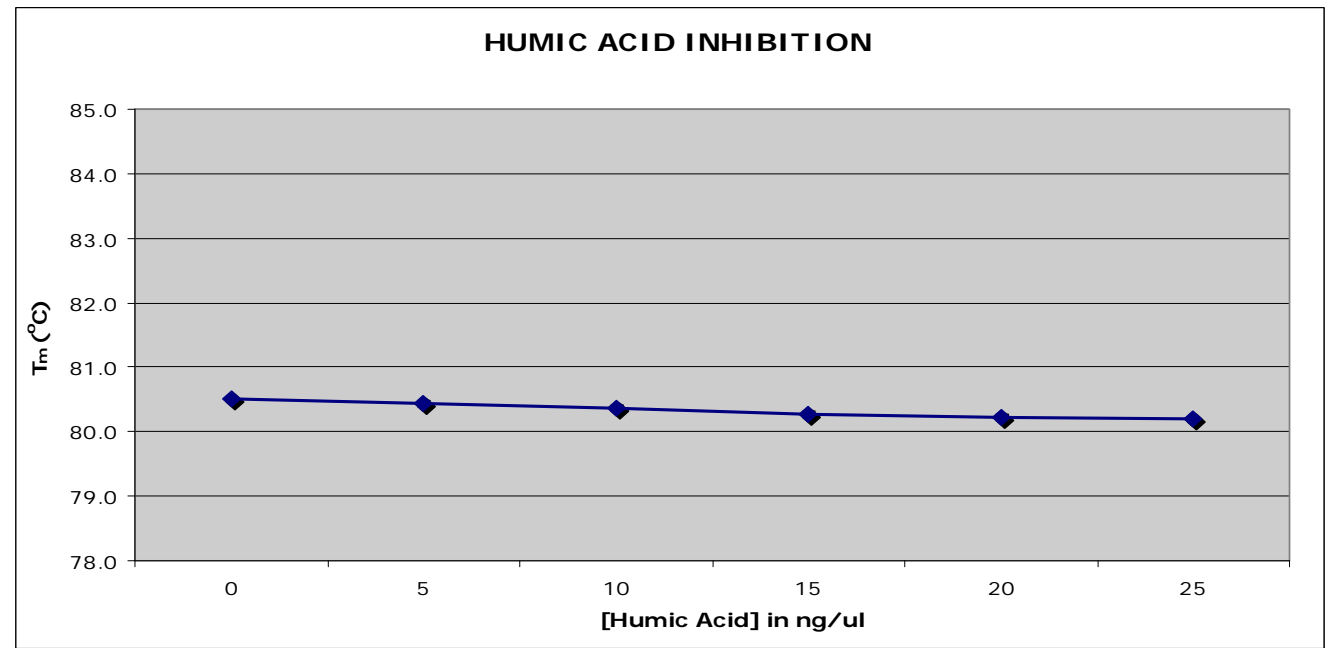

Figure 5-2d: $\mathrm{T}_{\mathrm{m}}\left({ }^{\circ} \mathrm{C}\right)$ versus increasing concentrations of humic acid inhibitor

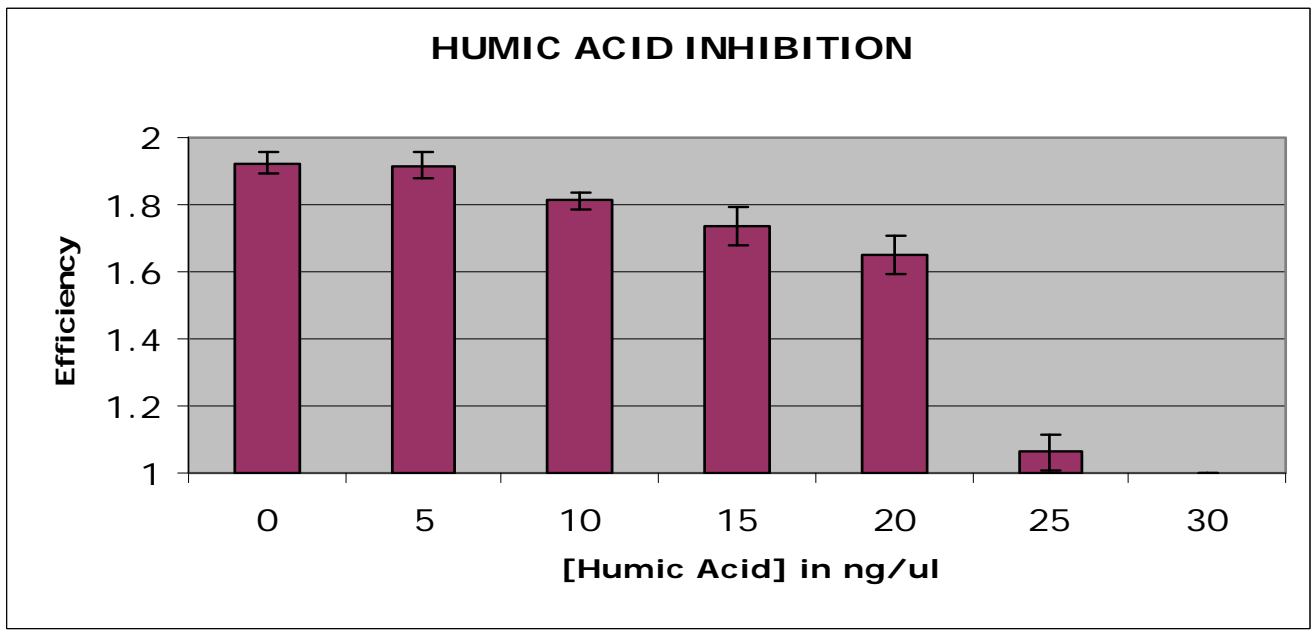

Figure 5-2e: Efficiency versus increasing concentrations of humic acid inhibitor 


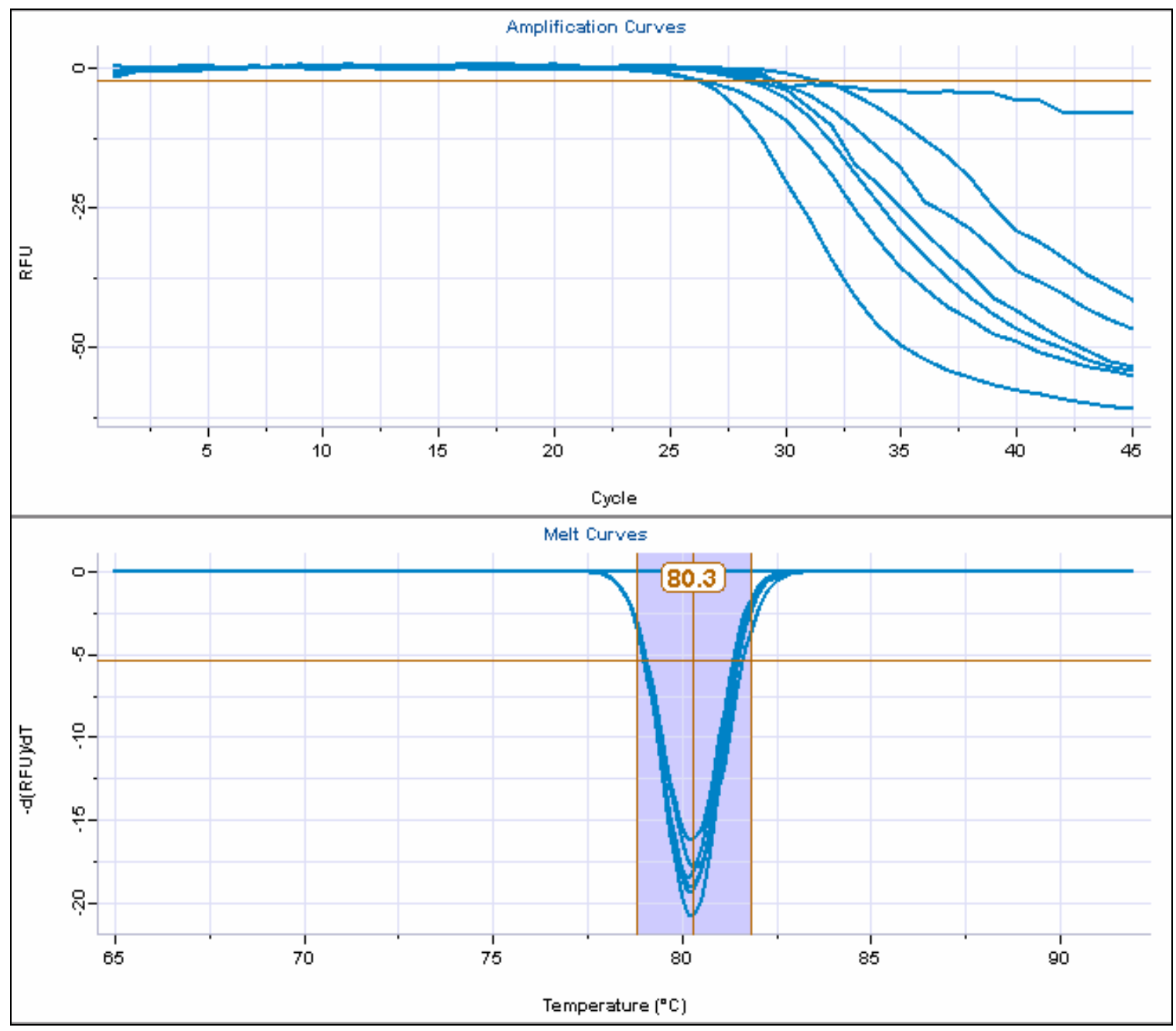

Figure 5-2f: Plexor HY amplification and melt curves plotting RFU versus cycle number for increasing humic acid concentrations for modified RNU2 sequence. Changes in Autosomal amplification (top) and melt (bottom) curves at the following concentrations of humic acid: 0ng/uL, 100ng/uL, 200ng/uL, 300ng/uL, 400ng/uL, 50ng/uL, 600ng/uL. 


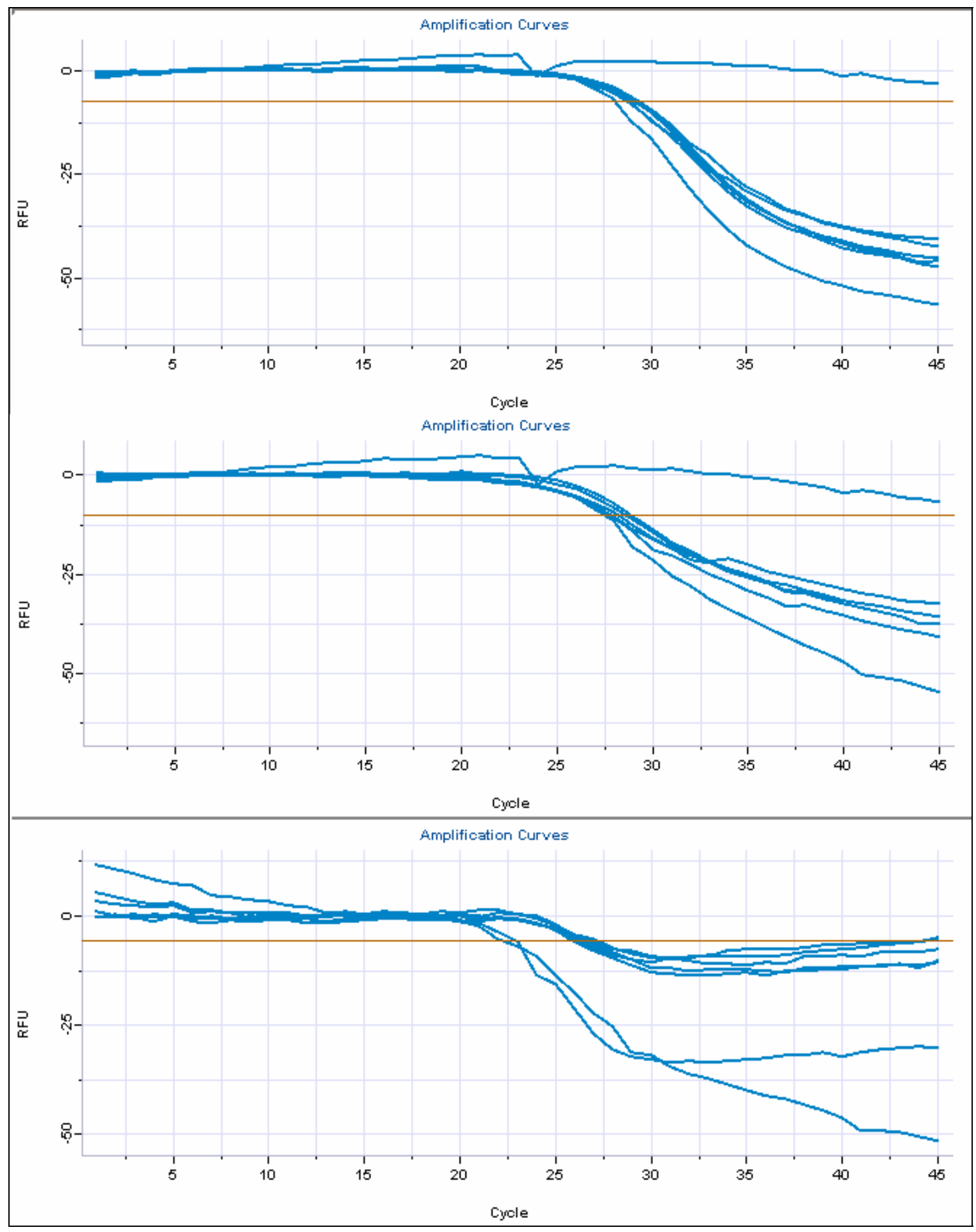

Figure 5-2g: Plexor HY amplification curves plotting RFU versus cycle number for increasing humic acid concentrations without BSA. Changes in Autosomal (top), Y Chromosomal (middle) and IPC (bottom) curves at the following concentrations of humic acid: $0 \mathrm{ng} / \mathrm{uL}, 1 \mathrm{ng} / \mathrm{uL}, 2 \mathrm{ng} / \mathrm{uL}, 3 \mathrm{ng} / \mathrm{uL}, 4 \mathrm{ng} / \mathrm{uL}, 5 \mathrm{ng} / \mathrm{uL}$. 


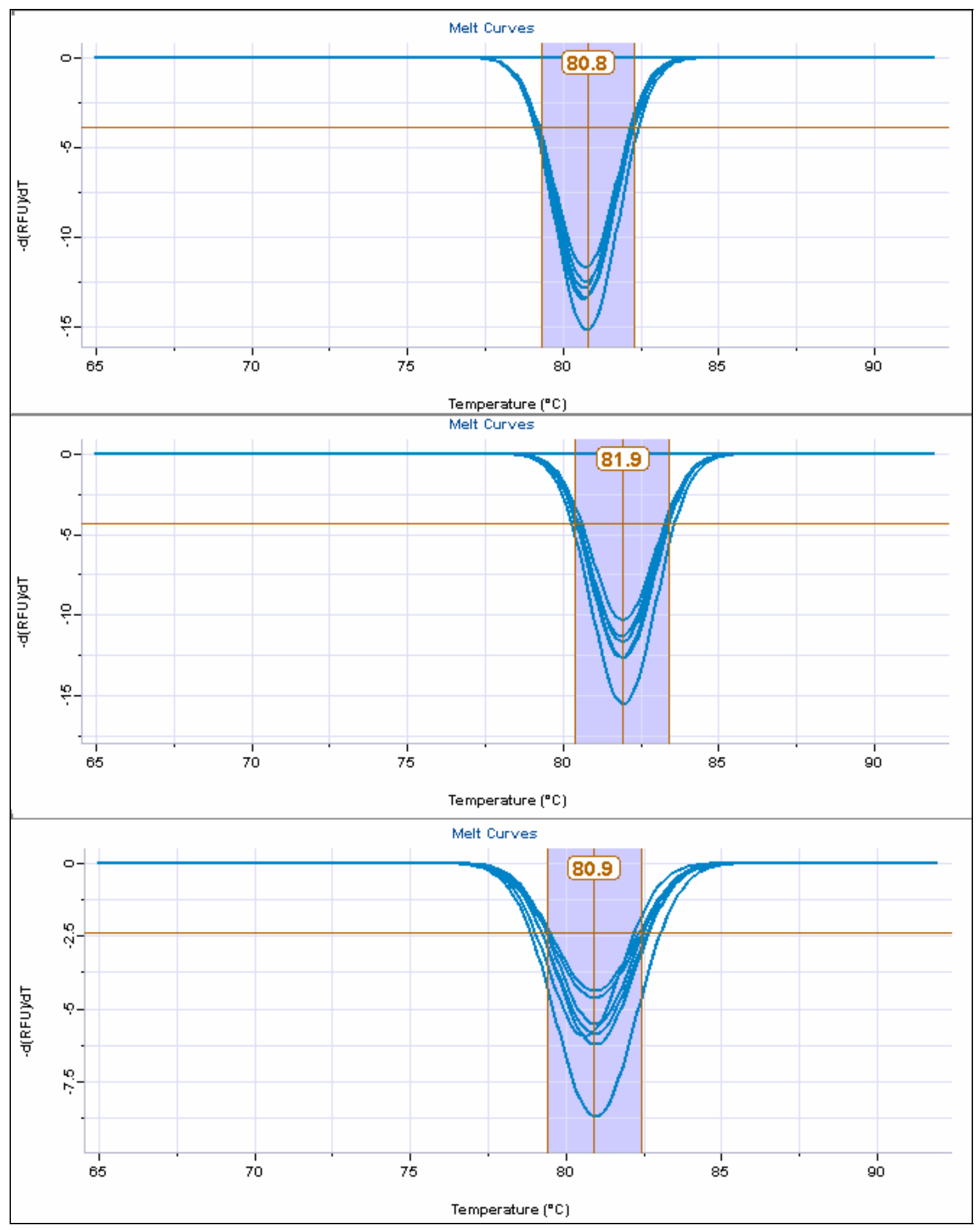

Figure 5-2h: Plexor HY melt curves plotting the rate of change of the RFU with time versus temperature for increasing humic acid concentrations without BSA. Changes in Autosomal (top), Y Chromosomal (middle) and IPC (bottom) curves at the following concentrations of humic acid: $0 \mathrm{ng} / \mathrm{uL}, 1 \mathrm{ng} / \mathrm{uL}, 2 \mathrm{ng} / \mathrm{uL}$, $3 n g / u L, 4 n g / u L, 5 n g / u L$. 


\section{$\underline{\text { Collagen }}$}

Collagen reduced the amplification efficiency, produced a slight shift in $\mathrm{C}_{\mathrm{T}}$ at higher concentrations, and gave a change in the melt curve for all amplicons (Figures 5$3 \mathrm{a}$ and $\mathrm{b}) . \mathrm{A} \mathrm{C}_{\mathrm{T}}$ increase of 4 cycles over the range of inhibitor concentrations along with a gradual change in slope of the amplification curve suggests an effect on amplification efficiency more than the blocking of available template (Figure 5-3c). There was an increase in $\mathrm{T}_{\mathrm{m}}$ of approximately $5{ }^{\circ} \mathrm{C}$ with $\pm 1{ }^{\circ} \mathrm{C}$ for the higher concentrations (Figure 53d). Relatively high amplification efficiencies were calculated for smaller concentrations of collagen up to $62.5 \mathrm{ng} / \mathrm{ul}$ (Figure 5-3e). Interestingly the effect of the collagen on the IPC was minimal except at the highest levels of inhibitor. This is a strong indicator of a sequence specific effect and is a troubling result because the IPC is more commonly used to detect PCR inhibition. Clearly for collagen inhibition, this strategy would fail at mid levels of the inhibitor.

The $T_{m}$ increased as inhibitor concentration increased, which signifies that collagen is prevents denaturing of the dsDNA and may be interfering through hydrogen bonding. In aqueous solution, a collagen-DNA aggregate forms and this interaction leads to the destruction of the collagen triple helix and stabilization of the DNA double helix structure (Mrevlishvili et al., 2005). Collagen could be a possible groove binder due to its triple helix structure and may allow wrapping throughout the DNA molecule. It is also a peptide and therefore susceptible to hydrogen bonding. These results suggest that collagen binds DNA as well as inhibits Taq, an effect concordant with previous SYBR green results. Plexor results tend to show the presence of both effects on Taq and on the DNA template. The results of Opel et al. showed that additional Taq and magnesium did 


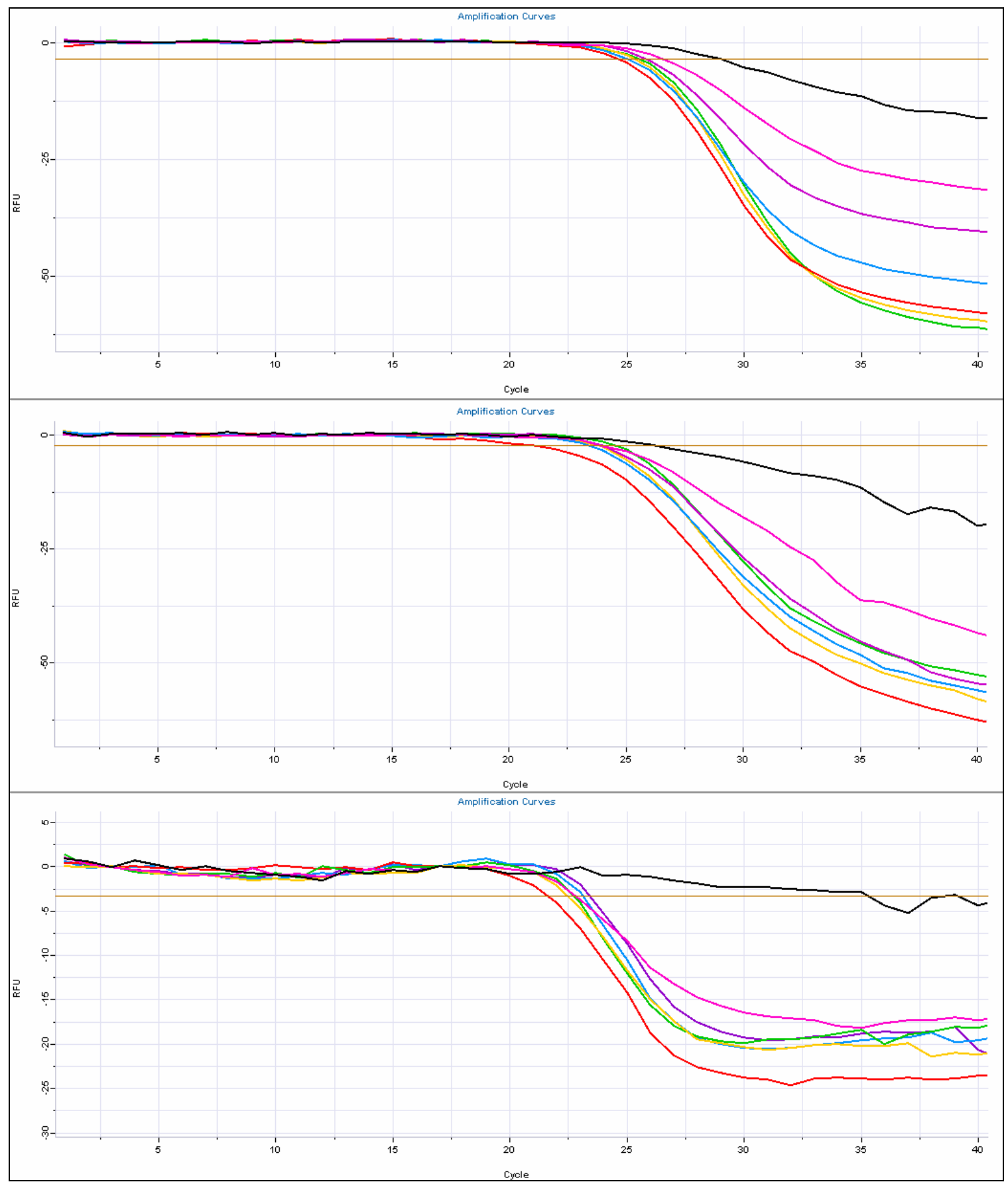

Figure 5-3a: Plexor HY amplification curves plotting RFU versus cycle number for increasing collagen concentrations. Changes in Autosomal (top), Y Chromosomal (middle) and IPC (bottom) curves at the following concentrations of collagen: 0ng/uL (red), 25ng/uL (orange), 37.5ng/uL (yellow), 50ng/uL (green), 62.5ng/uL (blue), 75ng/uL (purple), $87.5 \mathrm{ng} / \mathrm{uL}$ (pink), 100ng/uL (black). 


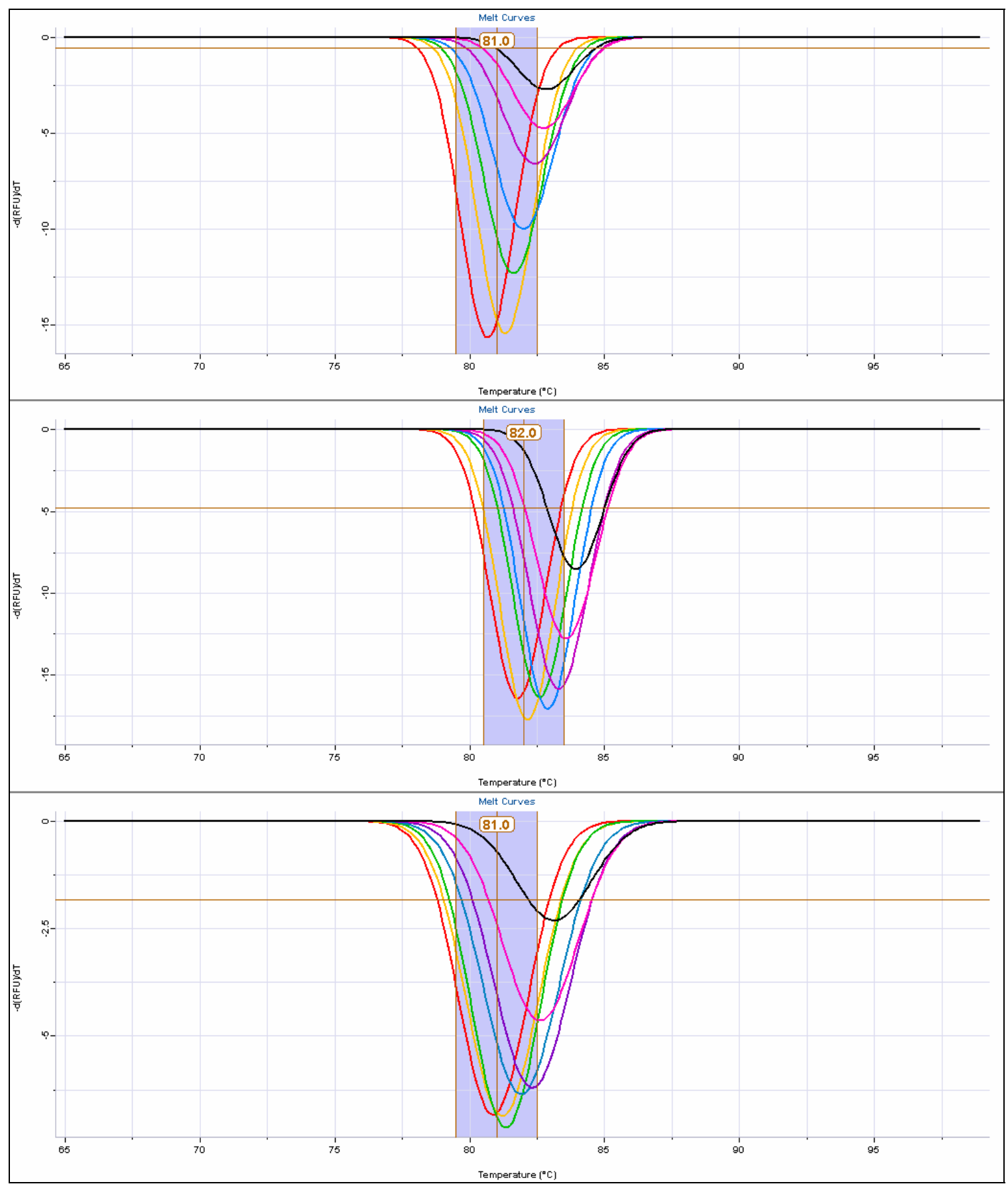

Figure 5-3b: Plexor HY melt curves plotting the rate of change of the RFU with time versus temperature for increasing collagen concentrations. Changes in Autosomal (top), Y Chromosomal (middle) and IPC (bottom) curves at the following concentrations of collagen: $0 \mathrm{ng} / \mathrm{uL}$ (red), 25ng/uL (orange), 37.5ng/uL (yellow), $50 \mathrm{ng} / \mathrm{uL}$ (green), 62.5ng/uL (blue), 75ng/uL (purple), 87.5ng/uL (pink), 100ng/uL (black). 


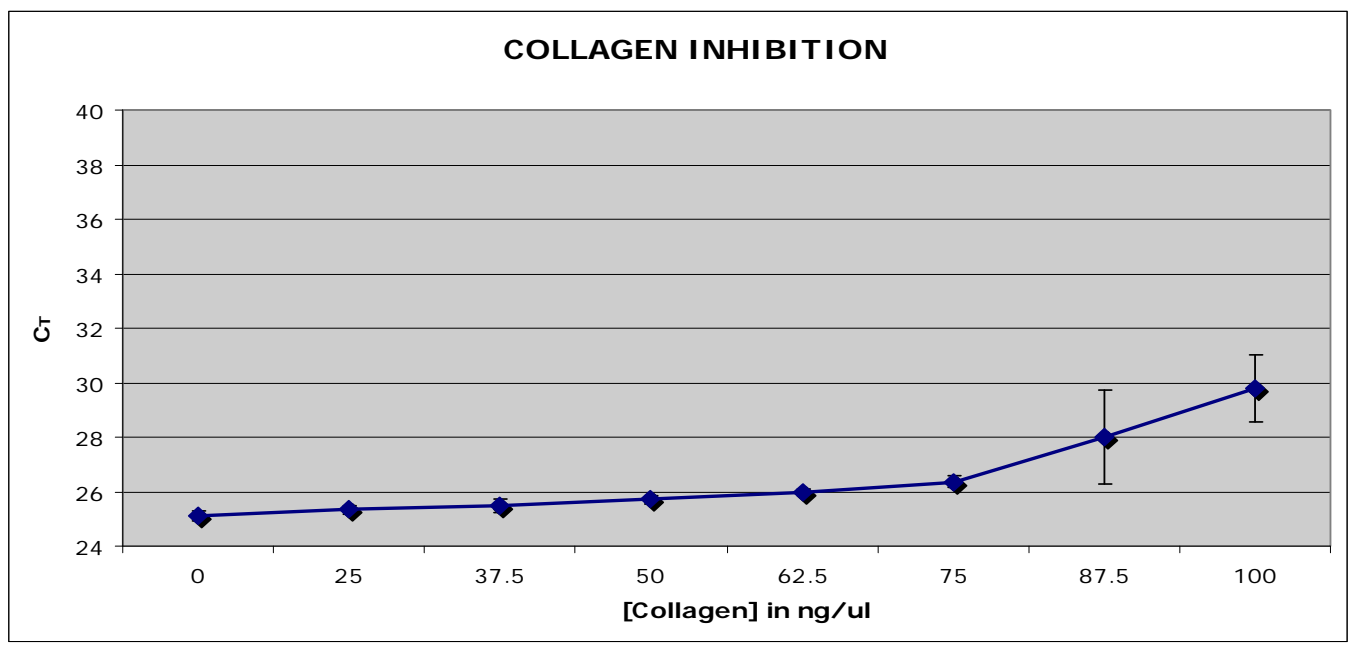

Figure 5-3c: $C_{T}$ versus increasing concentrations of collagen inhibitor

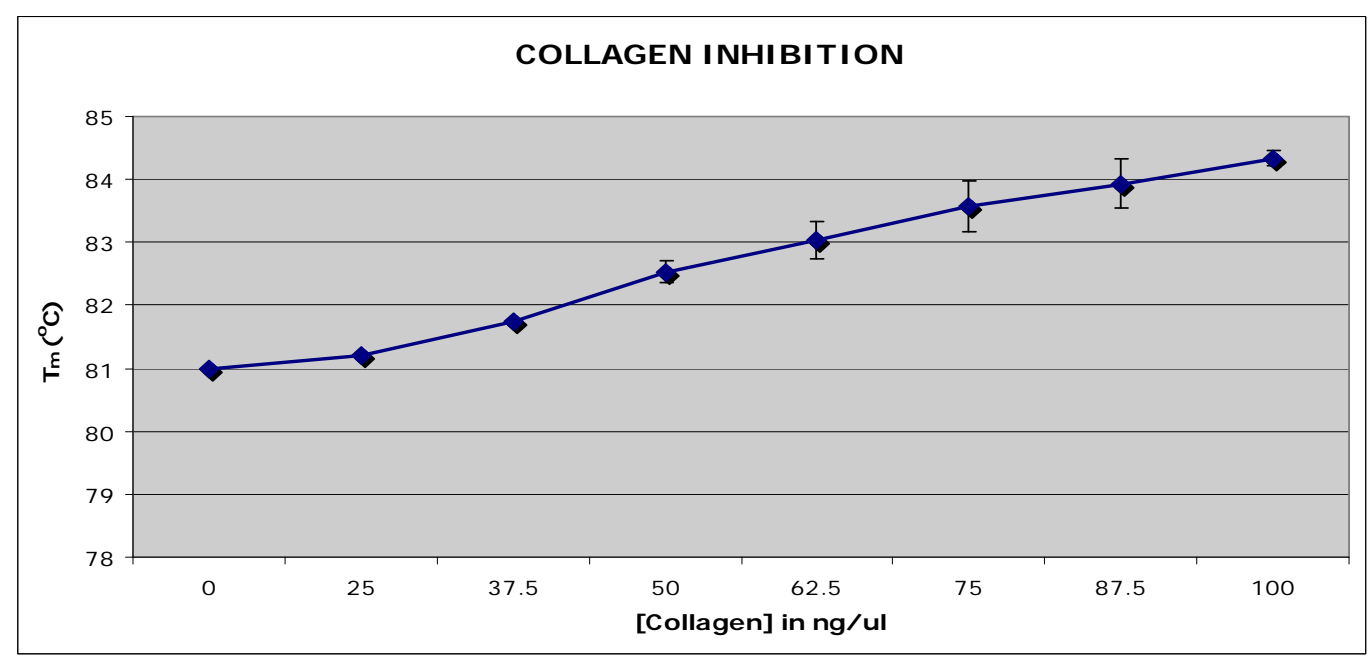

Figure 5-3d: $\mathrm{T}_{\mathrm{m}}\left({ }^{\circ} \mathrm{C}\right)$ versus increasing concentrations of collagen inhibitor

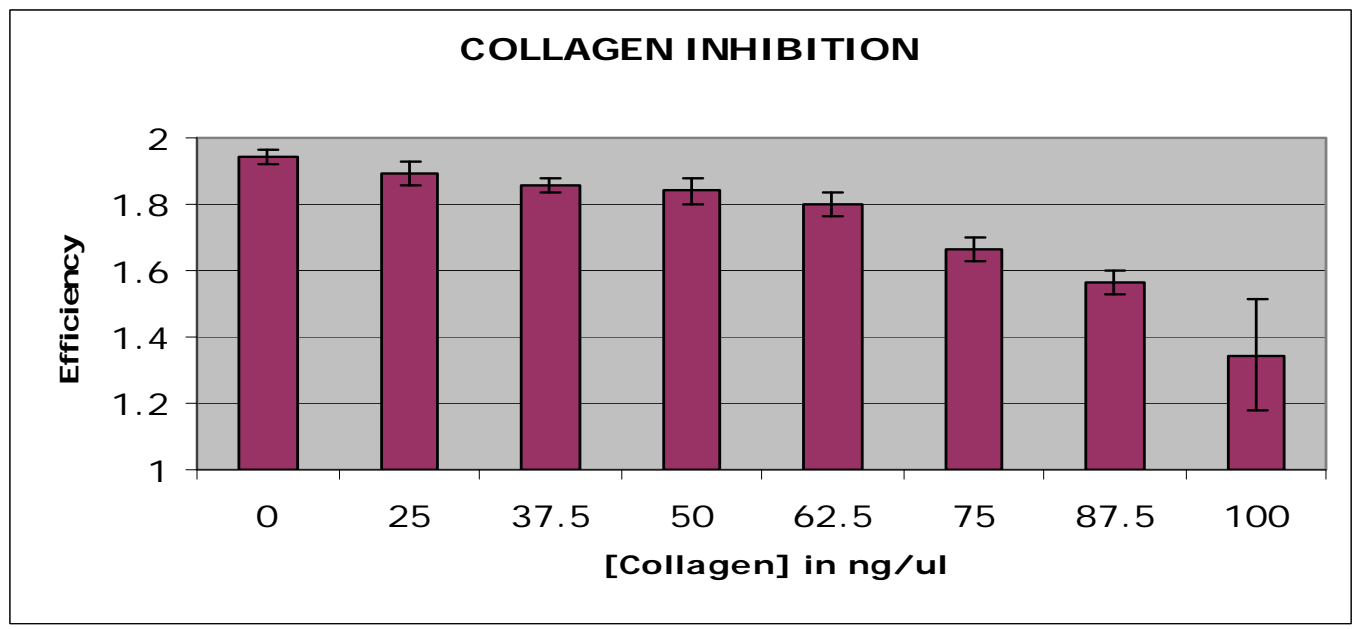

Figure 5-3e: Efficiency versus increasing concentrations of collagen inhibitor 
not appear to improve amplification of inhibited samples indicating that the mechanism of inhibition is not a result of binding or interference with magnesium. However, the shift in $\mathrm{T}_{\mathrm{m}}$ produced by collagen with SYBR green is opposite to that with Plexor (Opel et al., 2010). These differences could again be due to the interference of SYBR green binding. Interestingly, other research on collagen inhibition has stated that Taq polymerase had relatively low sensitivity to collagen (Kim et al., 2000).

\section{$\underline{\text { Phenol }}$}

Phenol showed a reduction in efficiency, a shift in $\mathrm{C}_{\mathrm{T}}$, and melt curve results that were contrary to that of collagen for all amplicons (Figures 5-4a and b). Phenol results were similar to collagen in some respect - it produced a minimal $\mathrm{C}_{\mathrm{T}}$ shift of 4 cycles, and a gradual decrease in slope of the amplification curve. This suggests Taq inhibition more than DNA binding effects just as in collagen (Figure 5-4c). However, the $\mathrm{T}_{\mathrm{m}}$ decreased by approximately $3{ }^{\circ} \mathrm{C}$ as inhibitor concentration increased, also indicating DNA binding effects (Figure 5-3d). There was a gradual reduction in amplification efficiecny as phenol concentration increased - an indication Taq inhibition (Figure 5-3e).

Like collagen, phenol exhibits both the effects of the inhibitor binding to the polymerase and DNA. Whereas Taq polymerase slowly deactivates and produces less amplified product, DNA binding to phenol results in a decrease in melting temperature, which produces weakening of the hydrogen bonds between bases and enhances denaturation. Although phenol is a protein denaturant, it may still promote unzipping of DNA through hydrogen bonding to ssDNA (Goldar et al., 2004). Since phenol is the simplest aromatic structure, it may not intercalate but slide in and out between bases, 


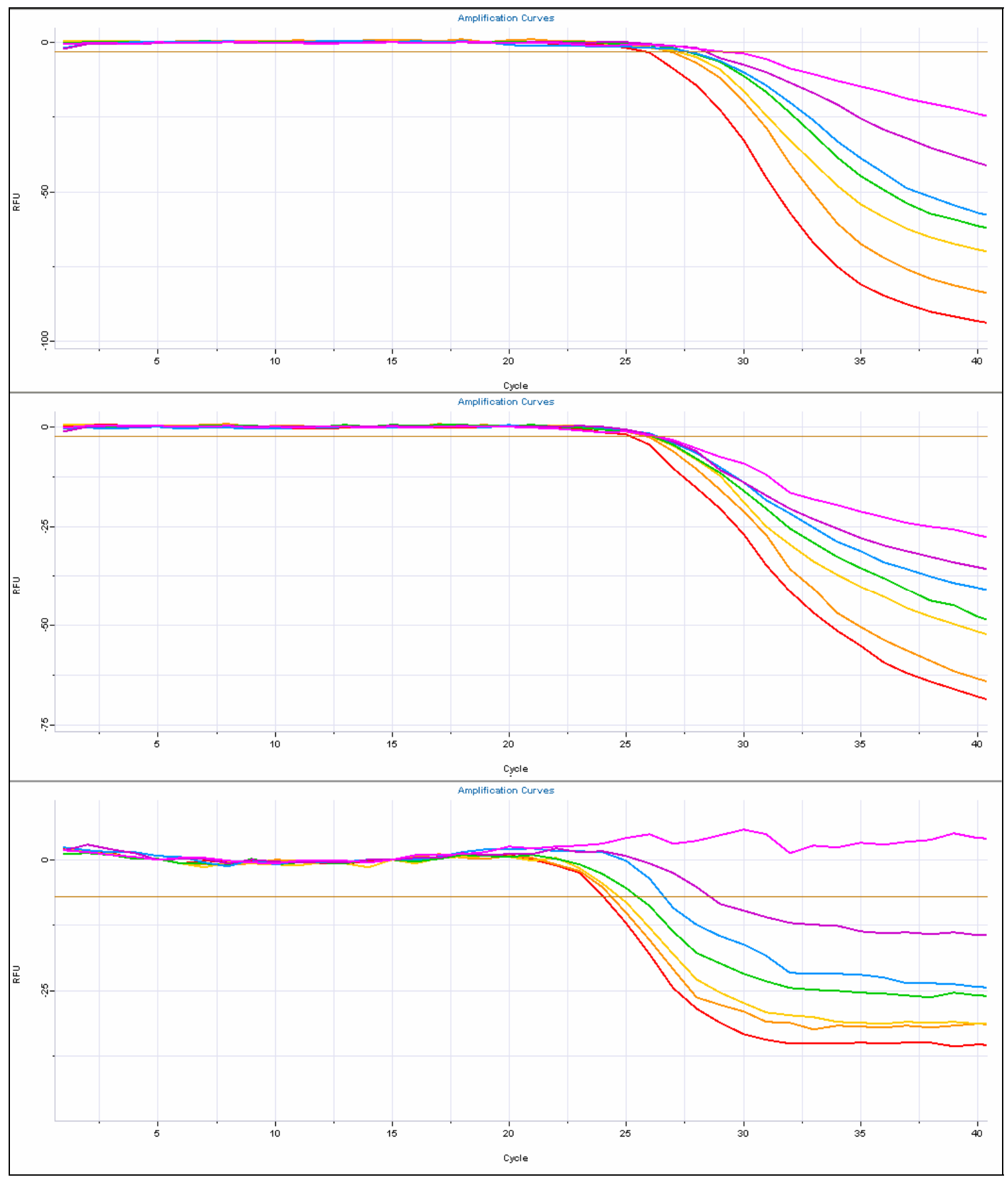

Figure 5-4a: Plexor HY amplification curves plotting RFU versus cycle number for increasing phenol concentrations. Changes in Autosomal (top), Y Chromosomal (middle) and IPC (bottom) curves at the following concentrations of phenol: $0 \mathrm{ug} / \mathrm{uL}$ (red), 33ug/uL (orange), 66ug/uL (yellow), 83ug/uL (green), 100ug/uL (blue), 116ug/uL (purple), 133ug/uL (pink). 


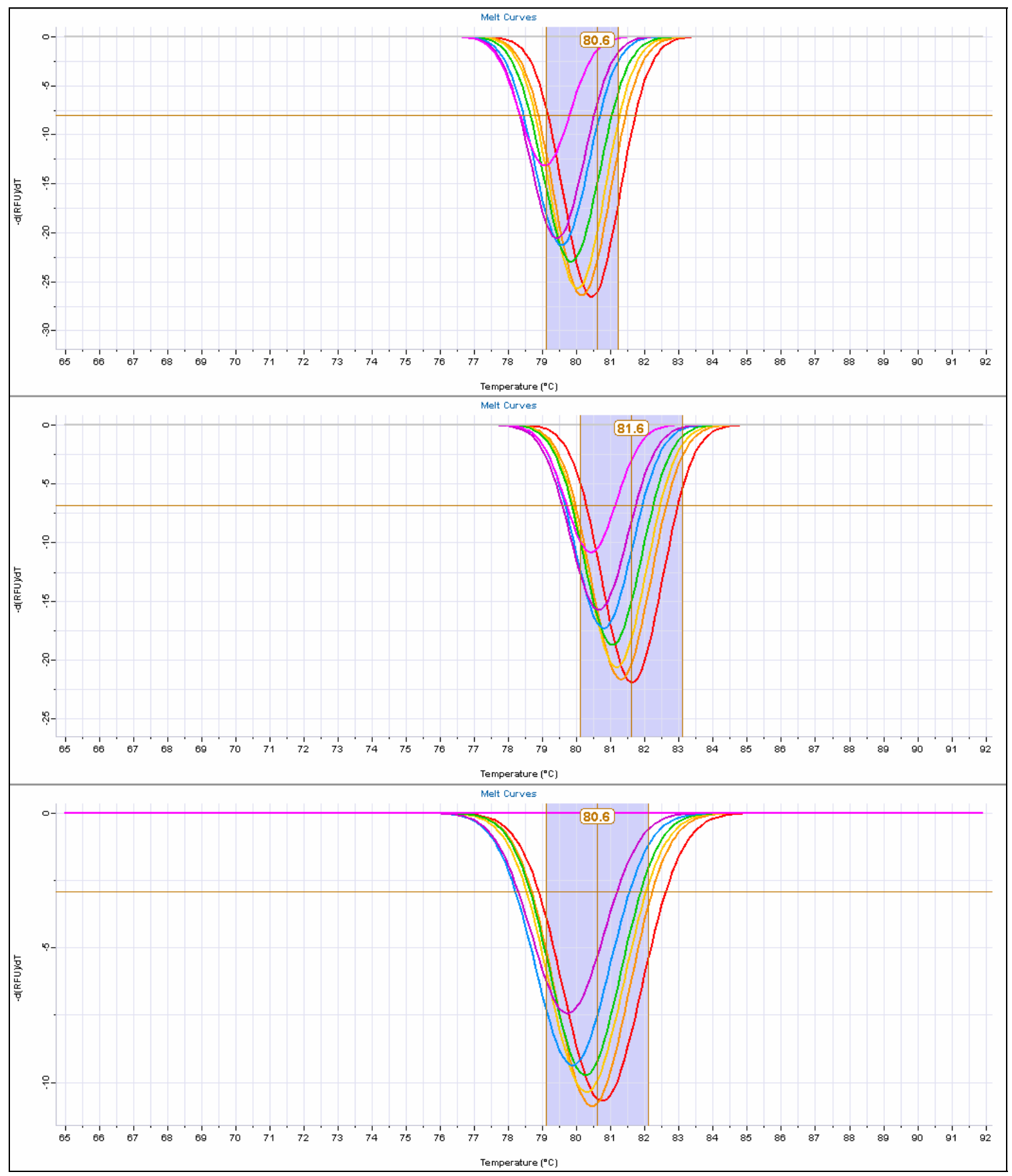

Figure 5-4b: Plexor HY melt curves plotting the rate of change of the RFU with time versus temperature for increasing phenol concentrations. Changes in Autosomal (top), Y Chromosomal (middle) and IPC (bottom) curves at the following concentrations of phenol: 0ug/uL (red), 33ug/uL (orange), 66ug/uL (yellow), 83ug/uL (green), 100ug/uL (blue), 116ug/uL (purple), 133ug/uL (pink). 


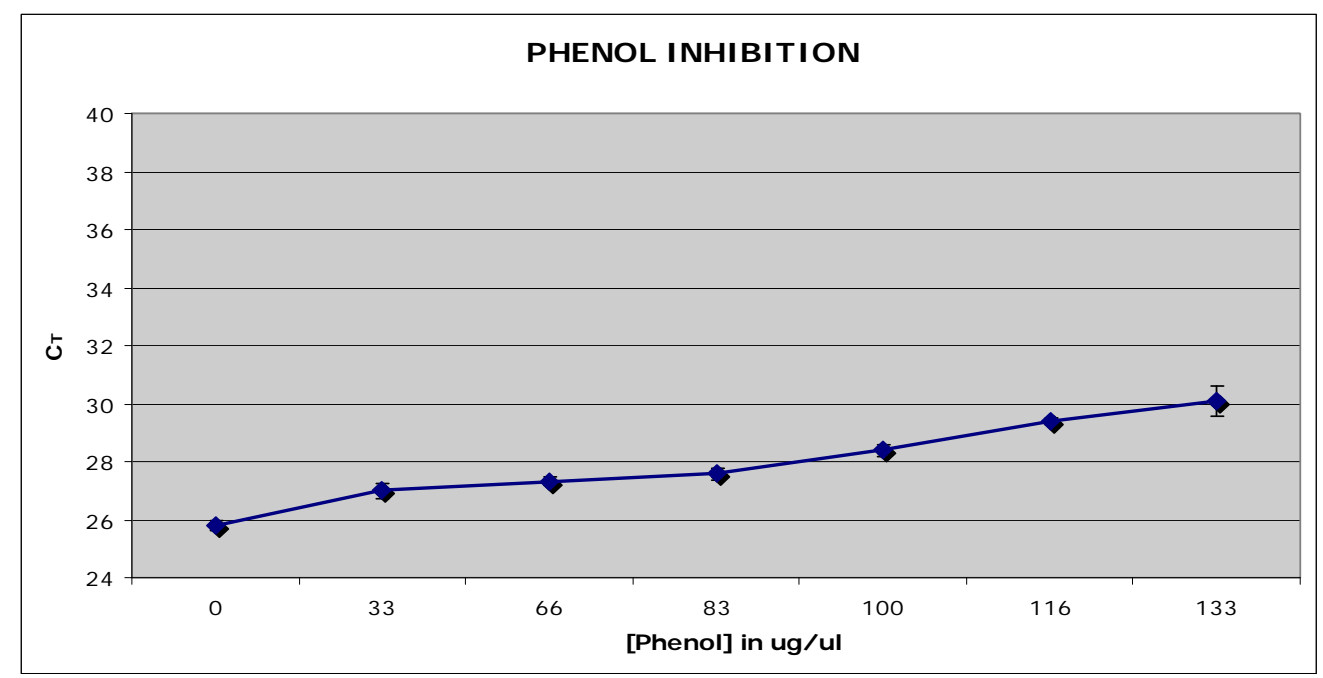

Figure 5-4c: $\mathrm{C}_{\mathrm{T}}$ versus increasing concentrations of phenol inhibitor

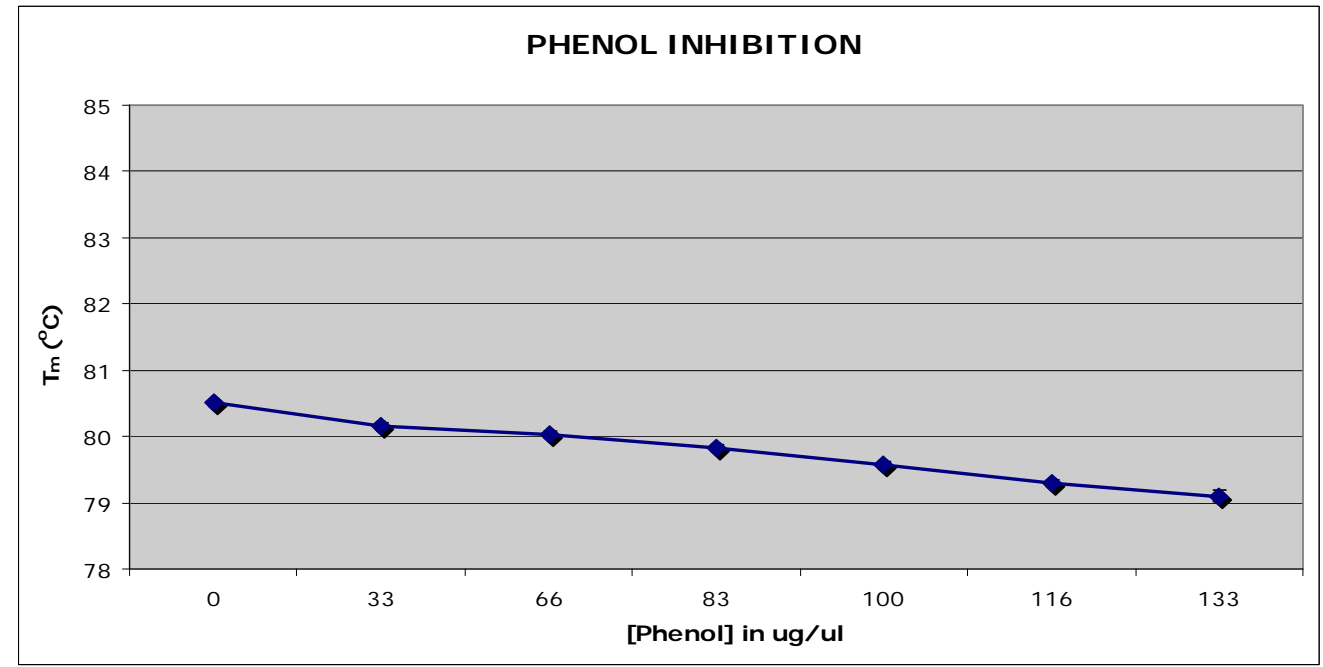

Figure 5-4d: $\mathrm{T}_{\mathrm{m}}$ in ${ }^{\circ} \mathrm{C}$ versus increasing concentrations of phenol inhibitor

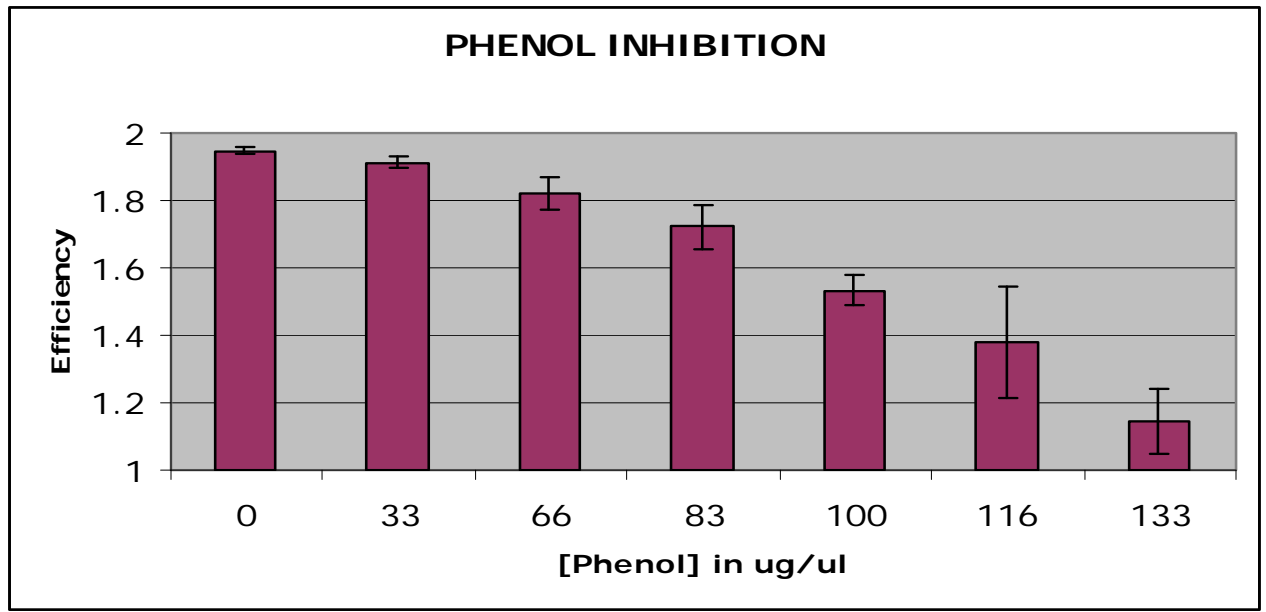

Figure 5-4e: Efficiency versus increasing concentrations of phenol inhibitor 
interfering with the sugar phosphate backbone. In traditional PCR followed by gel electrophoresis it is known that traces of phenol can completely inactivate the Taq polymerase (Katcher et al., 1994); however phenol is also known for direct DNA inhibition (Wiedbrauk et al., 1995).

\section{$\underline{\text { Tannic acid }}$}

Tannic acid produced a $\mathrm{C}_{\mathrm{T}}$ shift and a reduction of efficiency at higher concentrations of inhibitor for all amplicons (Figures 5-5a and b). The slope of the amplification curves was gradual and showed a minimal change in $\mathrm{C}_{\mathrm{T}}$ that was primarily an effect of changes in slope (Figure 5-5c), In addition there was an insignificant change in $\mathrm{T}_{\mathrm{m}}$ of $0.2^{\circ} \mathrm{C}$ (Figure $5-5 \mathrm{~d}$ ) and a gradual reduction in efficiency as inhibitor concentration increased (Figure 5-5e). Tannic acid was also further studied to see if amplicon length and absence of BSA could enhance results. The results suggest that in a similar fashion to humic acid, a loss of $\mathrm{C}_{\mathrm{T}}$ occurred that was not related to efficiency. This was particularly evident for the autosomal amplicon and less so for the others, indicating potential binding to the template. However there was minimal effect on the melt curve just like humic acid (Figures 5-5f and $\mathrm{g}$ ).

Previous research using SYBR Green also showed minimal changes in the melt curves but no change in the slope of the PCR amplification efficiency (Opel et al., 2010). These effects indicate a mixed mode inhibitor with weak binding to the DNA as well as interactions with the polymerase. Tannic acid contains a large number of electronegative groups and could be chelating the magnesium, inactivating the Taq. This would explain Plexor results with efficiency loss. For the larger amplicons, effects indicated by Opel et 


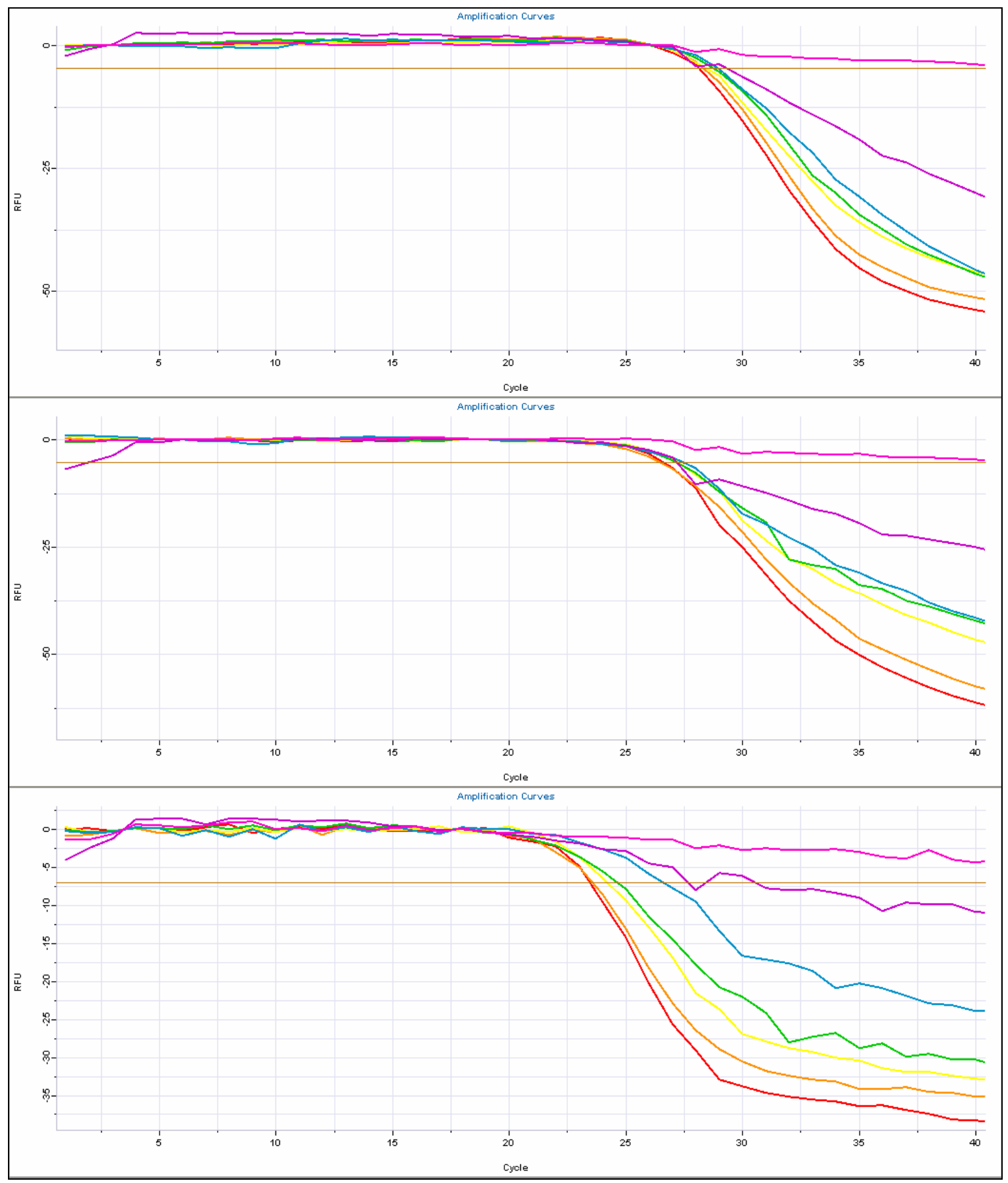

Figure 5-5a: Plexor HY amplification curves plotting RFU versus cycle number for increasing tannic acid concentrations. Changes in Autosomal (top), Y Chromosomal (middle) and IPC (bottom) curves at the following concentrations of tannic acid: $0 \mathrm{ng} / \mathrm{uL}$ (red), 3.75ng/uL (orange), $7.5 \mathrm{ng} / \mathrm{uL}$ (yellow), $11.25 \mathrm{ng} / \mathrm{uL}$ (green), $15 \mathrm{ng} / \mathrm{uL}$ (blue), $18.75 \mathrm{ng} / \mathrm{uL}$ (purple), $22.5 \mathrm{ng} / \mathrm{uL}$ (pink). 


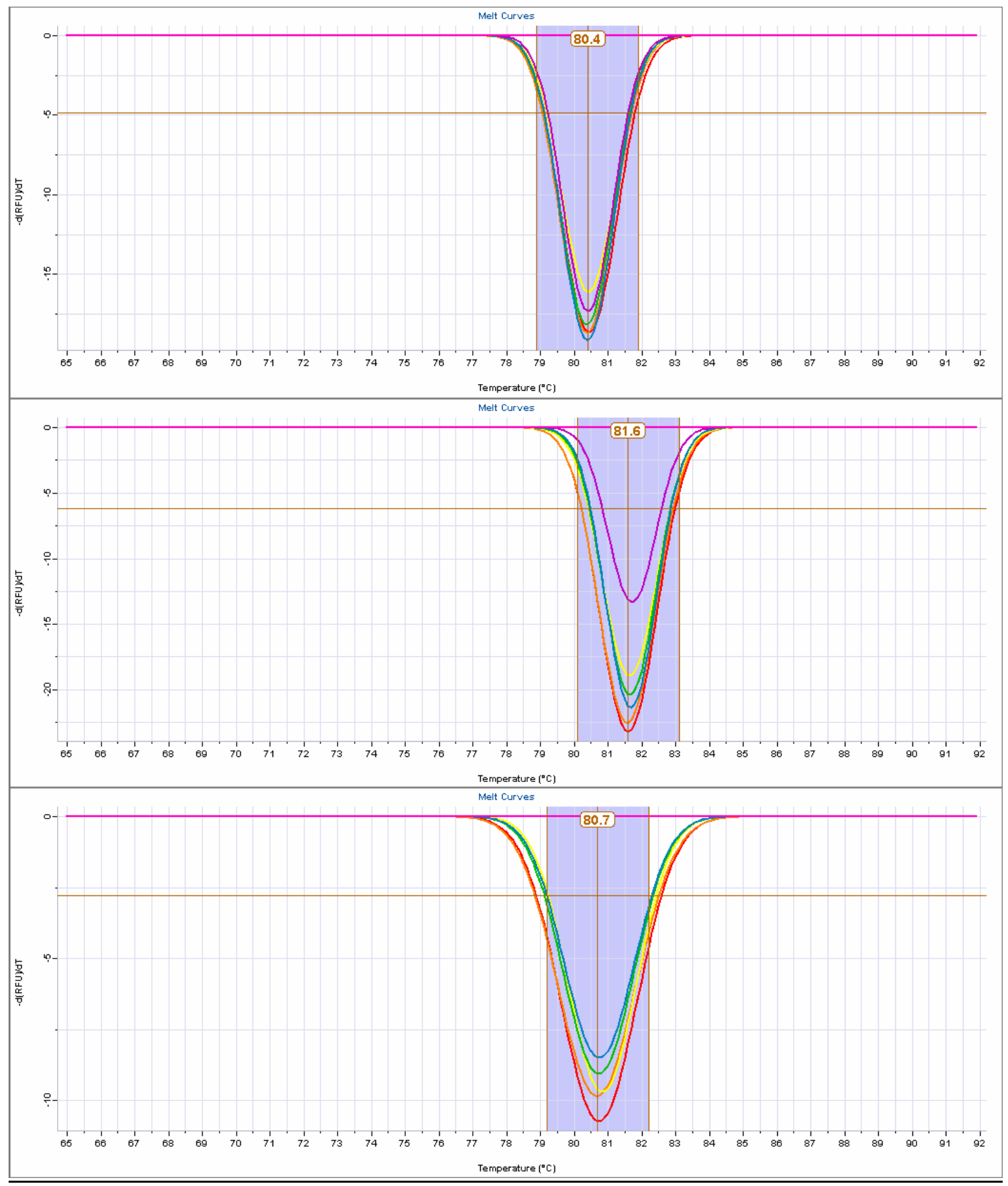

Figure 5-5b: Plexor HY melt curves plotting the rate of change of the RFU with time versus temperature for increasing tannic acid concentrations. Changes in Autosomal (top), Y Chromosomal (middle) and IPC (bottom) curves at the following concentrations of tannic acid: $0 \mathrm{ng} / \mathrm{uL}$ (red), 3.75ng/uL (orange), $7.5 \mathrm{ng} / \mathrm{uL}$ (yellow), 11.25ng/uL (green), 15ng/uL (blue), 18.75ng/uL (purple), 22.5ng/uL (pink). 


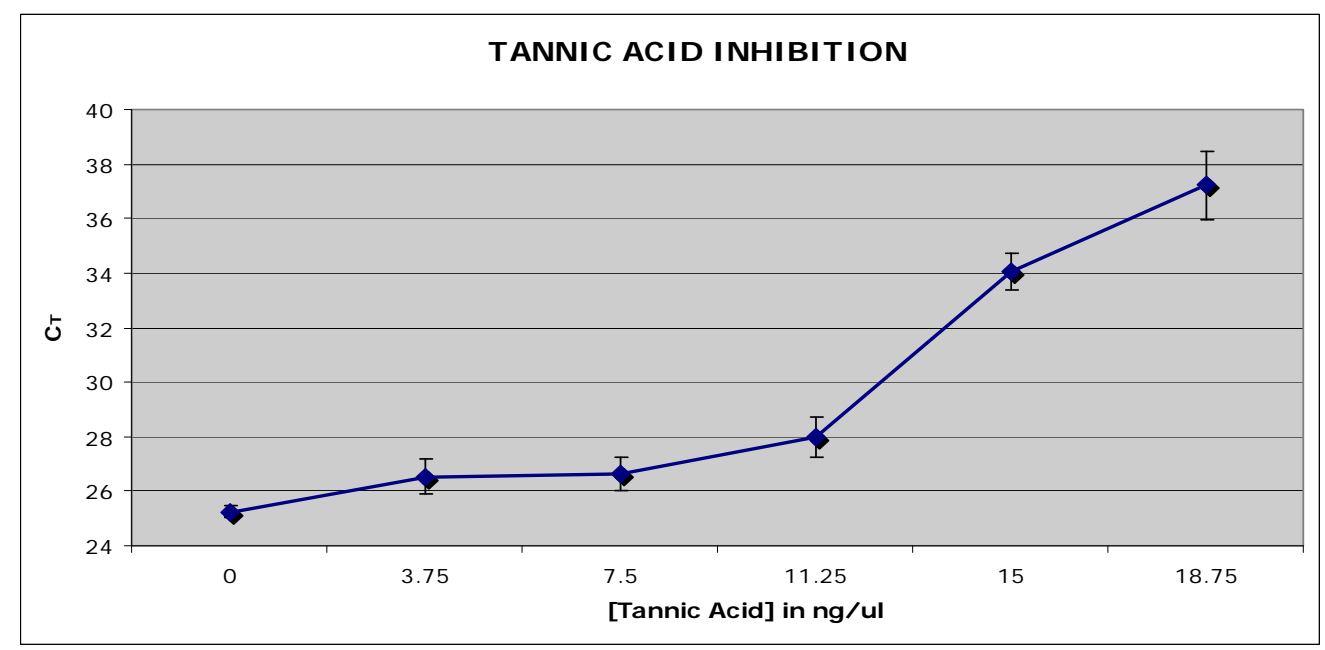

Figure 5-5c: $\mathrm{C}_{\mathrm{T}}$ versus increasing concentrations of tannic acid inhibitor

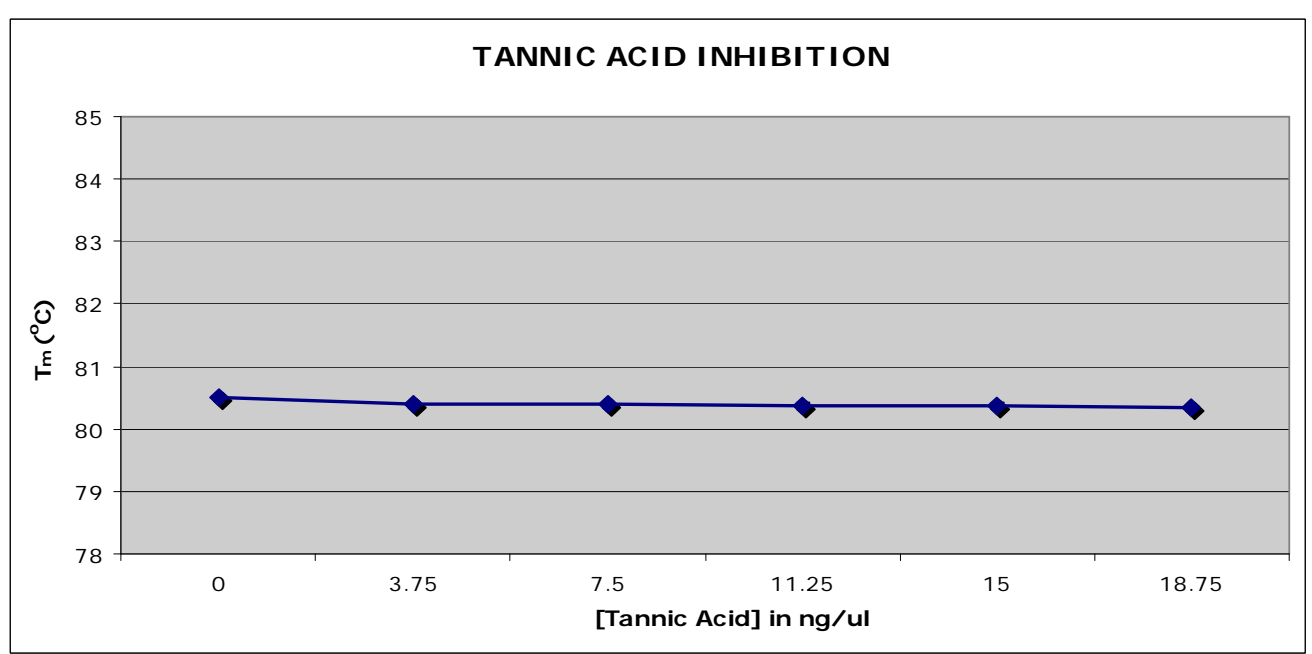

Figure 5-5d: Line $\mathrm{T}_{\mathrm{m}}\left({ }^{\circ} \mathrm{C}\right)$ versus increasing concentrations of tannic acid inhibitor

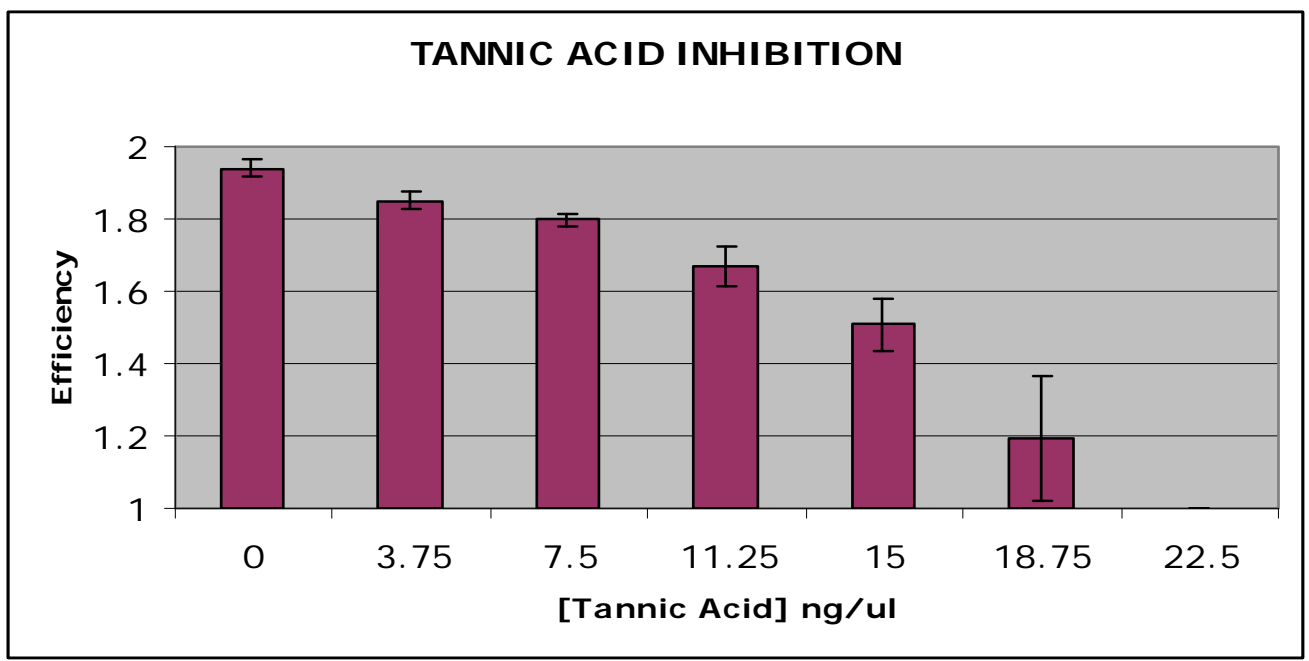

Figure 5-5e: Efficiency versus increasing concentrations of tannic acid inhibitor 


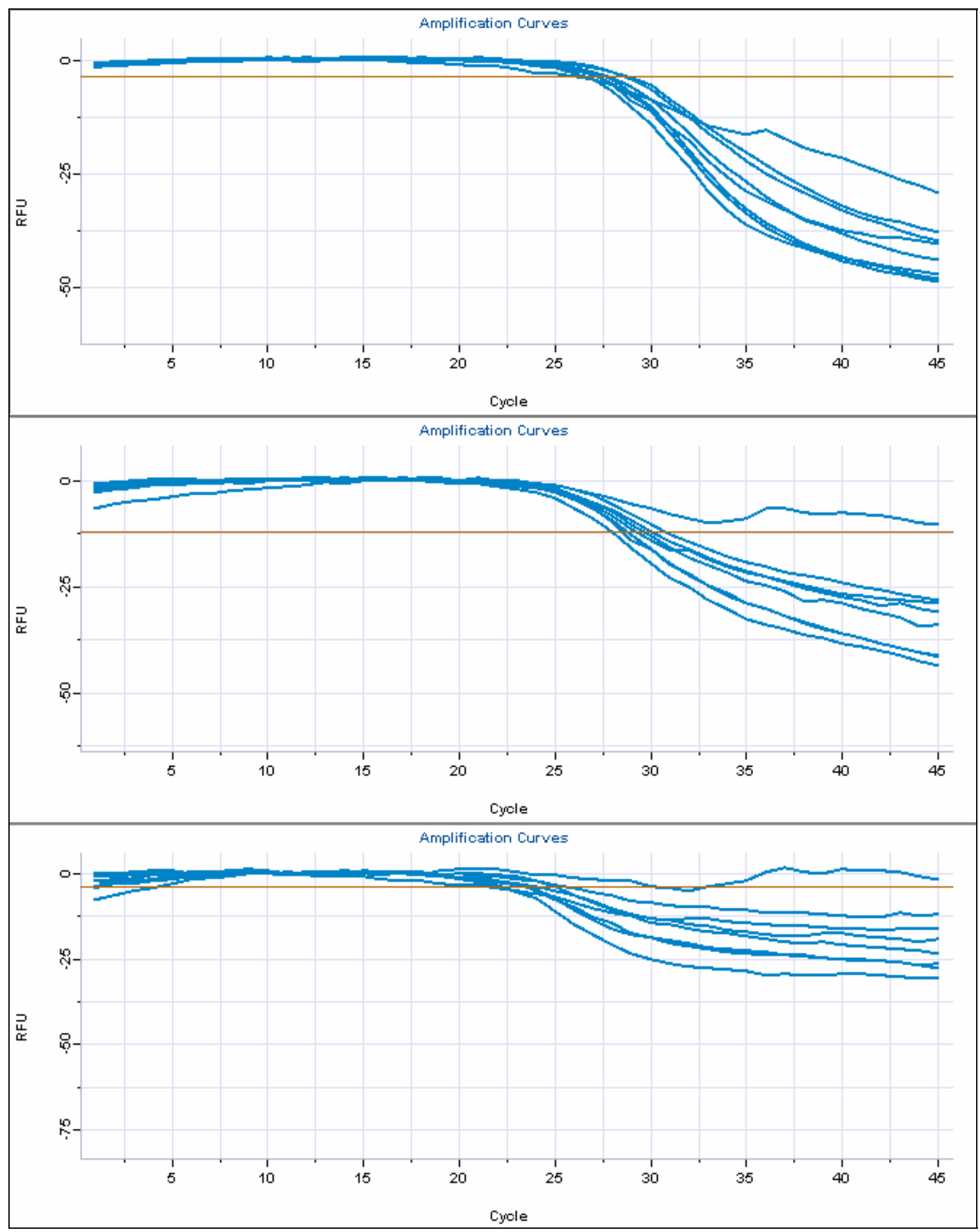

Figure 5-5f: Plexor HY amplification curves plotting RFU versus cycle number for increasing tannic acid concentrations without BSA. Changes in Autosomal (top), Y Chromosomal (middle) and IPC (bottom) curves at the following concentrations of tannic acid: $0 \mathrm{ng} / \mathrm{uL}, 1 \mathrm{ng} / \mathrm{uL}, 2 \mathrm{ng} / \mathrm{uL}, 3 \mathrm{ng} / \mathrm{uL}, 4 \mathrm{ng} / \mathrm{uL}, 5 \mathrm{ng} / \mathrm{uL}$, 6ng/uL, 7ng/uL. 


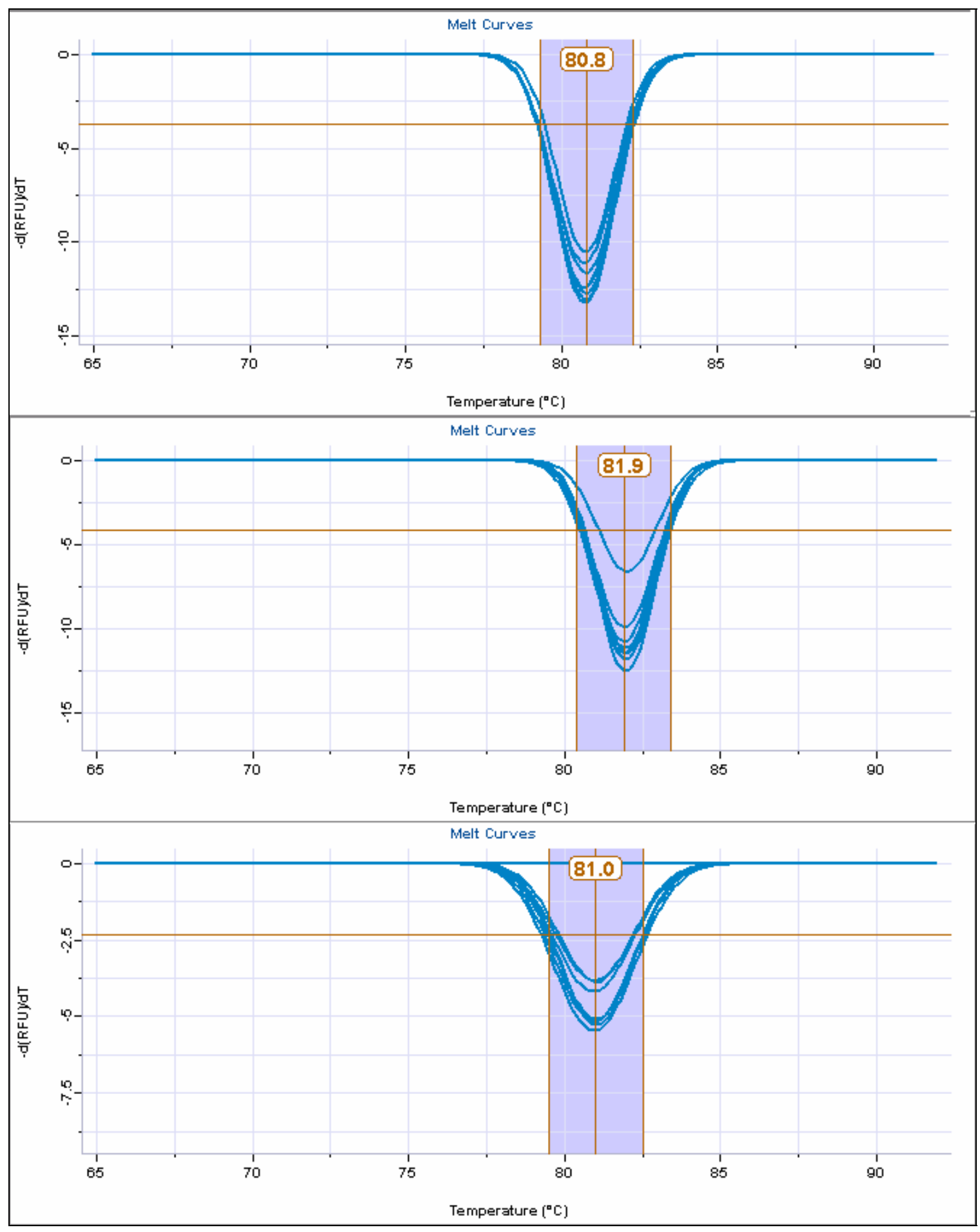

Figure 5-5g: Plexor HY melt curves plotting the rate of change of the RFU with time versus temperature for increasing tannic acid concentrations without BSA. Changes in Autosomal (top), Y Chromosomal (middle) and IPC (bottom) curves at the following concentrations of tannic acid: $0 \mathrm{ng} / \mathrm{uL}, 1 \mathrm{ng} / \mathrm{uL}, 2 \mathrm{ng} / \mathrm{uL}$, 3ng/uL, 4ng/uL, 5ng/uL, 6ng/uL, 7ng/uL. 
al. are more apparent. While there are still not melt curve effects, increases in $\mathrm{C}_{\mathrm{T}}$ for IPC with relatively no change in slope indicates a potential loss in amplicon availability. For the TaqMan probe-based assay, another hypothesis was proposed that the free phenolic groups in oligomeric compounds, including tannic acid and humic acid, oxidize to form quinones that covalently bond and inactivate the Taq (Kontanis et al., 2006). Excess Taq and magnesium using SBR Green improved the reaction (Opel et al., 2010) and supports a potential mechanism of tannic acid as a Taq inhibitor through binding magnesium.

\section{$\underline{\text { Hematin }}$}

Increasing concentrations of hematin produced a shift in $\mathrm{C}_{\mathrm{T}}$ that differed between the three amplicons. For the autosomal amplicons, the shift in $\mathrm{C}_{\mathrm{T}}$ appeared to be related to a loss of template, while that for the Y and IPC amplicons was more the result of a changes in amplification efficiencies (Figures 5-6a). A decrease in $T_{m}$ was also seen, similar to that with phenol (Figure 5-6b). As expected, autosomal curves displayed a more pronounced shift in $T_{m}$, again indicating a stronger DNA binding effect with this amplicon. Hematin produced a $\mathrm{C}_{\mathrm{T}}$ shift of approximately 10 cycles, which suggests effective DNA concentration was reduced (Figure 5-6c). However, $\mathrm{T}_{\mathrm{m}}$ decreased by approximately $3^{\circ} \mathrm{C}$ as inhibitor concentration increased (Figure 5-3d). Hematin had a significant reduction in efficiency at concentrations of $60 \mathrm{uM}$ and higher (Figure 5-3e).

The porphyrin structure of hematin may allow chelation with the magnesium ions, producing the efficiency changes (Akane et al., 1994). However, it is unclear how DNA binding effects are occurring. The effects of the longer amplicons could be as a result of the relative size of the inhibitor. Hematin is a larger molecule than calcium, which is a 


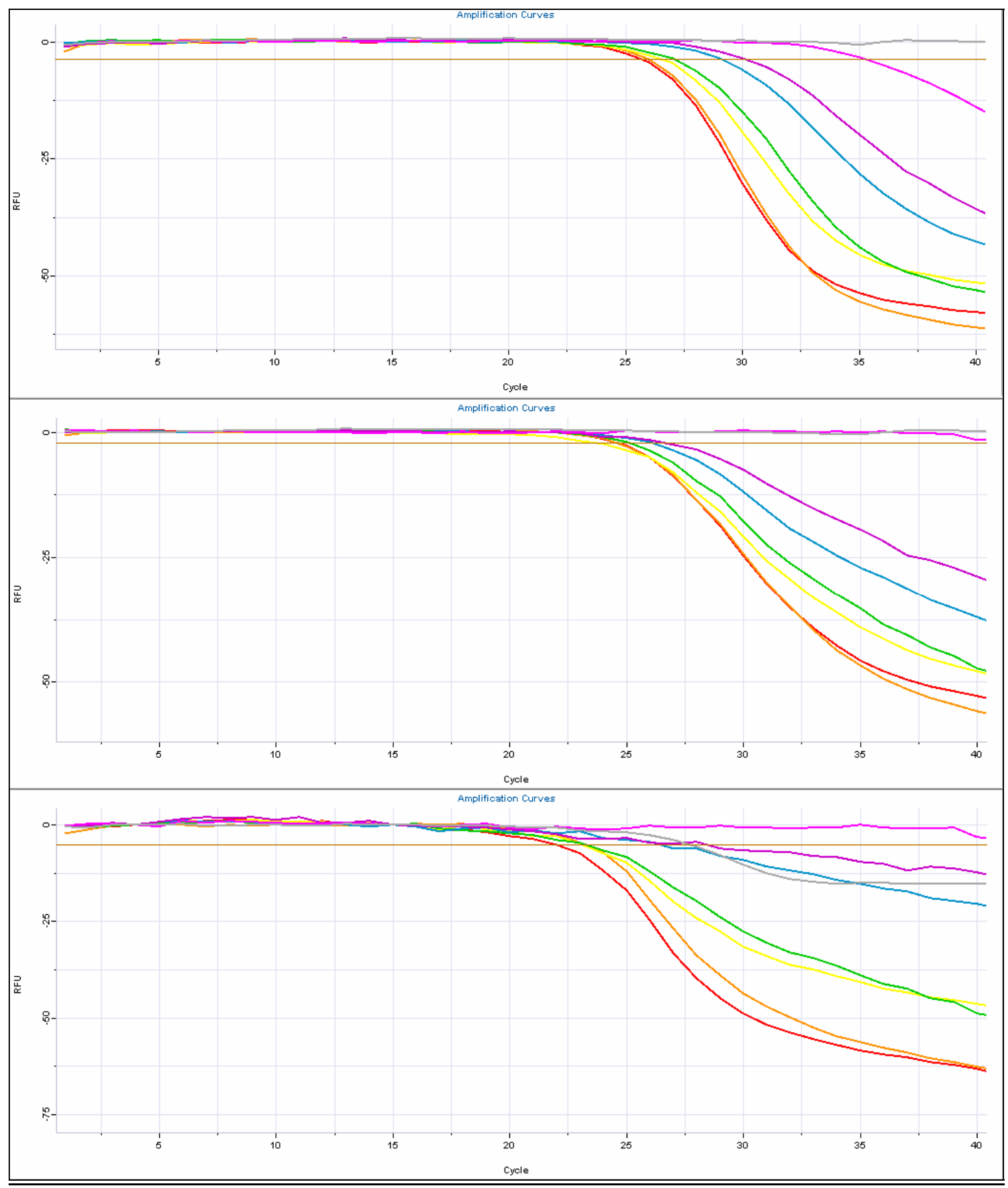

Figure 5-6a: Plexor HY amplification curves plotting RFU versus cycle number for increasing hematin concentrations. Changes in Autosomal (top), Y Chromosomal (middle) and IPC (bottom) curves at the following concentrations of hematin: 0uM (red), 15uM (orange), 30uM (yellow), 45uM (green), 60uM (blue), $75 \mathrm{uM}$ (purple), 90uM (pink), $105 \mathrm{mM}$ (grey). 


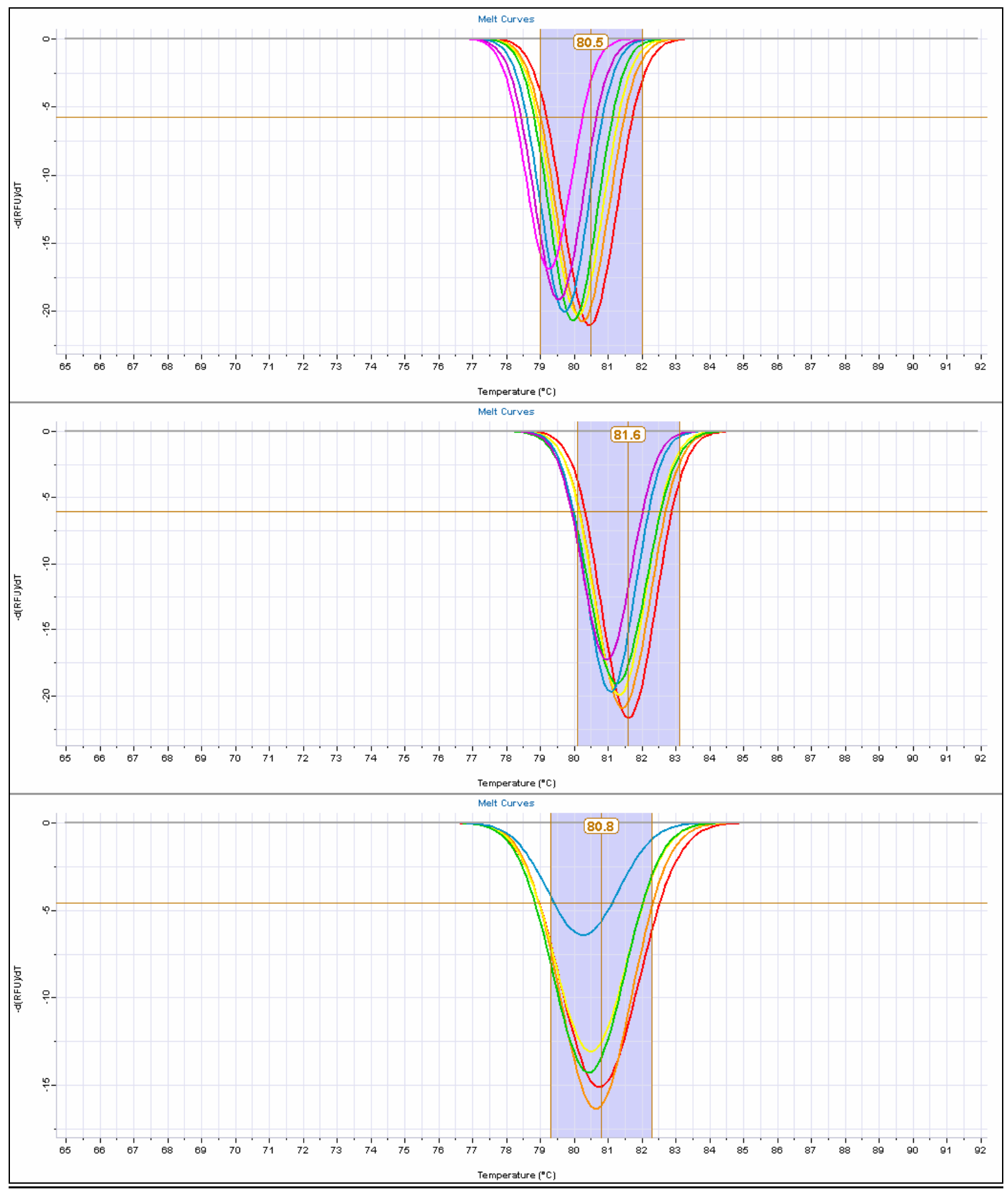

Figure 5-6b: Plexor HY melt curves plotting the rate of change of the RFU with time versus temperature for increasing hematin concentrations. Changes in Autosomal (top), Y Chromosomal (middle) and IPC (bottom) curves at the following concentrations of hematin: 0uM (red), 15uM (orange), 30uM (yellow), $45 \mathrm{uM}$ (green), 60uM (blue), 75uM (purple), 90uM (pink), 105mM (grey). 


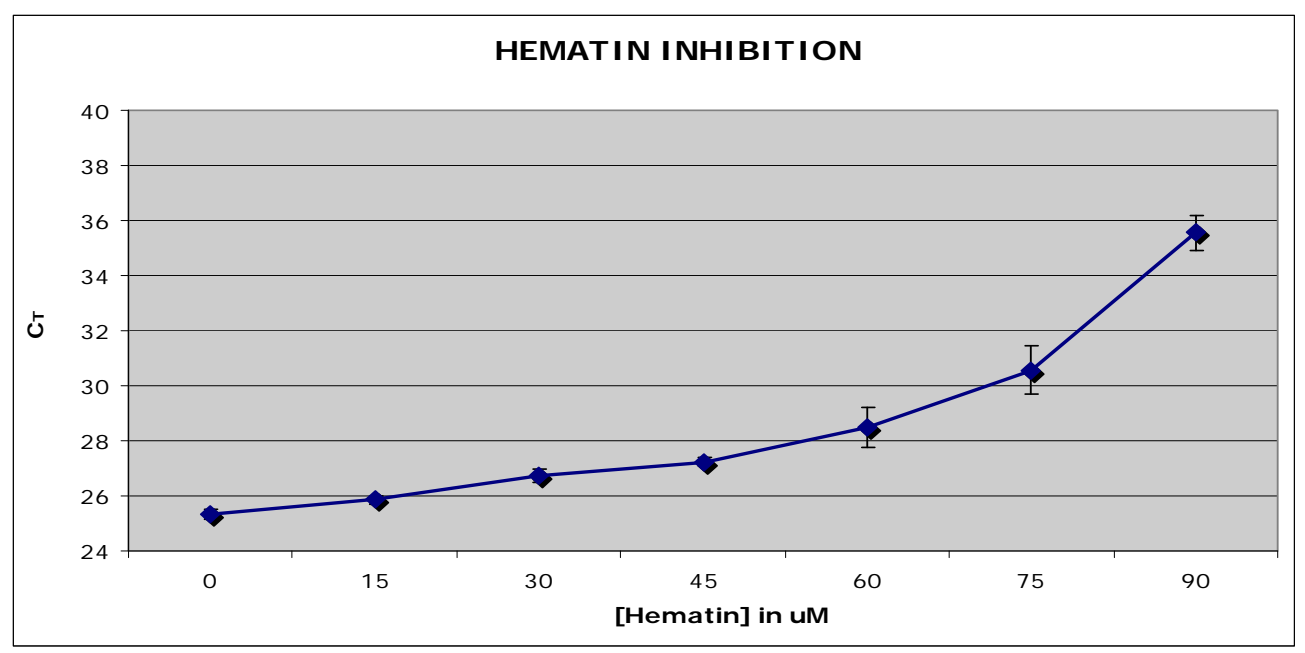

Figure 5-6c: $C_{T}$ versus increasing concentrations of hematin inhibitor

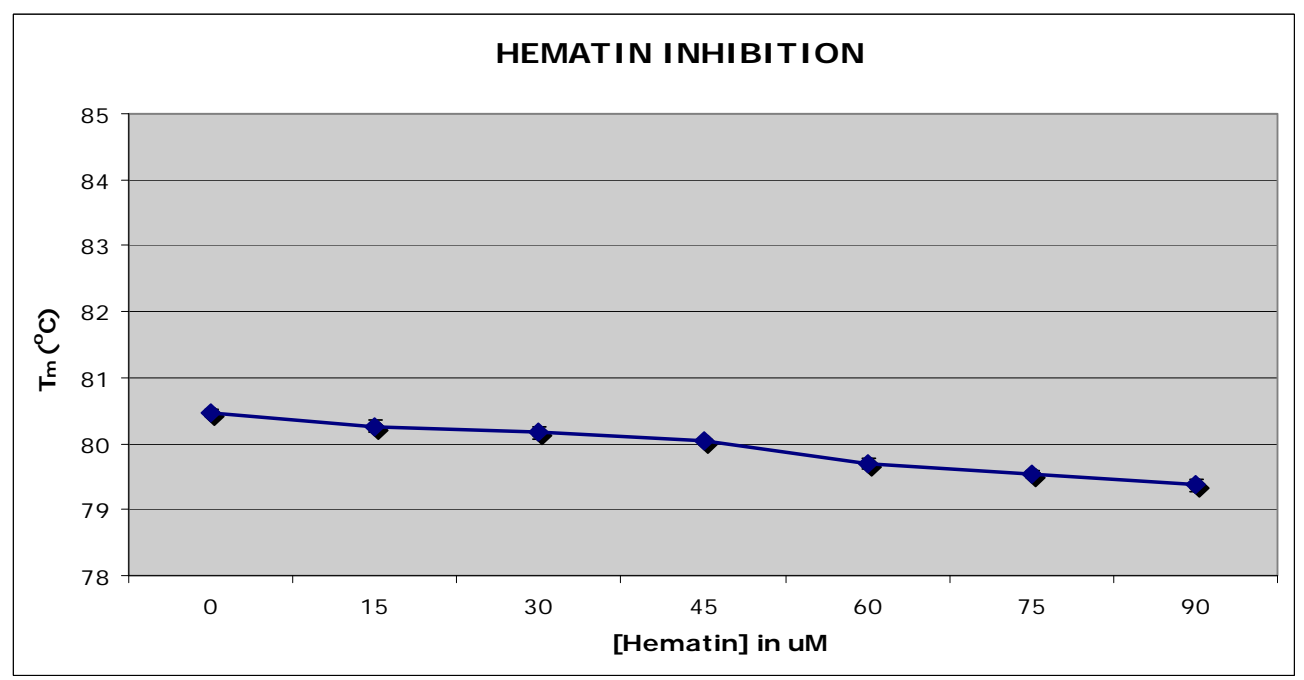

Figure 5-6d: $\mathrm{T}_{\mathrm{m}}\left({ }^{\circ} \mathrm{C}\right)$ versus increasing concentrations of hematin inhibitor

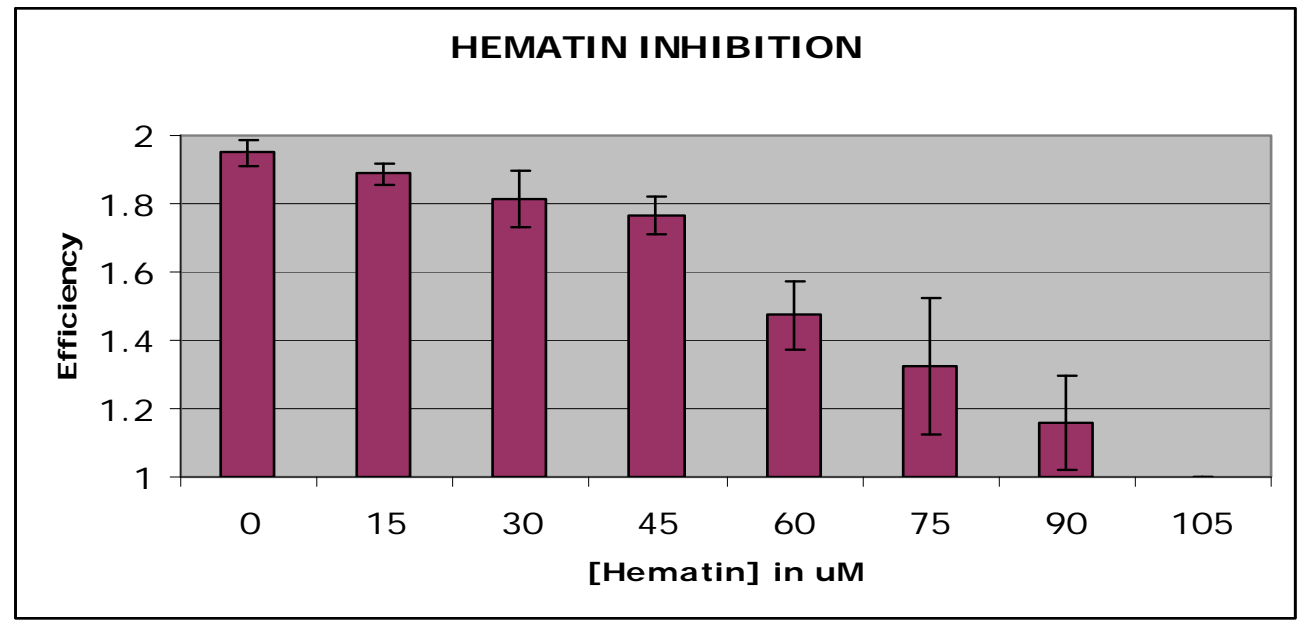

Figure 5-6e: Efficiency versus increasing concentrations of hematin inhibitor 
possibly why melt curve effects were not observed with the largest amplicon length.

Results using SYBR Green were somewhat different than Plexor with this inhibitor. Minimal effects of melt curves and increases in $\mathrm{C}_{\mathrm{T}}$ indicated reversable DNA binding. Traditional PCR and electrophoresis results confirmed that hematin inhibits Taq polymerase activity (Alkane et al., 1994). Additional Taq did not reduce inhibition by hematin, but additional magnesium increased the effects of inhibition (Opel et al., 2010). Additional SYBR Green studies mentioned that hematin inhibition may cause modification, degradation or adsorption of a fluorescent dye (Kermekchiev et al., 2009).

\section{$\underline{\text { Melanin }}$}

As the concentration of melanin increased there were minimal changes in efficiency, a lowering of $\mathrm{T}_{\mathrm{m}}$ and a gradual increase in $\mathrm{C}_{\mathrm{T}}$ for all amplification curves (Figures 5-7a and b). Changes in $\mathrm{C}_{\mathrm{T}}$ were approximately 10 cycles and were consistent with a loss of available template (Figure $5-7 \mathrm{c}$ ). The $\mathrm{T}_{\mathrm{m}}$ had a $1.5^{\circ} \mathrm{C}$ range and decreased as inhibitor concentration increased (Figure 5-7d). Melanin also showed no significant efficiency loss (Figure 5-7e). These results are consistent with melanin binding DNA.

These data are also very similar to those seen with SYBR green. In the report by Opel et al., there were minimal changes in the slope of the amplification curve, large changes in melt curves and an increase in $\mathrm{C}_{\mathrm{T}}$ with increasing melanin. Additional Taq and magnesium did not improve amplification for inhibited samples (Opel et al., 2010). Other results using traditional PCR and gel electrophoresis suggested melanin was a Taq inhibitor and the melanin-Taq complexes formed had a reversible effect (Eckhart et al., 2000). In contrast, Plexor results did not show strong effects on Taq amplification. 


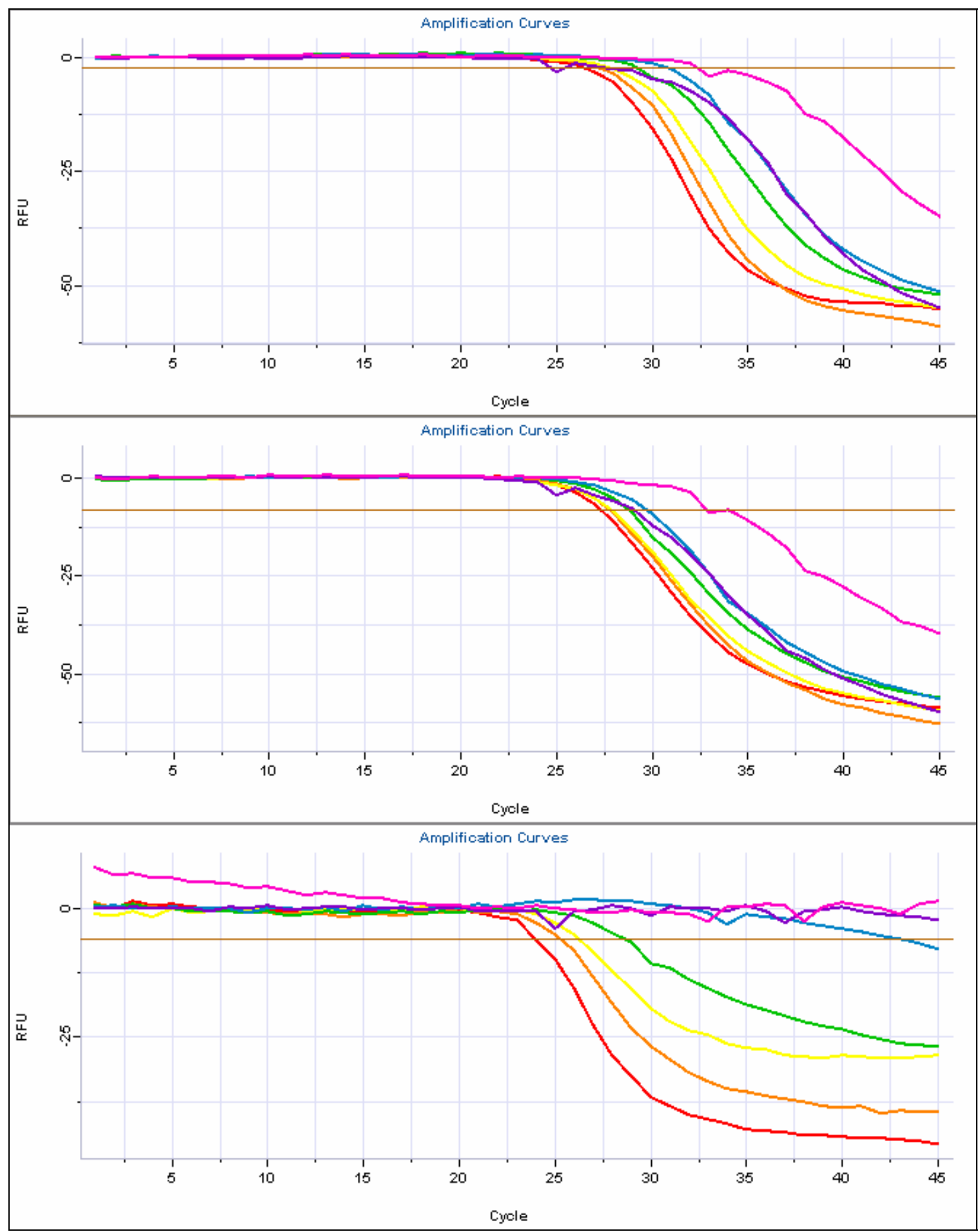

Figure 5-7a: Plexor HY amplification curves plotting RFU versus cycle number for increasing melanin concentrations. Changes in Autosomal (top), Y Chromosomal (middle) and IPC (bottom) curves at the following concentrations of melanin: $0 \mathrm{ug}$ (red), 10ug/uL (orange), 20ug/uL (yellow), 30ug/uL (green), 40ug/uL (blue), 50ug/uL (purple), 60ug/uL (pink). 


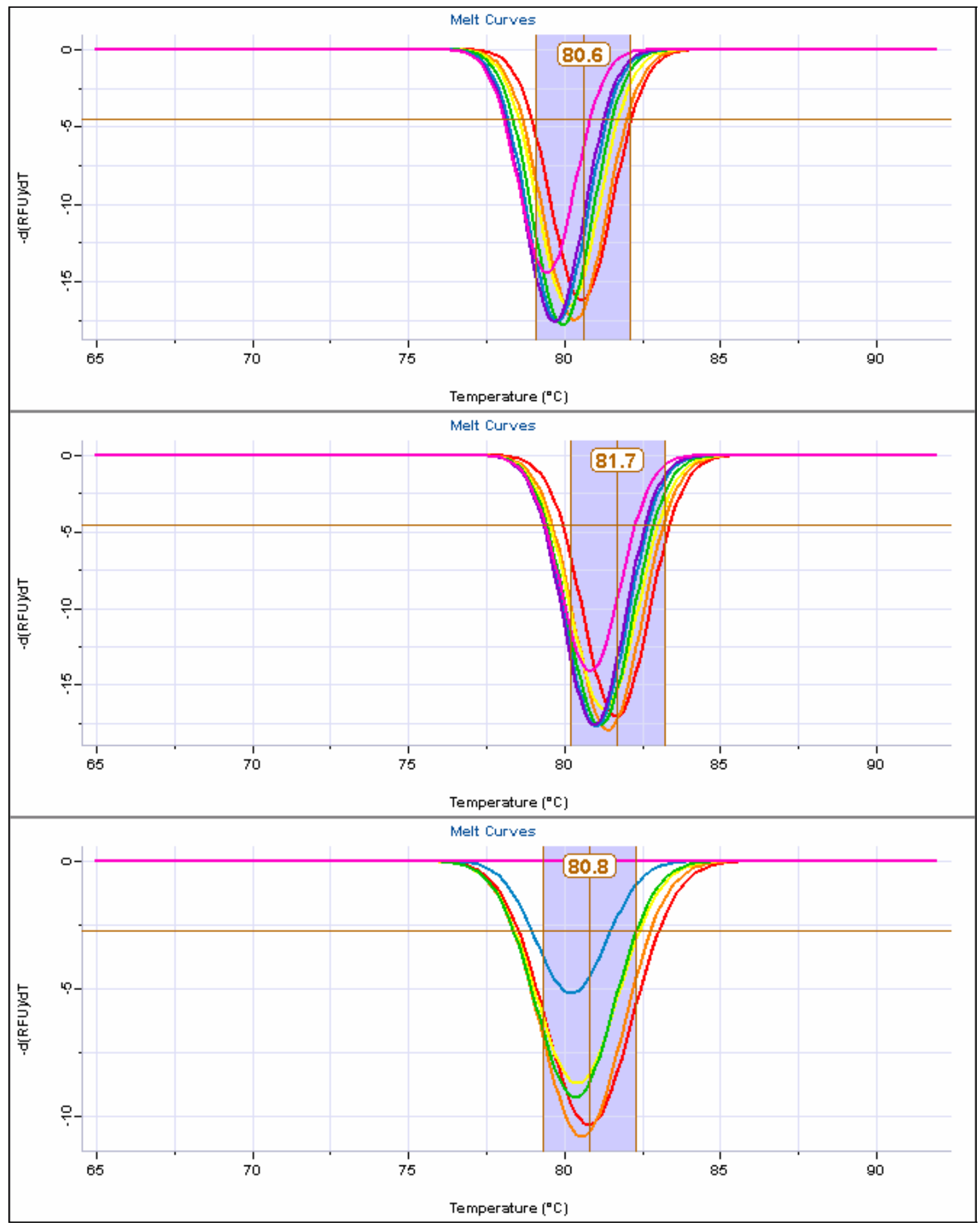

Figure 5-7b: Plexor HY melt curves plotting the rate of change of the RFU with time versus temperature for increasing melanin concentrations. Changes in Autosomal (top), Y Chromosomal (middle) and IPC (bottom) curves at the following concentrations of melanin: 0ug (red), 10ug/uL (orange), 20ug/uL (yellow), 30ug/uL (green), 40ug/uL (blue), 50ug/uL (purple), 60ug/uL (pink). 


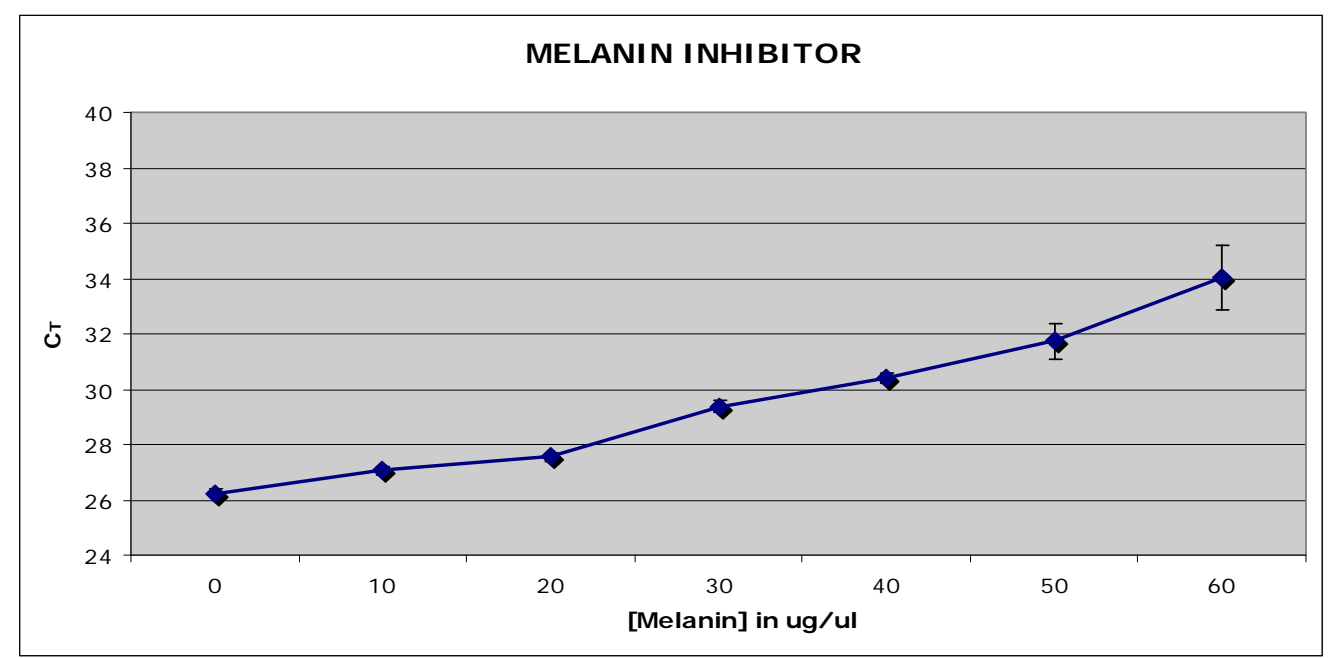

Figure 5-7c: $\mathrm{C}_{\mathrm{T}}$ versus increasing concentrations of melanin inhibitor

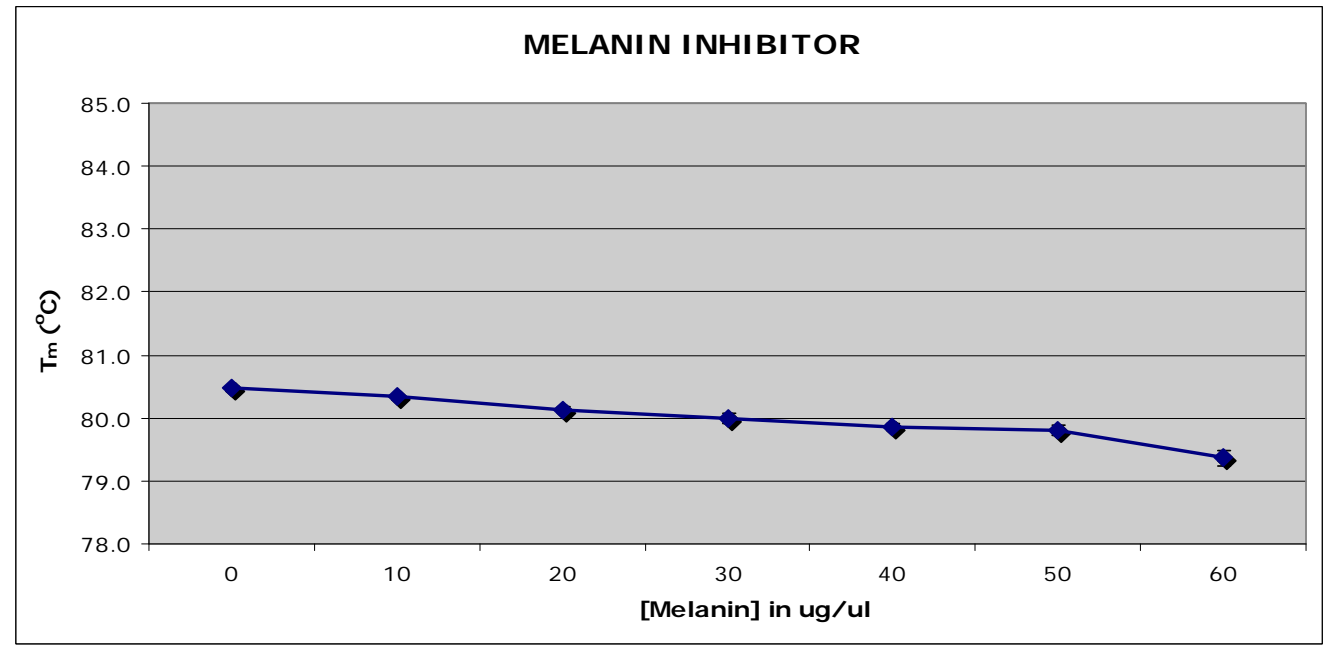

Figure 5-7d: $\mathrm{T}_{\mathrm{m}}\left({ }^{\circ} \mathrm{C}\right)$ versus increasing concentrations of melanin inhibitor

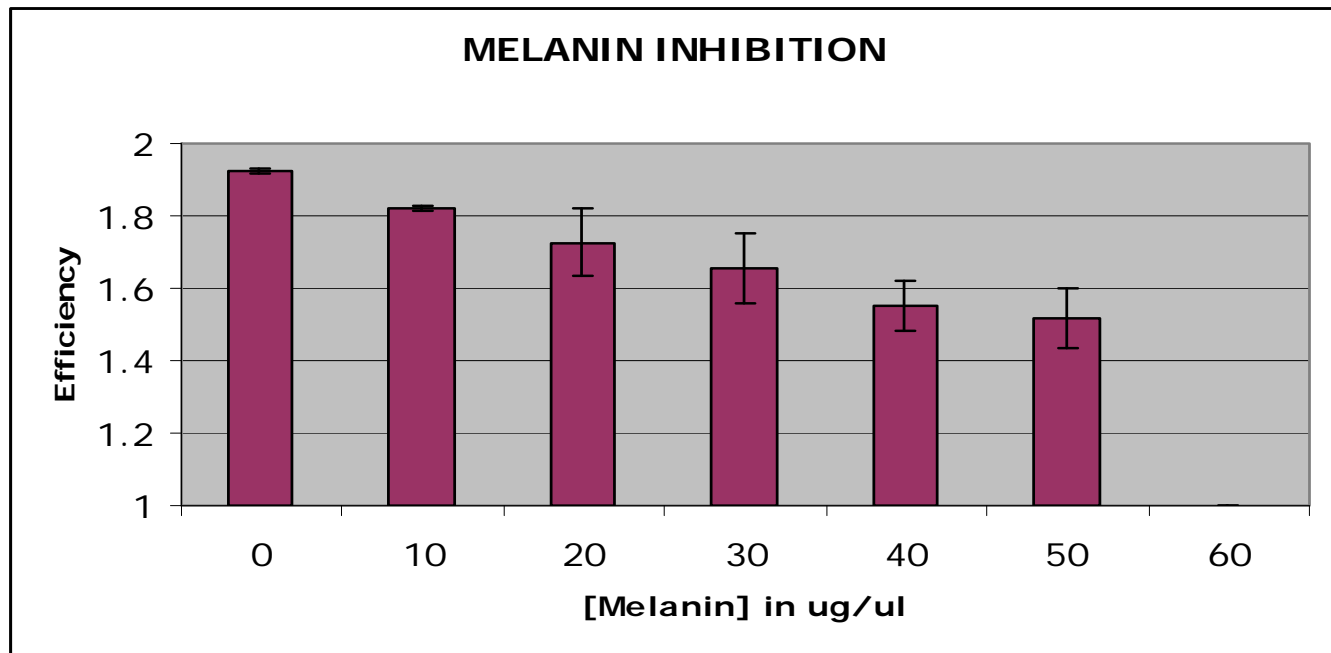

Figure 5-7e: Efficiecny versus increasing concentrations of melanin inhibitor 


\section{$\underline{\text { Bile salts }}$}

Bile salts showed similar results to melanin - a change in the efficiency of the reaction and melt curve effects, and an increase in $\mathrm{C}_{\mathrm{T}}$ values for autosomal, $\mathrm{Y}$ and IPC curves (Figures 5-8a and b). There was a large $C_{T}$ shift of 11 cycles (Figure5-8c) with minimal effects on amplification curves. There was also a $0.5^{\circ} \mathrm{C}$ decrease in $\mathrm{T}_{\mathrm{m}}$ (Figure 5-8d). However, the shift in $T_{m}$ was less consistent than with earlier samples with the largest shift occurring $0.2^{\circ} \mathrm{C}$ from the lowest inhibited samples. The subsequent samples produced a $0.1^{\circ} \mathrm{C}$ shift. The efficiency values of bile salts were similar to that of melanin, generating no significant loss of efficiency (Figure 5-8e). These changes in the slopes in the amplification curves are consistent with bile salts binding DNA.

Bile salts contain both polar and nonpolar regions and are known protein denaturants. Previous research indicated that, bile salts are inhibitory of Taq (Al-Soud et al., 2001). However these results tend to indicate more of an effect on DNA template availability. Previous studies suggested that heating was efficient in reducing the PCR inhibitory effects of bile salts (Al-Soud et al., 2006). Al-Soud also showed that by adding BSA the inhibitory effects were reduced. However, results suggest possible DNA interference possibly through the formation of complexes between DNA and protein molecules making the DNA inaccessible for the polymerase. Plexor results suggest bile salts could be possibly affecting both, however the melt curve effects are not sufficient proof of this. 


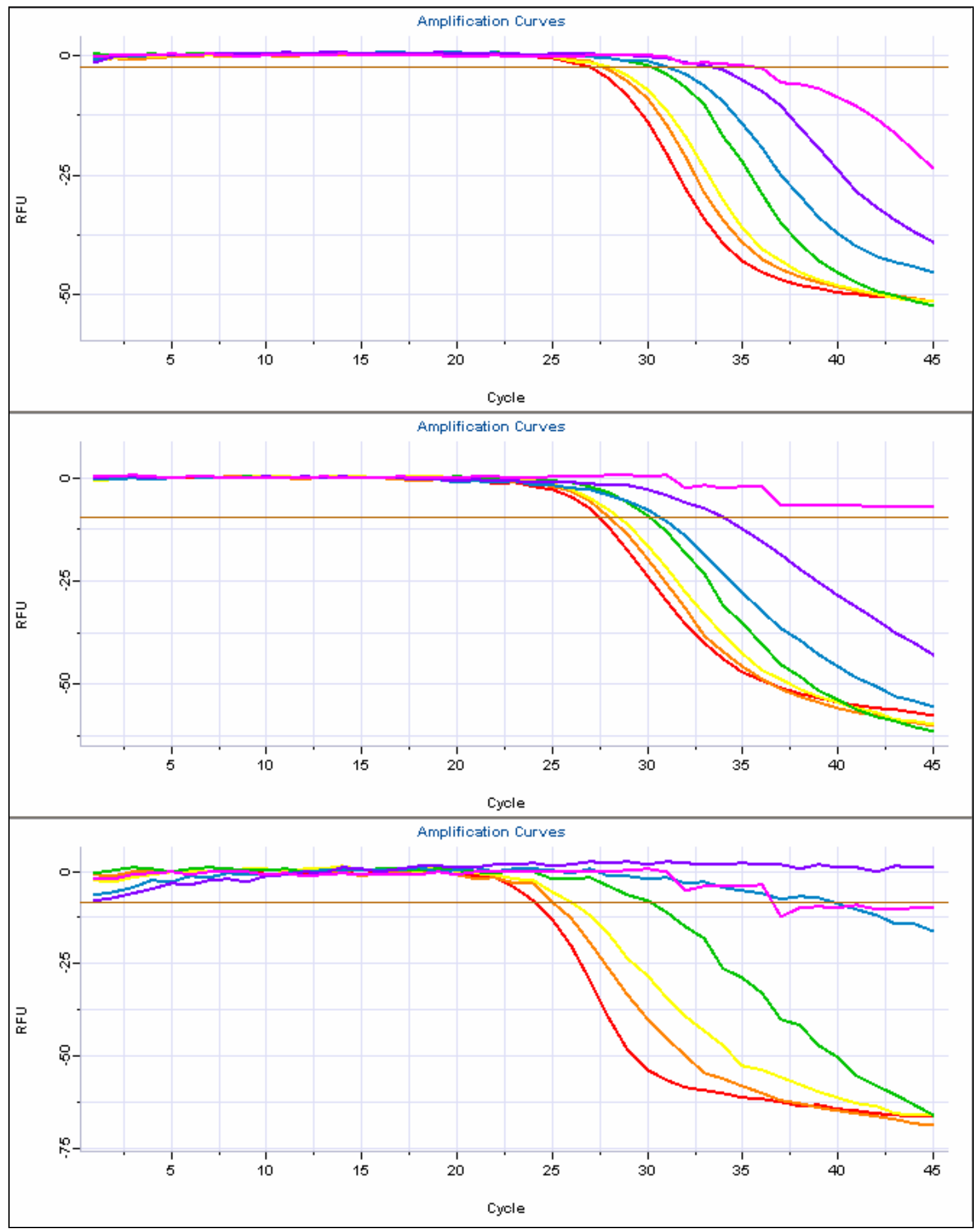

Figure 5-8a: Plexor HY amplification curves plotting RFU versus cycle number for increasing bile salts concentrations. Changes in Autosomal (top), Y Chromosomal (middle) and IPC (bottom) curves at the following concentrations of bile salts: $0 \mathrm{ug}$ (red), $0.25 \mathrm{ug} / \mathrm{uL}$ (orange), $0.5 \mathrm{ug} / \mathrm{uL}$ (yellow), $0.75 \mathrm{ug} / \mathrm{uL}$ (green), $1 \mathrm{ug} / \mathrm{uL}$ (blue), $1.25 \mathrm{ug} / \mathrm{uL}$ (purple), 1.5ug/uL (pink). 


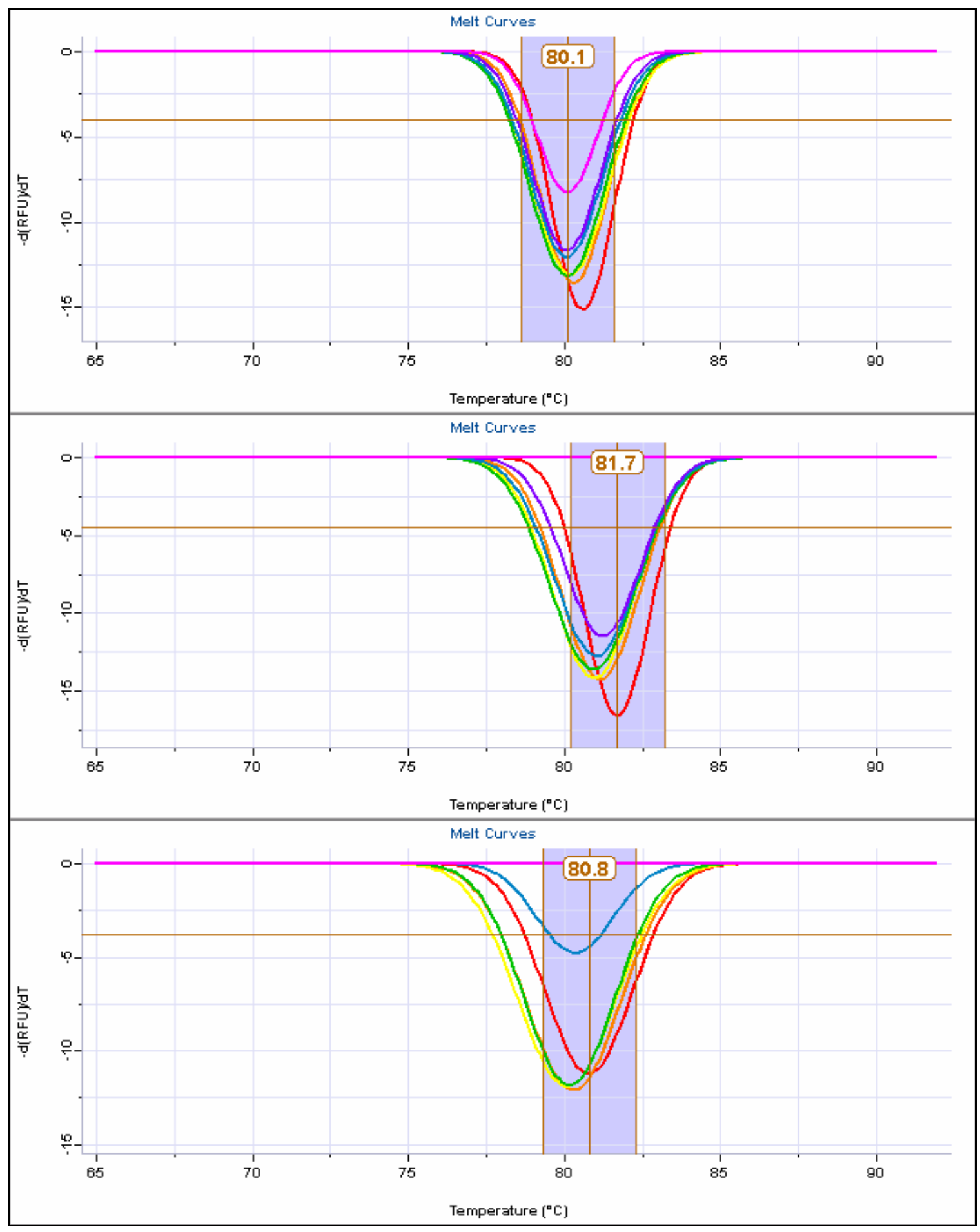

Figure 5-8b: Plexor HY melt curves plotting the rate of change of the RFU with time versus temperature for increasing bile salts concentrations. Changes in Autosomal (top), Y Chromosomal (middle) and IPC (bottom) curves at the following concentrations of bile salts: $0 \mathrm{ug}$ (red), $0.25 \mathrm{ug} / \mathrm{uL}$ (orange), $0.5 \mathrm{ug} / \mathrm{uL}$ (yellow), $0.75 \mathrm{ug} / \mathrm{uL}$ (green), 1ug/uL (blue), 1.25ug/uL (purple), 1.5ug/uL (pink). 


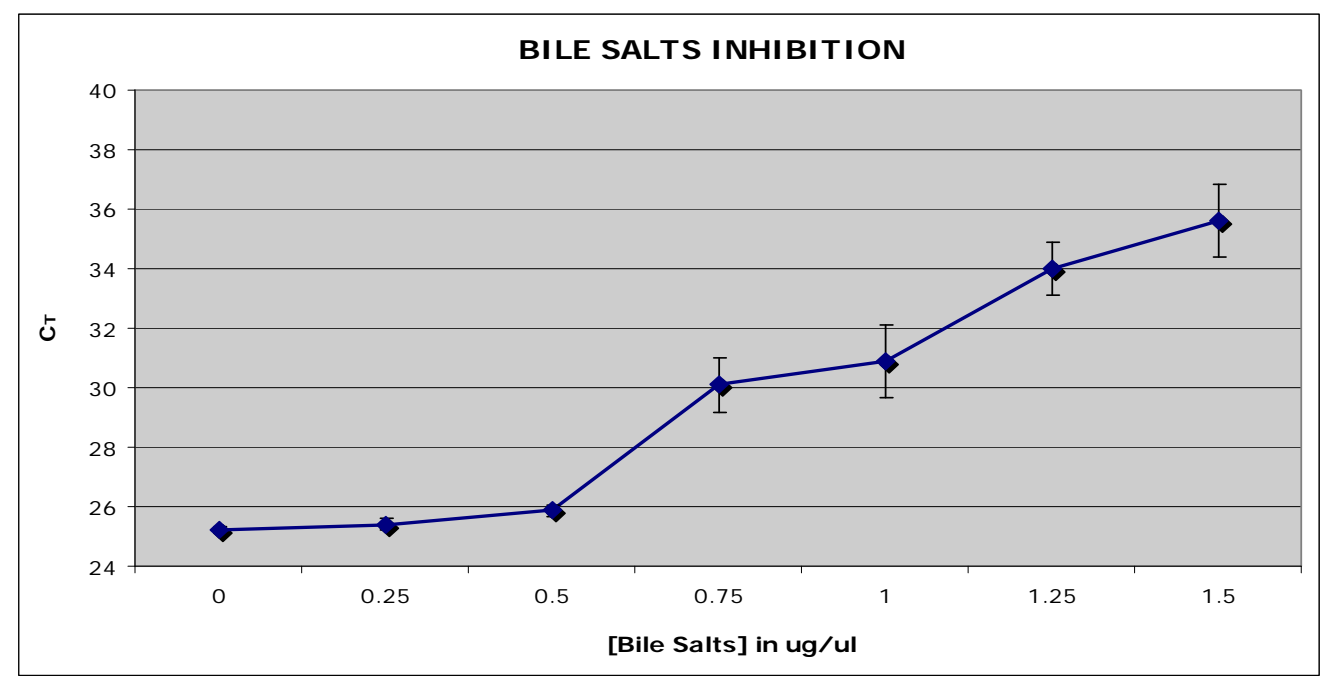

Figure 5-8c: $\mathrm{C}_{\mathrm{T}}$ versus increasing concentrations of bile salts inhibitor.

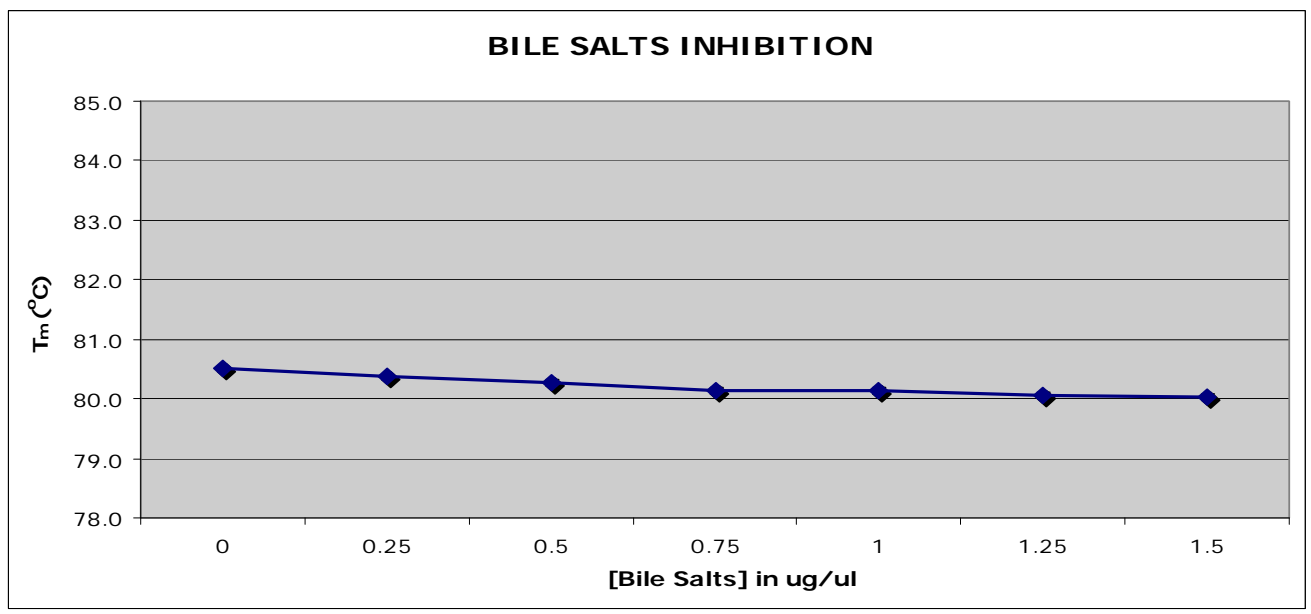

Figure 5-8d: $\mathrm{T}_{\mathrm{m}}\left({ }^{\circ} \mathrm{C}\right)$ versus increasing concentrations of bile salts inhibitor

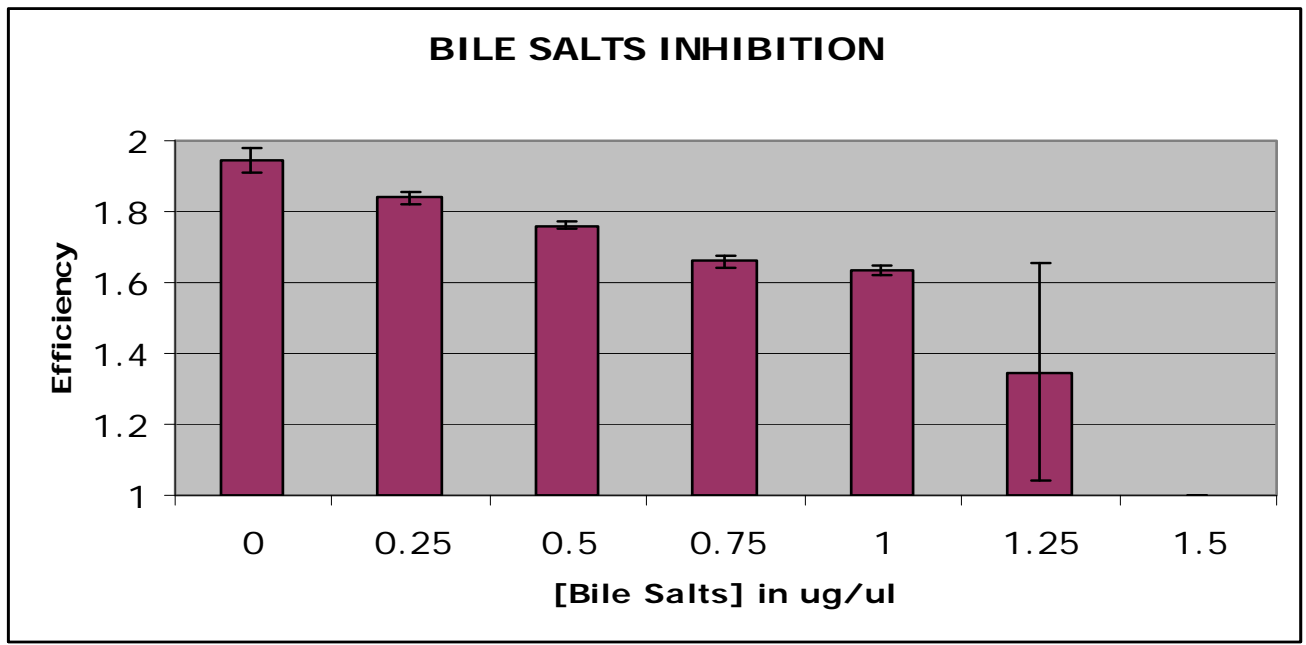

Figure 5-8e: Efficiency versus increasing concentrations of bile salts inhibitor 
Urea

Urea showed slight increase in $\mathrm{C}_{\mathrm{T}}$ values and relative loss of relative efficiency for all amplicons (Figure 5-9a). The melt curve effects show loss of signal and small changes in $T_{m}$ at longer amplicon lengths, indicating minimal DNA binding (Figure 5-9b). The $C_{T}$ shifts had a 2 cycle range, excluding the highest inhibitor concentration (1.2M) and the increase in $C_{T}$ was more related to changes in slope than loss of template (Figure 9c). The $\mathrm{T}_{\mathrm{m}}$ for the control and inhibited samples varies by $1.5^{\circ} \mathrm{C}$ (Figure 5-9d). This shift is not sufficient enough to indicate specific DNA binding; however, is still a possibility. The shape of the slope in the amplification curves showed a loss of efficiency for samples inhibited with urea, especially those at higher concentrations of inhibitor (Figure 5-9e). This is an indication of Taq inhibition.

Urea is known to be a potent inhibitor of non-covalent bonding and therefore may act directly on the polymerase, or it may prevent primer annealing (Khan et al., 1991). However, primer annealing problems might be expected to produce a delay in $\mathrm{C}_{\mathrm{T}}$ indicating a reduction in the availability of DNA template. Other research concluded that heating of the PCR sample for a longer duration did not relieve inhibition (Behzadbehbahani et al., 1997). Plexor results would support the fact that urea shows mixed mode effects as Plexor results indicate it a possible DNA and Taq inhibitor. 


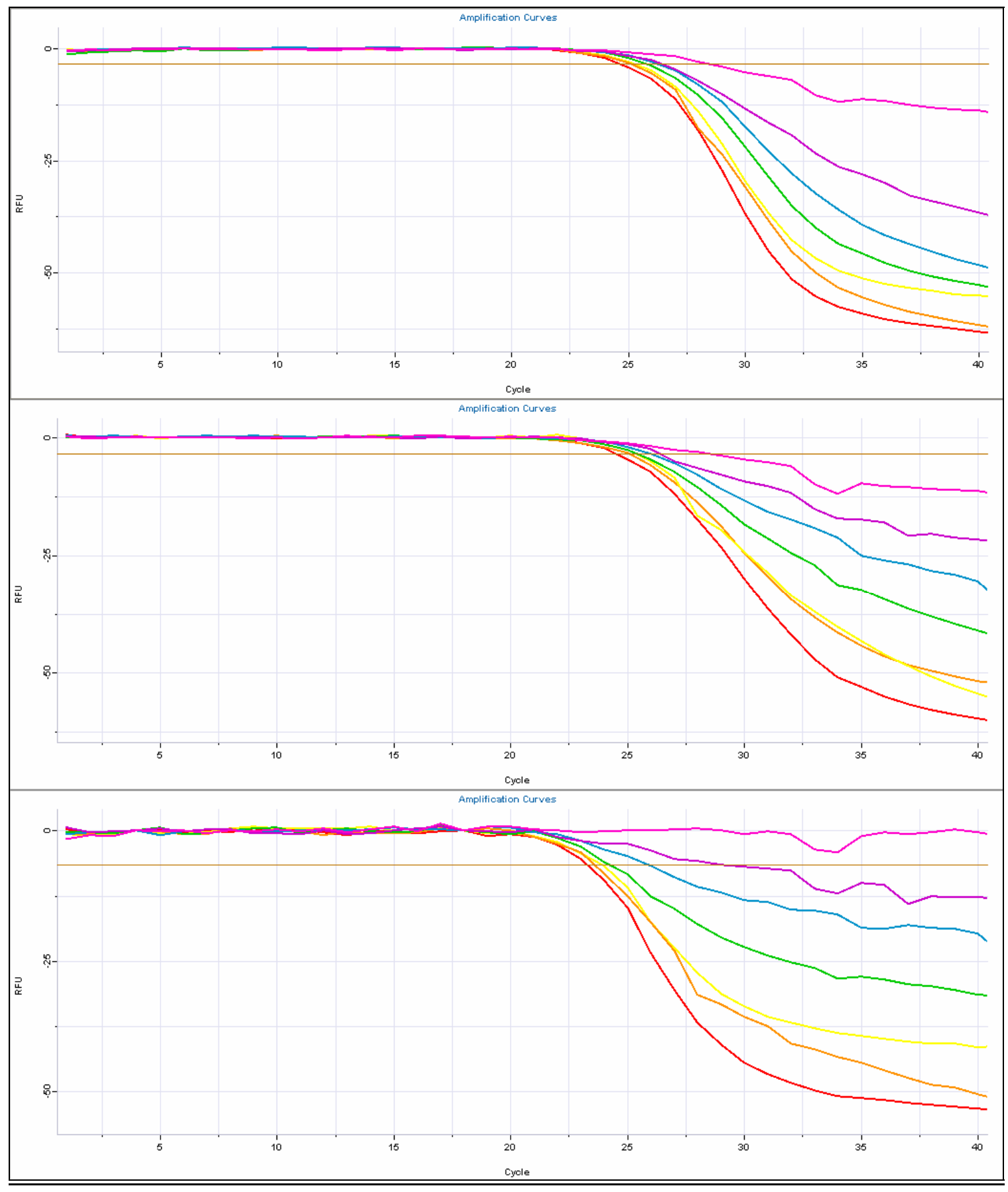

Figure 5-9a: Plexor HY amplification curves plotting RFU versus cycle number for increasing urea concentrations. Changes in Autosomal (top), Y Chromosomal (middle) and IPC (bottom) curves at the following concentrations of urea: $0 \mathrm{mM}$ (red), $200 \mathrm{mM}$ (orange), $400 \mathrm{mM}$ (yellow), $600 \mathrm{mM}$ (green), $800 \mathrm{mM}$ (blue), 1000mM (purple), 1200mM (pink). 


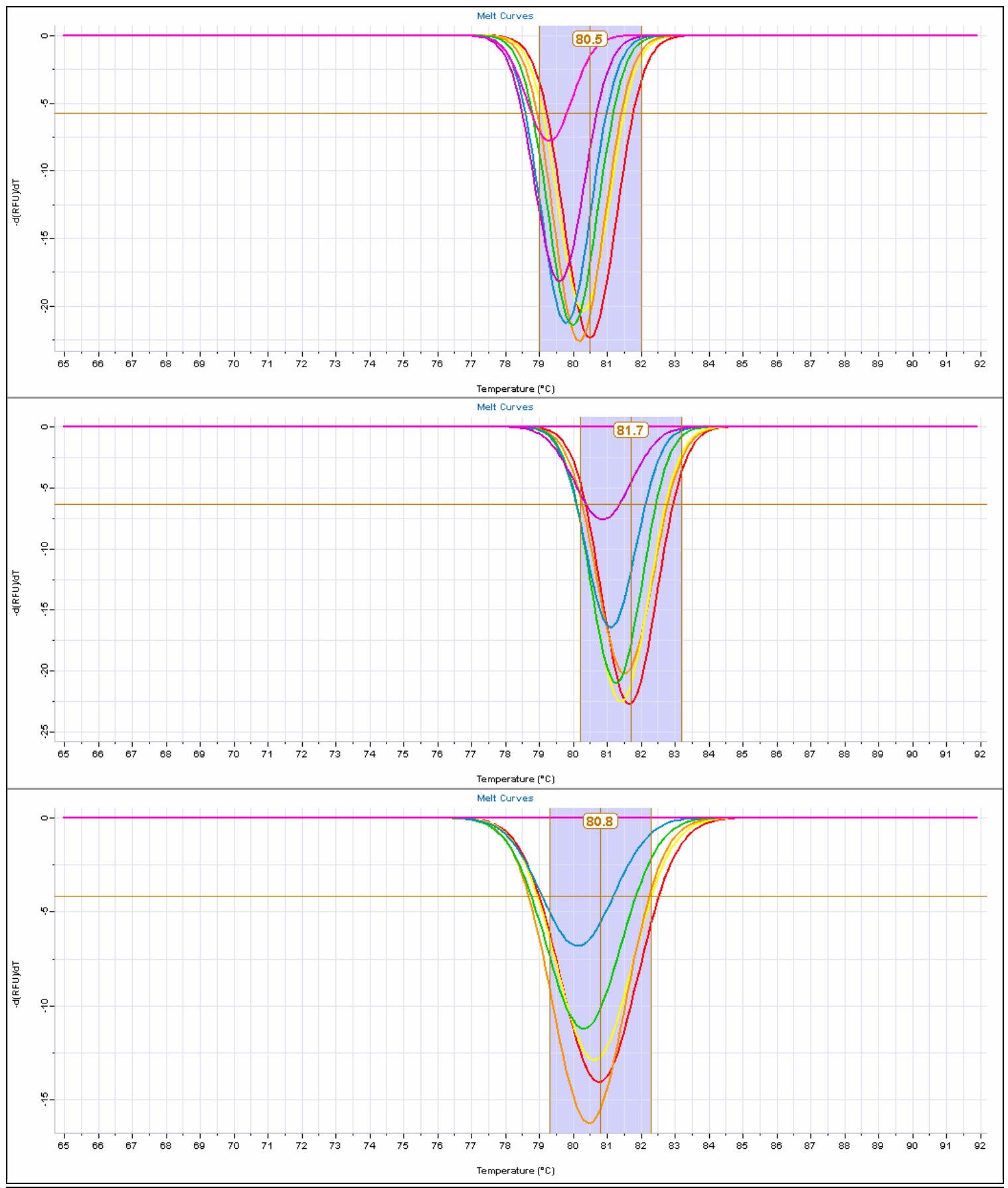

Figure 5-9b: Plexor HY melt curves plotting the rate of change of the RFU with time versus temperature for increasing urea concentrations. Changes in Autosomal (top), Y Chromosomal (middle) and IPC (bottom) curves at the following concentrations of urea: $0 \mathrm{mM}$ (red), $200 \mathrm{mM}$ (orange), $400 \mathrm{mM}$ (yellow), $600 \mathrm{mM}$ (green), $800 \mathrm{mM}$ (blue), $1000 \mathrm{mM}$ (purple), $1200 \mathrm{mM}$ (pink). 


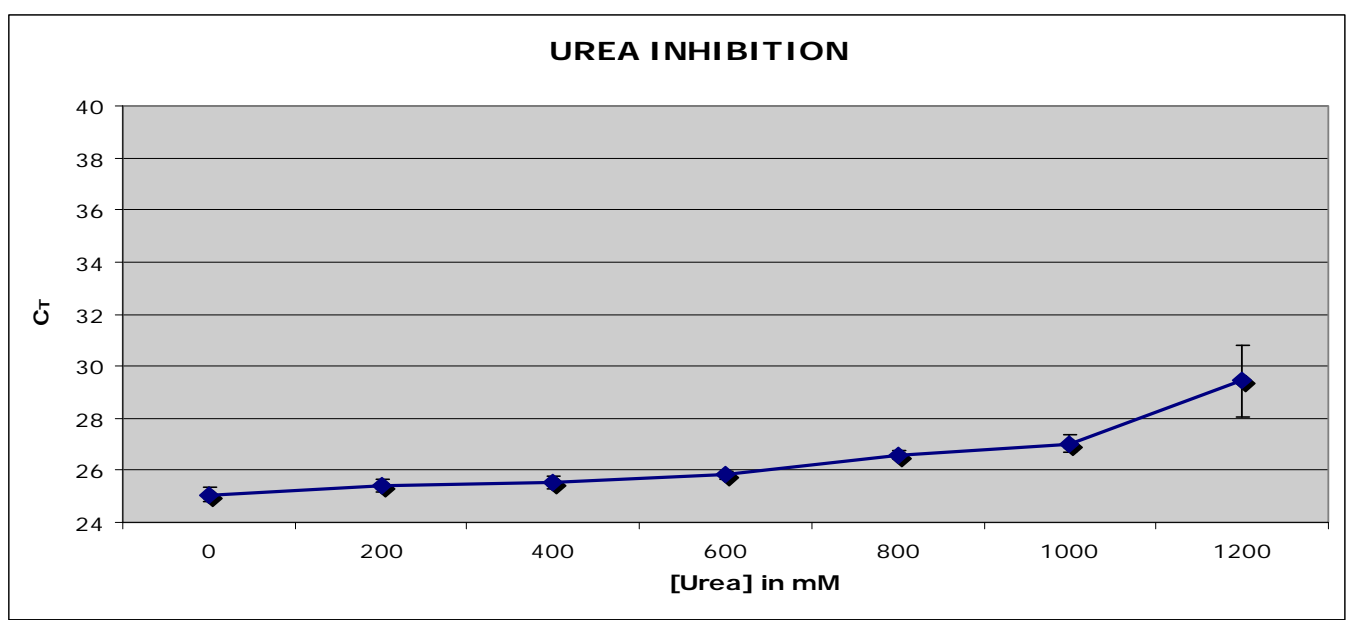

Figure 5-9c: $\mathrm{C}_{\mathrm{T}}$ versus increasing concentrations of urea inhibitor

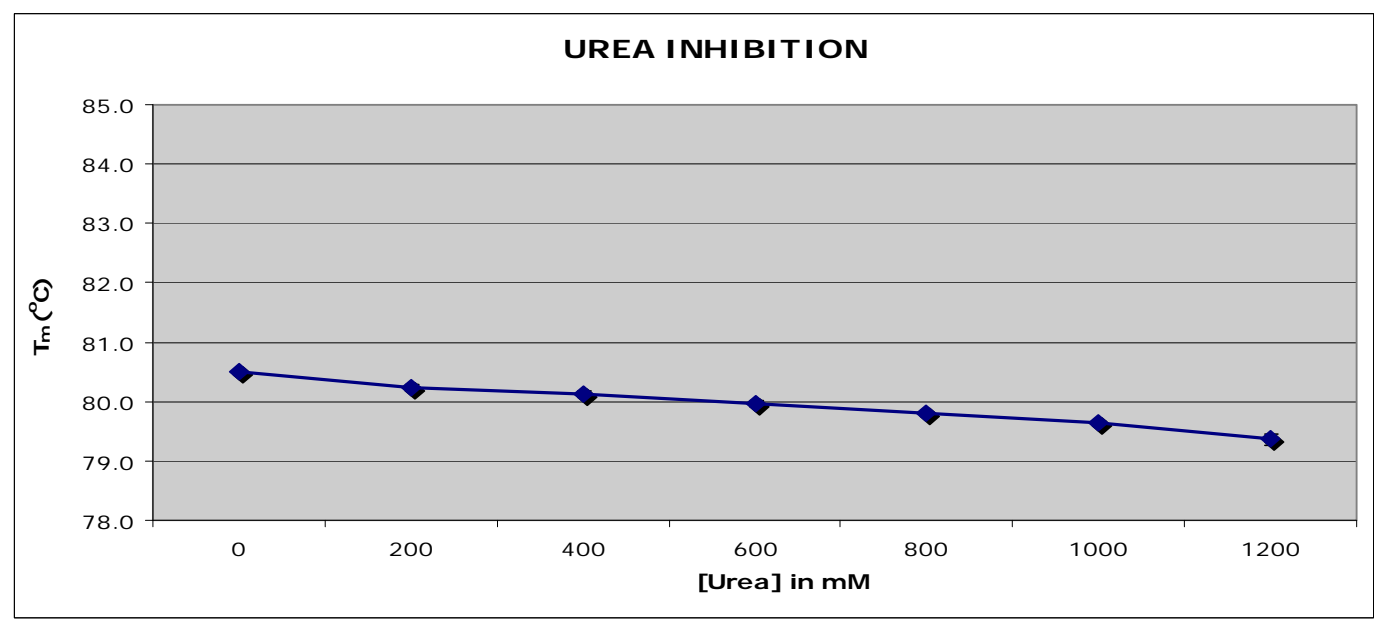

Figure 5-9d: $\mathrm{T}_{\mathrm{m}}\left({ }^{\circ} \mathrm{C}\right)$ versus increasing concentrations of urea inhibitor

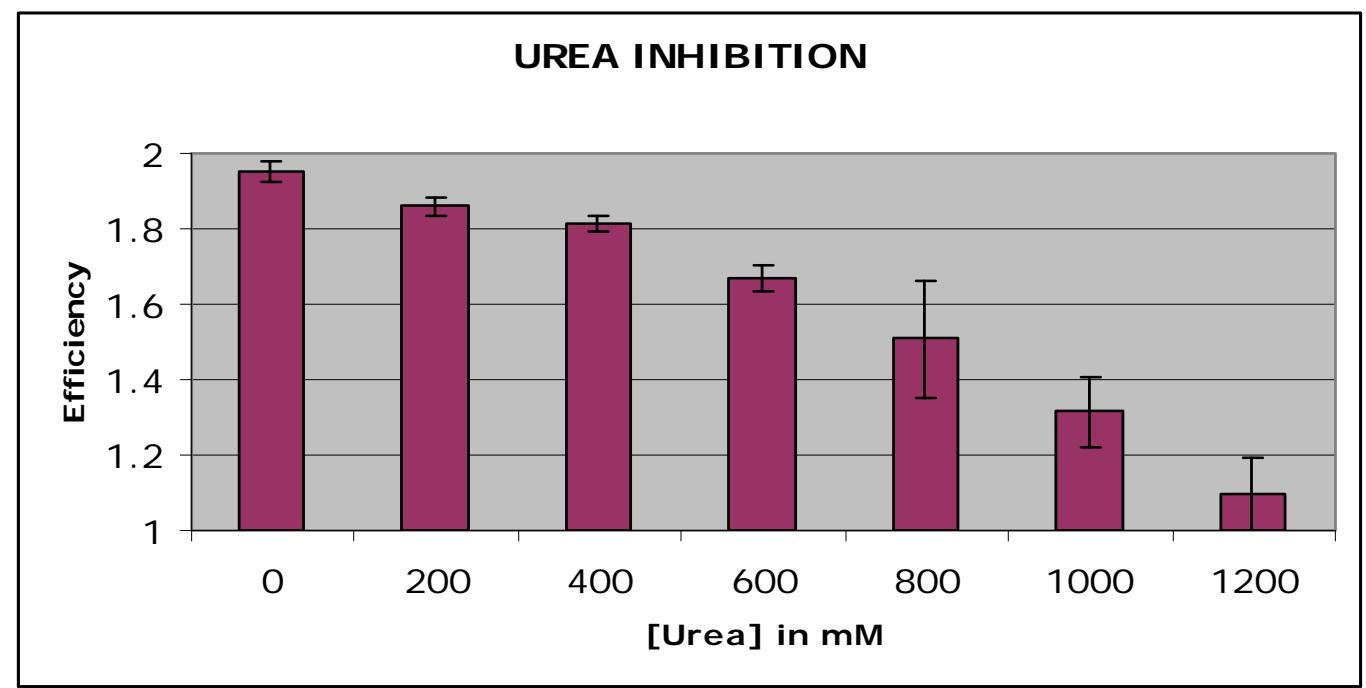

Figure 5-9e: Efficiency versus increasing concentrations of urea inhibitor 
Results for EDTA produced minimal changes in the efficiency of the reaction, significant $C_{T}$ shifts, and minor shifts in the melt curve (Figures 5-10a and b). A $C_{T}$ shift of approximately 10 cycles was related to loss of template and not a slope effect (Figure 5-10c). Autosomal and Y amplification results clearly indicate DNA binding and not efficiency problems. There was also a significant change in $\mathrm{T}_{\mathrm{m}}$ of $3^{\circ} \mathrm{C}$ (Figure $5-10 \mathrm{~d}$ ). Interestingly, there was no loss of fluorescent signal in the melt curves for autosomal amplicons. This may be a size or sequence effect. EDTA amplification curves showed relatively low efficiencies at concentrations of inhibitor greater than $1.6 \mathrm{mM}$ (Figure 510e).

Since EDTA is a divalent cation complexing agent, it was expected to inhibit the reaction by chelating magnesium ions that are necessary for the activity of DNA polymerase. However, there was minimal effect on the amplification efficiency thus the inhibition mechanism of EDTA may be related to its ability to inhibit DNA synthesis by taking out the counter ions, which likely drive the sugar phosphate backbone apart (Wiedbrauk et al., 1995).

\section{$\underline{\text { Guanidinium }}$}

Guanidinium showed insignificant changes in efficiency and $\mathrm{C}_{\mathrm{T}}$ for the autosomal results when compared to Y and IPC (Figure 5-11a). There were also and major shifts in the melt curve for all amplicons (Figures5-11b). Shifts in $\mathrm{C}_{\mathrm{T}}$ appeared to be more related to amplification efficiency than to loss of template (Figure 5-11c). Like collagen, guanidinium increased in $\mathrm{T}_{\mathrm{m}}$ as inhibitor concentration increased indicating binding to 


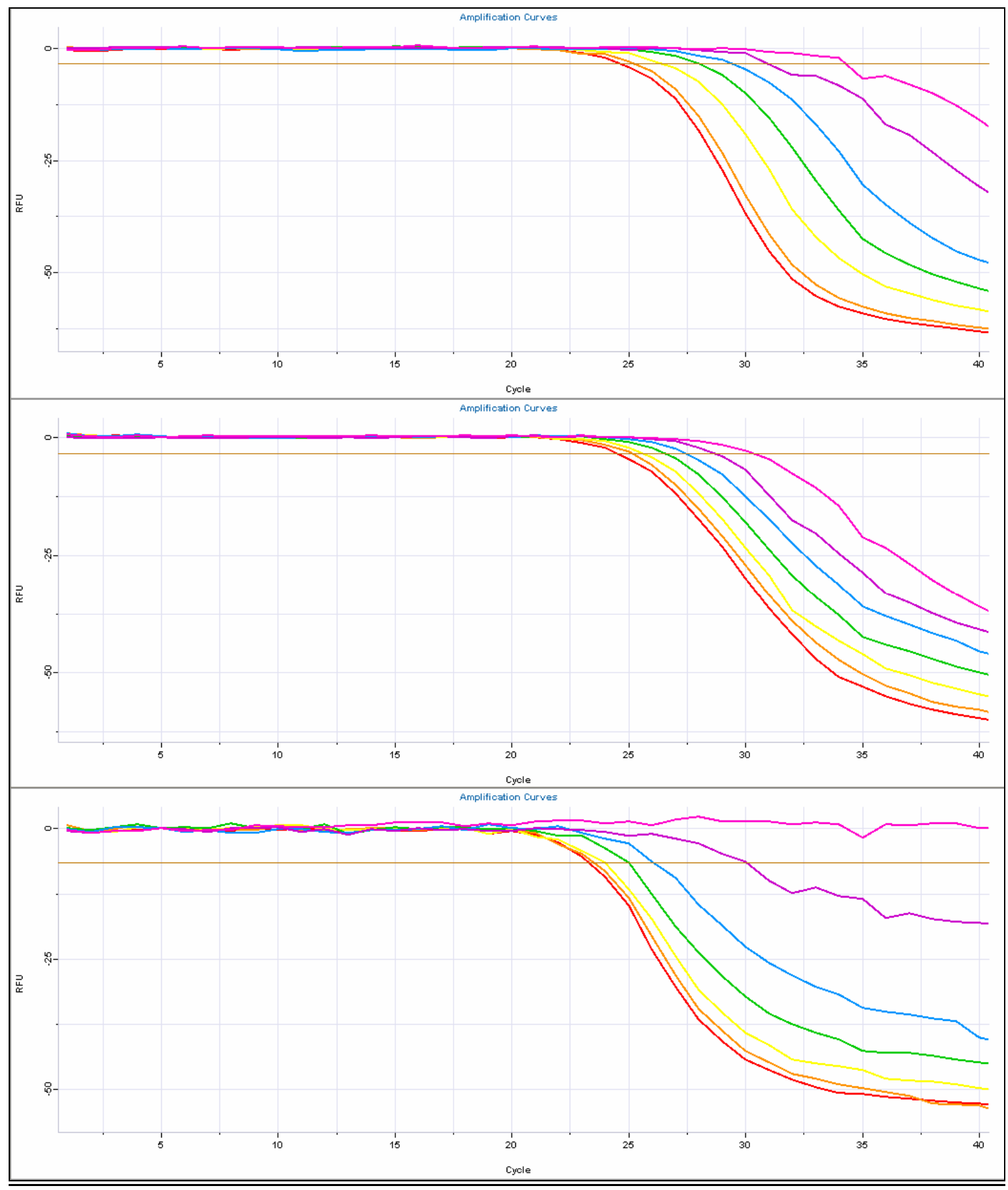

Figure 5-10a: Plexor HY amplification curves plotting RFU versus cycle number for increasing EDTA concentrations. Changes in Autosomal (top), Y Chromosomal (middle) and IPC (bottom) curves at the following concentrations of EDTA: $0 \mathrm{mM}$ (red), $0.4 \mathrm{mM}$ (orange), $0.8 \mathrm{mM}$ (yellow), $1.2 \mathrm{mM}$ (green), $1.6 \mathrm{mM}$ (blue), $2 \mathrm{mM}$ (purple), $2.4 \mathrm{mM}$ (pink). 


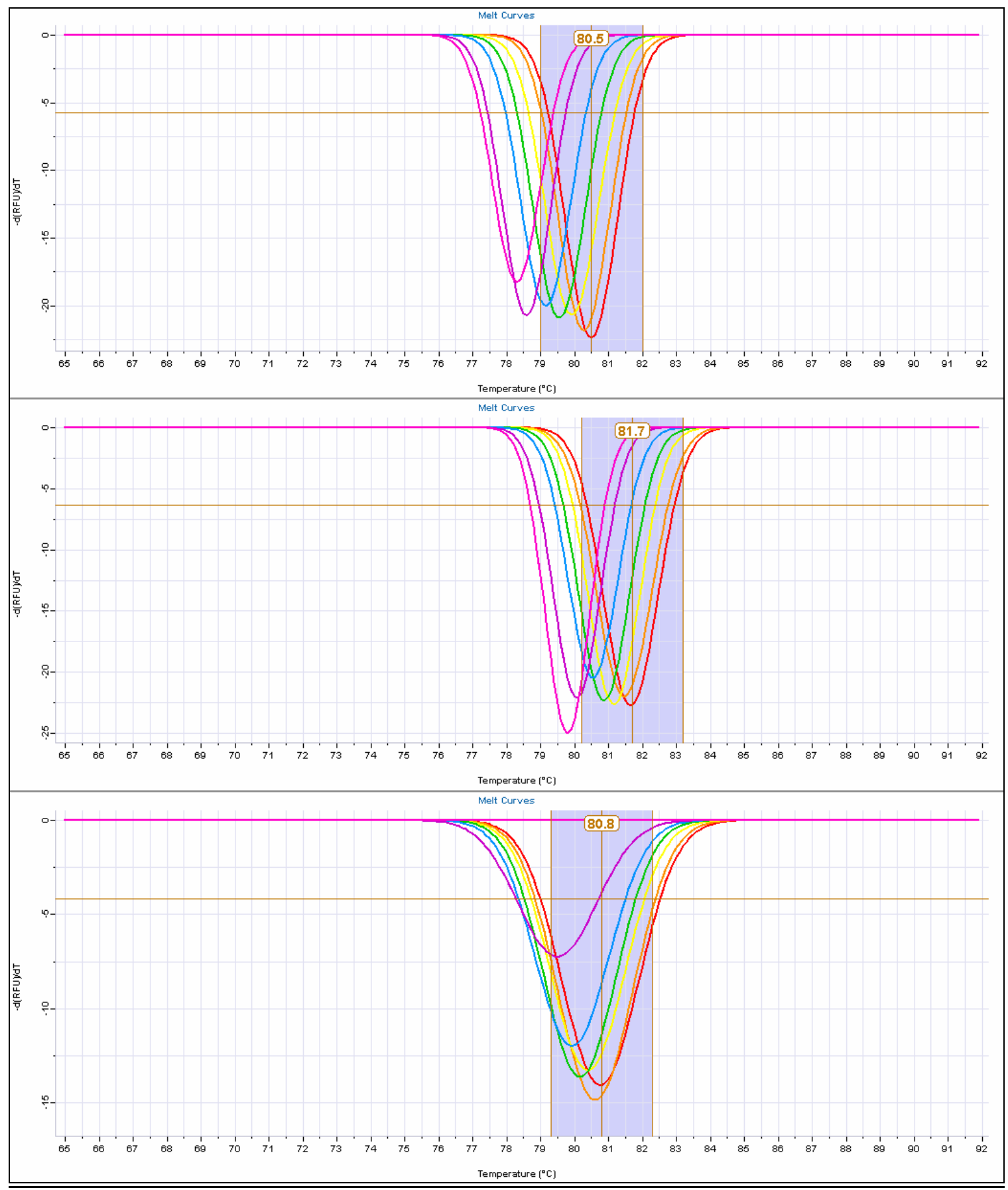

Plexor HY melt curves plotting the rate of change of the RFU with time versus temperature for increasing EDTA concentrations. Changes in Autosomal (top), Y Chromosomal (middle) and IPC (bottom) curves at the following concentrations of EDTA: $0 \mathrm{mM}$ (red), $0.4 \mathrm{mM}$ (orange), $0.8 \mathrm{mM}$ (yellow), $1.2 \mathrm{mM}$ (green), $1.6 \mathrm{mM}$ (blue), $2 \mathrm{mM}$ (purple), $2.4 \mathrm{mM}$ (pink). 


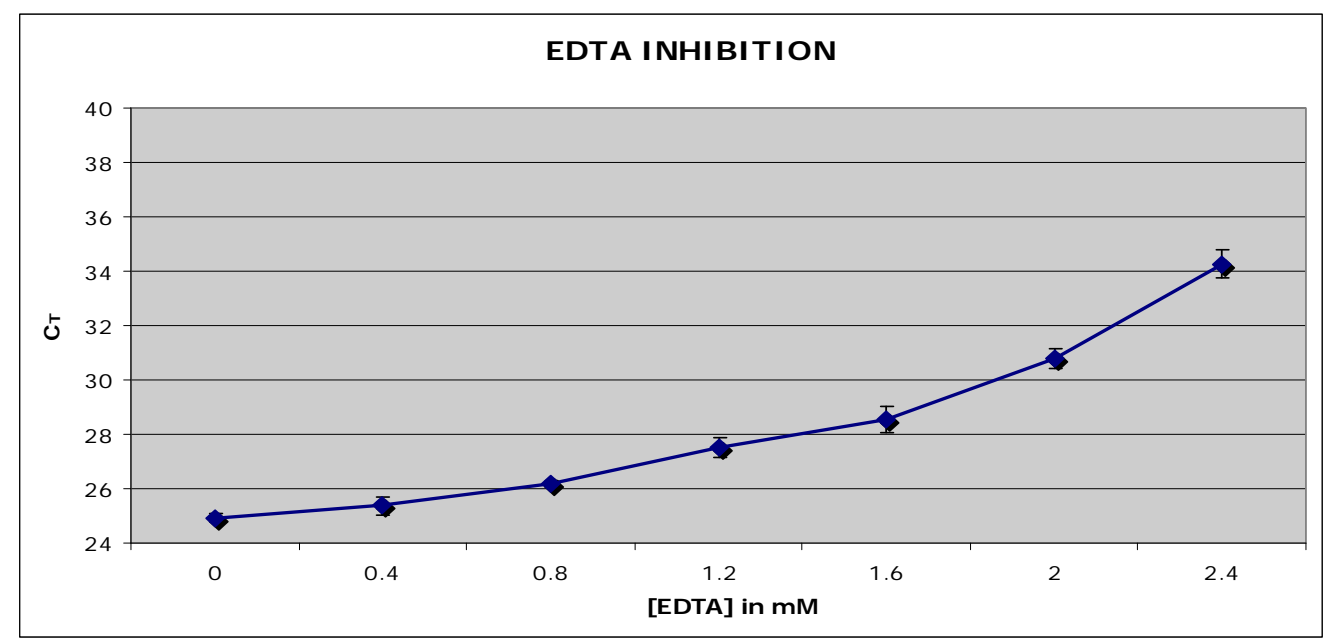

Figure 5-10c: $\mathrm{C}_{\mathrm{T}}$ versus increasing concentrations of EDTA inhibitor

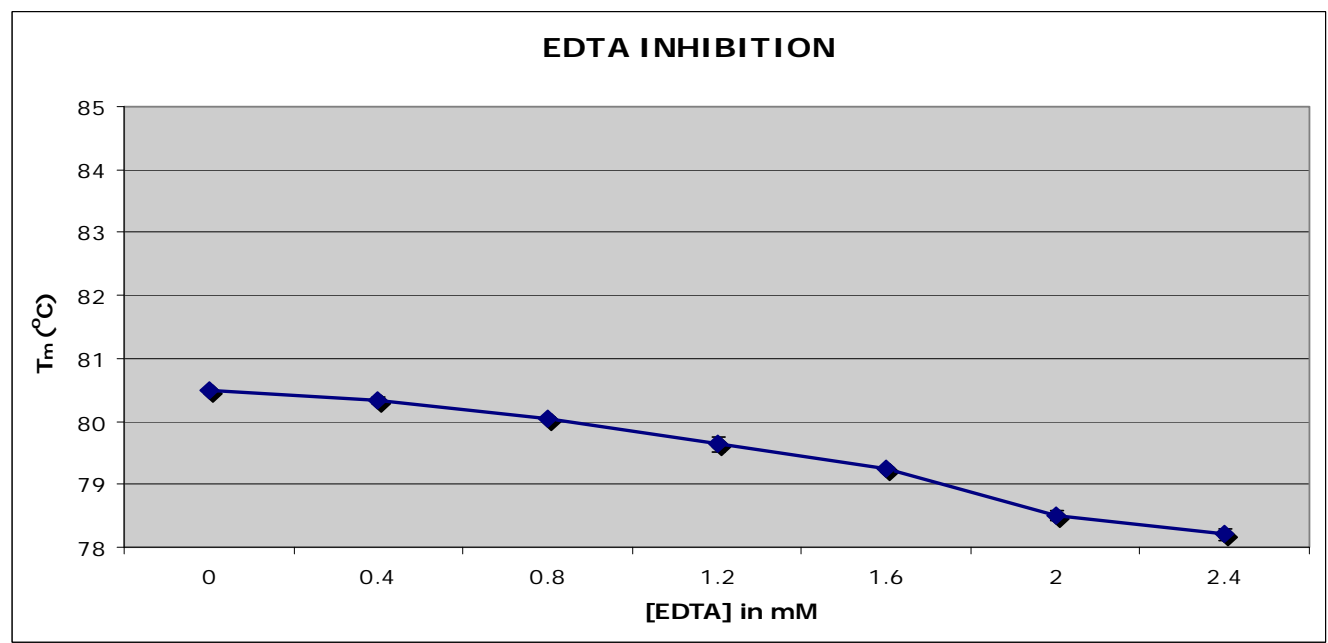

Figure 5-10d: $\mathrm{T}_{\mathrm{m}}\left({ }^{\circ} \mathrm{C}\right)$ versus increasing concentrations of EDTA inhibitor

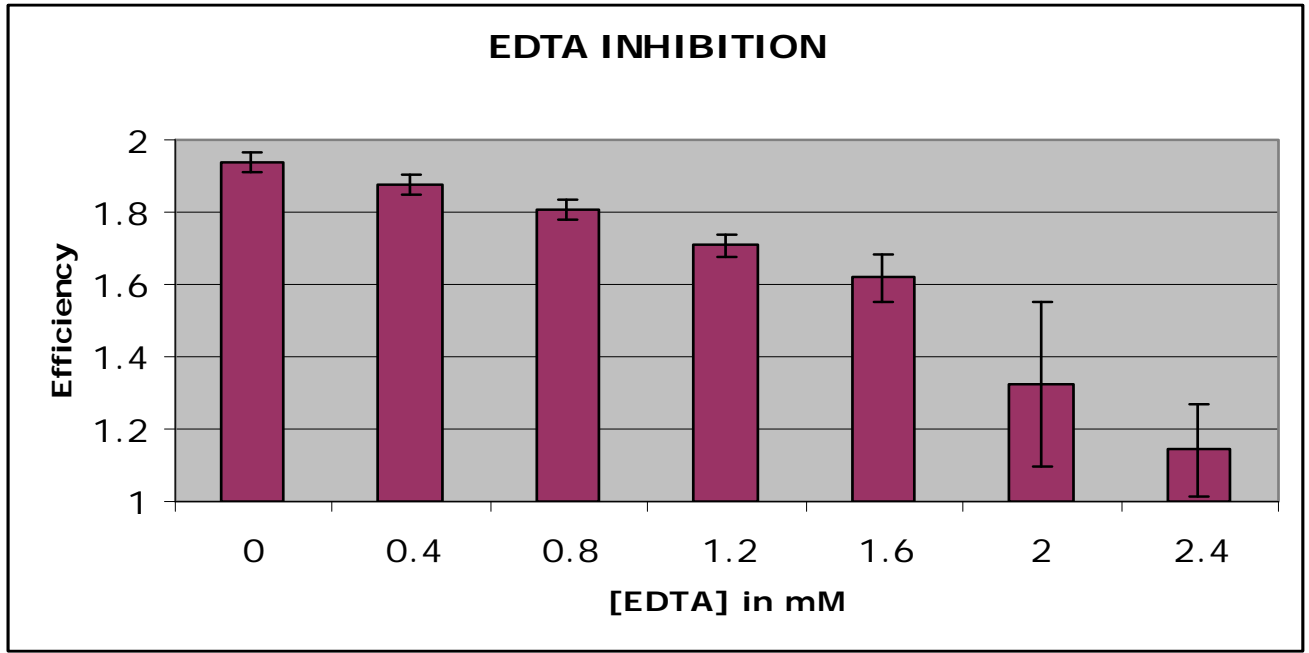

Figure 5-10e: Efficiency versus increasing concentrations of EDTA inhibitor 
the DNA rather than disruption. The $\mathrm{T}_{\mathrm{m}}$ range was approximately $3^{\circ} \mathrm{C}$ (Figure $5-11 \mathrm{~d}$ ). The amplification efficiency values for guanidinium were significantly low at $7.5 \mathrm{ug} / \mathrm{ul}$ (Figure 5-10e). Overall, the results indicate a mixed mode of inhibition with effects on Taq amplification efficiency as well as DNA binding.

Guanidinium is similar in structure to urea and are both denaturants; however, the results show opposing effects. Whereas urea is neutral at physiological $\mathrm{pH}$ 's, guanidinium is protonated and as a result could possibly be shielding the phosphates, keeping the structure intact instead of denaturing the DNA molecule. Previous research shows that higher temperatures are required to denature DNA with increasing concentrations of guanidinium (Huang, 1968). 


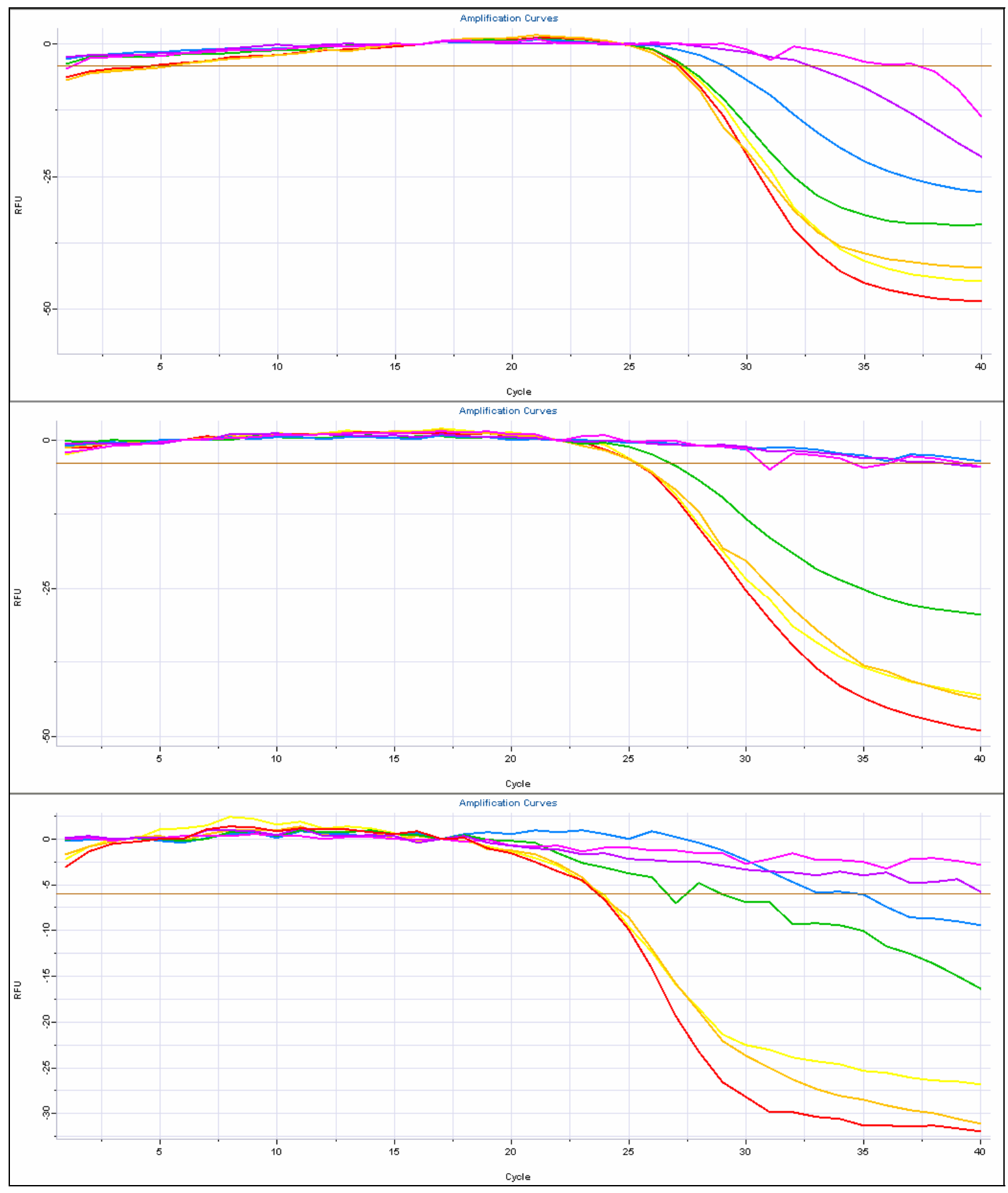

Figure 5-11a: Plexor HY amplification curves plotting RFU versus cycle number for increasing guanidinium concentrations. Changes in Autosomal (top), Y Chromosomal (middle) and IPC (bottom) curves at the following concentrations of guanidinium: Oug (red), 1.5ug (orange), 3ug (yellow), 4.5ug (green), 6ug (blue), 7.5ug (purple), 9ug (pink). 


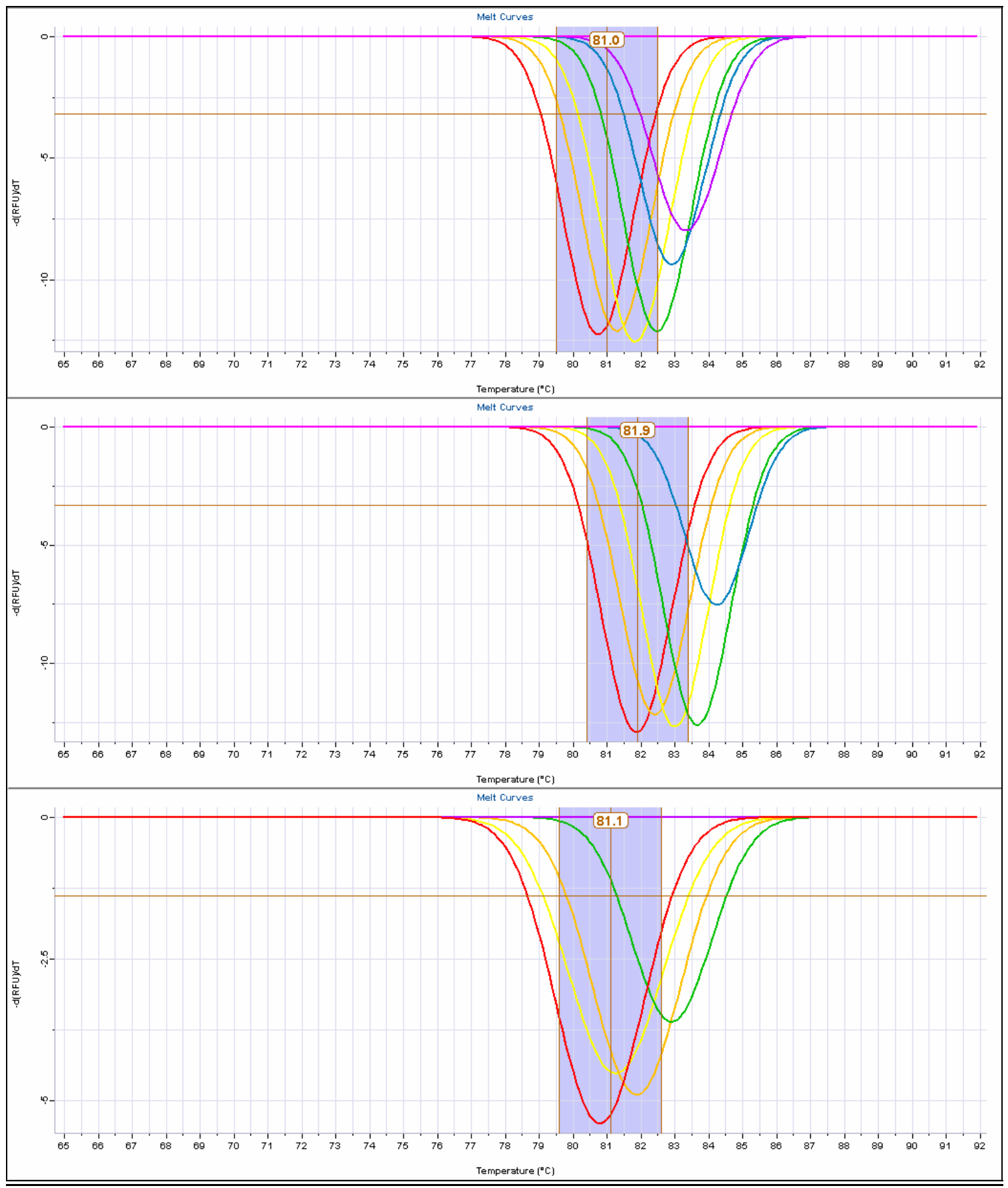

Figure 5-11b: Plexor HY melt curves plotting the rate of change of the RFU with time versus temperature for increasing guanidinium concentrations. Changes in Autosomal (top), Y Chromosomal (middle) and IPC (bottom) curves at the following concentrations of guanidinium: 0ug (red), 1.5ug (orange), 3 ug (yellow), 4.5ug (green), 6ug (blue), 7.5ug (purple), 9ug (pink). 


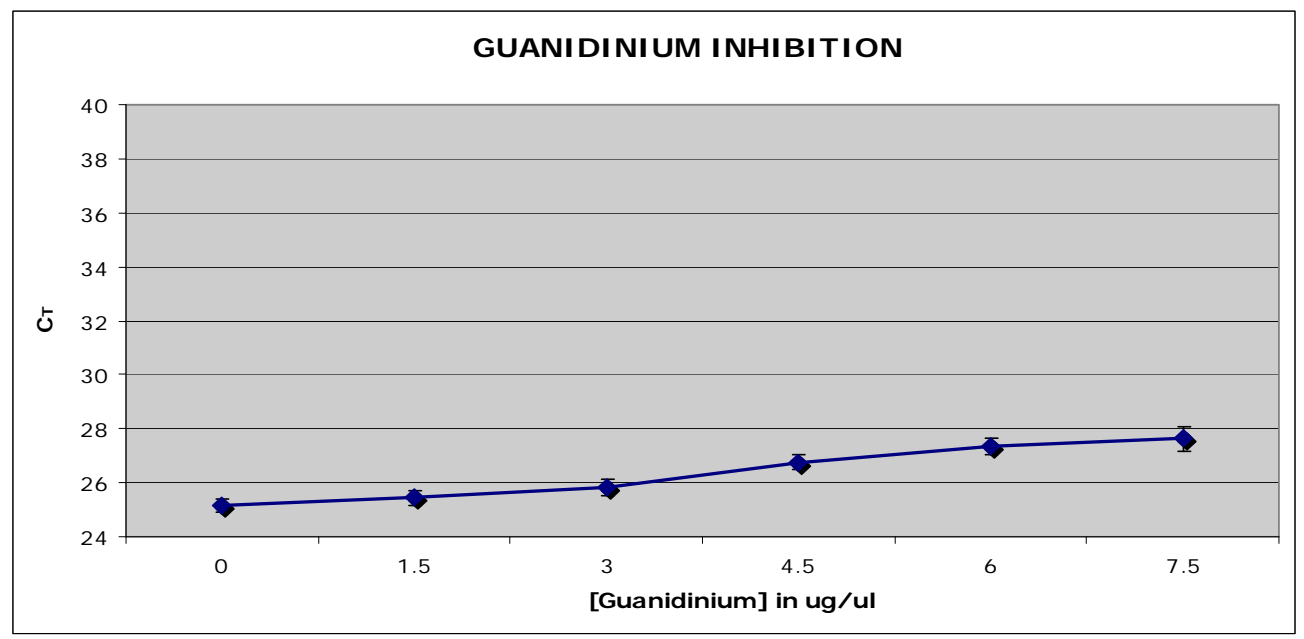

Figure 5-11c: $\mathrm{C}_{\mathrm{T}}$ versus increasing concentrations of guanidinium inhibitor

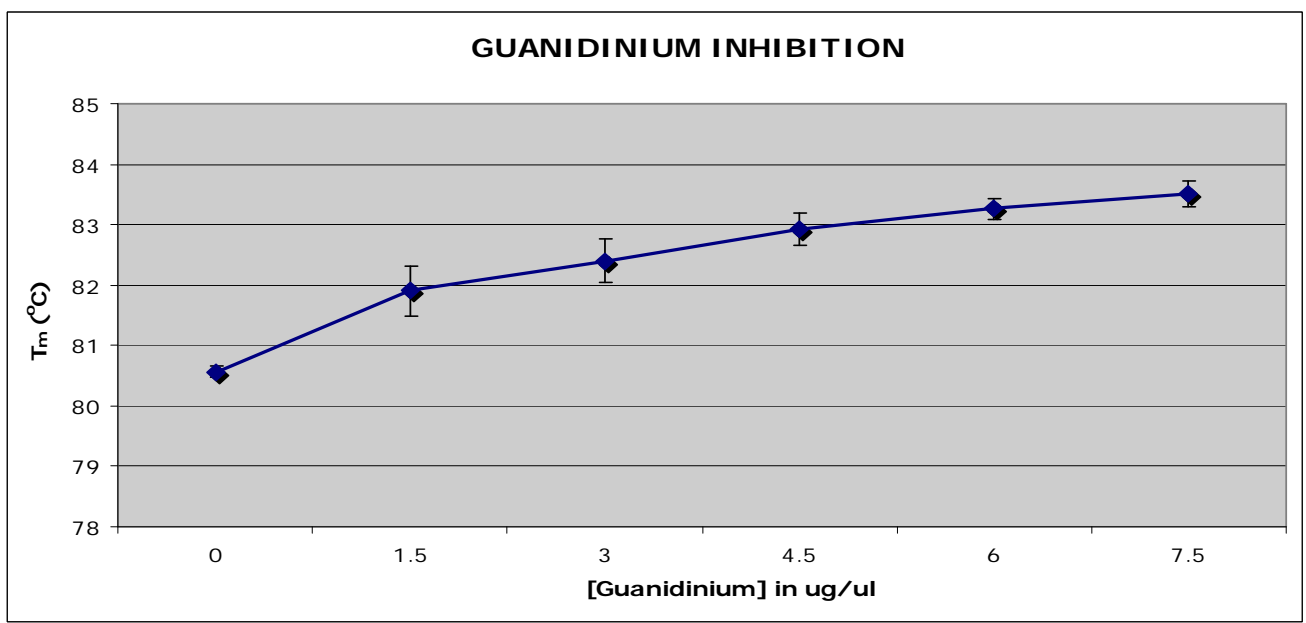

Figure 5-11d: $\mathrm{T}_{\mathrm{m}}\left({ }^{\circ} \mathrm{C}\right)$ versus increasing concentrations of guanidinium inhibitor

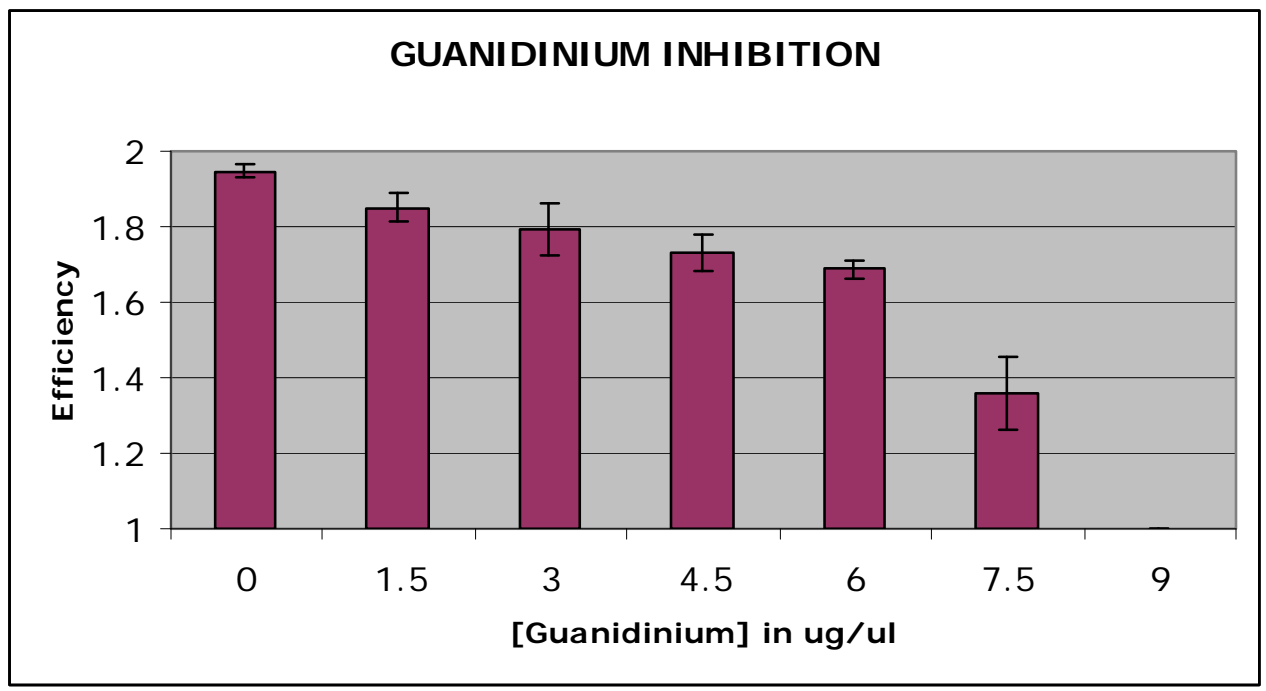

Figure 5-11e: Efficiency versus increasing concentrations of guanidinium inhibitor 


\subsection{Short Tandem Repeat (STR) Analysis}

Calcium STR results showed a generic loss of larger alleles. This effect is commonly seen in all inhibitors because smaller loci have more reistance to inhibitor binding. This was also consistent with the inhibitor binding to the Taq polymerase.

For humic acid, the STR results produced both sequence specific and size dependent allele dropout, showing loss of the same loci found with calcium as well as Amelogenin and D3S1358. Humic acid binding DNA is a possible factor.

Collagen STR results showed effects on the polymerase and locus specific DNA binding. When compared to humic acid, collagen affected more loci. Interestingly phenol and EDTA produced drop-out of the same loci as collagen.Urea produced allele drop-out of two additional loci. These results are consistent with a mixed mode effect - inhibitor binding both Taq and DNA.

Table 5-1 shows the effects of allele drop-out at various concentrations of some of the previously studied inhibitors. 
Table 5-1: STR effects on qPCR inhibitors

\begin{tabular}{|l|l|l||}
\hline INHIBITOR & CONCENTRATION & \multicolumn{1}{c||}{ ALLELE DROP-OUT } \\
\hline Calcium & $1 \mathrm{mM}$ & D6, TPOX, D18, CSF, FGA, PD, PE \\
\hline Calcium & $2 \mathrm{mM}$ & D6, TPOX, D18, CSF, FGA, PD, PE \\
\hline Humic Acid & $16 \mathrm{ng} / \mathrm{ul}$ & AM, D3, D18, CSF, FGA, PD, PE \\
\hline Humic Acid & $24 \mathrm{ng} / \mathrm{ul}$ & AM, D3, D18, CSF, FGA, PD, PE \\
\hline Collagen & $16 \mathrm{ng} / \mathrm{ul}$ & AM, D3, D7, TPOX, D18, CSF, FGA, PD, PE \\
\hline Collagen & $24 \mathrm{ng} / \mathrm{ul}$ & AM, D3, D7, TPOX, D18, CSF, FGA, PD, PE \\
\hline Phenol & $3.3 \mathrm{mg} / \mathrm{ul}$ & AM, D3, D7, TPOX, D18, CSF, FGA, PD, PE \\
\hline Phenol & $4.2 \mathrm{mg} / \mathrm{ul}$ & AM, D3, D7, TPOX, D18, CSF, FGA, PD, PE \\
\hline Urea & $200 \mathrm{mM}$ & $\begin{array}{l}\text { AM, D3, D2, D7, D8, D16, TPOX, D18, CSF, FGA, } \\
\text { PD, PE }\end{array}$ \\
\hline Urea & $600 \mathrm{mM}$ & $\begin{array}{l}\text { AM, D3, D2, D7, D8, D16, TPOX, D18, CSF, FGA, } \\
\text { PD, PE }\end{array}$ \\
\hline EDTA & $3 \mathrm{mM}$ & AM, D3, D16, TPOX, D18, CSF, FGA, PD, PE \\
\hline EDTA & $9 \mathrm{mM}$ & AM, D3, D16, TPOX, D18, CSF, FGA, PD, PE \\
\hline
\end{tabular}




\section{CONCLUSION}

The purpose of this research is to provide the forensic community with information addressing the problems associated with inhibition of various source contaminants commonly found in crime scenes. Polymerase chain reaction inhibition can most easily be studied using qPCR assays with known concentrations of DNA template and inhibitor. These data will aid in the careful analysis of forensic samples by identifying binding mechanisms through changes in amplification and melt curves, as well as provide complementary information produced by the amplification of internal control sequences.

In analysis of inhibition by qPCR, several mechanisms have been observed using a variety of known PCR inhibitors that affect the reaction in at least one manner. Inhibitors such as calcium and tannic acid seem to interfere with the Taq polymerase through the magnesium cofactor. The addition of Taq or magnesium has proven to relieve inhibition but the extent to which this method will help has yet to be determined (Opel et al., 2010). For those inhibitors that bind to the DNA by intercalating or groove binding, the sequence of the amplicon as well as molecular structure are likely to determine the level of inhibition. Melanin and bile salts interfere with the DNA molecule through the formation of complexes. Both inhibitors have no effect on Taq addition (Opel et al., 2010). The remaining inhibitors experienced a mixed mode effect by interfering with both the DNA and Taq. Although these inhibitors show similar modes of inhibiton, their inhibition technique may vary. Urea and guanidinium, for example, are similar in structure and bind to both DNA and Taq polymerase; however, one facilitates 
denaturation and the other promotes hydrogen bonding of the complemntary base pairs, keeping the dsDNA in tact.

In commercial kits for qPCR assays, addition of BSA to the reaction mix reduces inhibition and is one of the few treatments that does not dilute the sample. Other treatments, including purification with silica based spin columns or rinsing the sample with $\mathrm{NaOH}$ result in a loss of DNA template (Chung, 2004). Purification of the sample with low melting temperature agarose can remove inhibitors but the DNA template is diluted by half (Chung, 2004). Therefore, for samples that are highly degraded or of low template DNA, these methods are not feasible. Knowledge of the type of inhibitor present, based on the qPCR data, will also help analysts select the method which would effectively remove the inhibitors without compromising the amount of DNA or further compromising the PCR reaction. Future research in this area could begin to classify inhibitors based on specific treatment methods. A standard protocol could therefore be generated and implemented based on the analysis of pretreated forensic samples.

The application of qPCR to detect PCR inhibition can provide useful data for laboratories confronted with such samples. Inhibitors such as calcium, humic acid and collagen affect STR amplification in different ways. Depending on the type of inhibition, different effects can be seen in the STR results. Sequence specific inhibition and allele dropout is often seen with inhibitors that bind DNA. However, allele drop-out does not necessarily mean inhibition, as degraded and low template samples can produce similar results. Detection of inhibition using STR results may not always be possible, which is why qPCR data and melt curve analysis can be so useful when poor results are seen. The identification of inhibition will also help the analyst determine the appropriate STR kits 
for these challenged samples, such as MiniSTRs and other newer more robust STR multiplexes.

The results presented in this thesis demonstrate that melt curve analysis combined with qPCR can aid in the prediction of PCR inhibition. In the future, the effects of inhibition will continue to need to be assessed through qPCR assays and STR analysis. The effect of inhibitors on low copy and artificially degraded DNA should intensively be studied, as well as the effect of inhibition and degradation on the analysis of mixtures. This information, will positively impact the forensic community by providing tools and guidelines for the improved analysis of human DNA from compromised samples. 


\section{REFERENCES}

Abd-Elsalam KA. Bioinformatic tools and guideline for PCR primer design. Afr. J. Biotechnology 2003; 2(5): 91-95.

Al-Soud WA, Rådström P. Purification and Characterization of PCR-Inhibitory Components in Blood Cells. J. Clin. Microbiol. 2001; 39(2): 485-93.

Al-Soud WA, Rådström P. Capacity of Nine Thermostable DNA Polymerases To Mediate DNA Amplification in the Presence of PCR-Inhibiting Samples. Appl. Environ. Microbiol. 1998; 64(10): 3748-53.

Akane A, Matsubara K, Nakamura H, Takahashi S, Kimura K. Identification of the heme compound copurified with deoxyribonucleic acid (DNA) from bloodstains, a major inhibitor of polymerase chain reaction (PCR) amplification. J. Forensic Sci. 1994; 39:362-372.

Aronson J. DNA fingerprinting on trial: the dramatic early history of a new forensic technique. Endeavour 2005; 29 (3):126-131.

Altria KD. Capillary electrophoresis guidebook: Principles, operation, and applications. Humana Press: Totowa, NJ, USA 1995.

Behzadbehbahani A, Klapper PE, Vallely PJ, Cleator GM. Detection of BK virus in urine by polymerase chain reaction: a comparison of DNA extraction methods. J. Virol. Methods 1997; 67:161-166.

Bessetti J. An Introduction to PCR Inhibitors. Profiles in DNA 2007; 10(1).

Bickley J, Short JK, McDowell G, Parkes HC. Polymerase chain reaction (PCR) detection of Listeria monocytogenes in diluted milk and reversal of PCR inhibition caused by calcium ions. Lett. Appl. Microbiol. 2008; 22 (2): 153-158.

Bisschop PH, Bandsma RH, Stellaard F, ter Harmsel A, Meijer AJ, Sauerwein HP, Kuipers F, Romijn JA. Low-fat, high-carbohydrate and high-fat, low-carbohydrate diets decrease primary bile acid synthesis in humans. Am. J. Clin Nutr. 2004; 79(4): 570-6.

Botstein D, White R, Skulnick M, Davis RW. Construction of a genetic linkage map in man using restriction fragment length polymorphisms. Am. J. Hum. Genet. 1980; 32: 314-31.

Bourke MT, Scherczinger CA, Ladd C, Lee HC. NaOH Treatment to Neutralize Inhibitors of Taq Polymerase. J. Forensic Sci. 1999; 44(5): 1046-50. 
Braid MD, Daniels LM, Kitts CL. Removal of PCR Inhibitors from Soil DNA by Chemical Flocculation. J. Microbiol. Meth. 2003; 52: 389-393.

Budowle B, Moretti TR, Baumstark AL, Defenbaugh DA, Keys KM. Population data on the thirteen CODIS core short tandem repeat loci in African Americans, U.S. Caucasians, Hispanics, Bahamians, Jamaicans and Trinidadians. J. Forensic Sci. 1999; 44(6):127786.

Bustin SA. Absolute quantification of mRNA using real-time reverse transcription polymerase chain reaction. J. Mol. Endocrinol. 2000; 25:169-193.

Butler JM. Forensic DNA Typing, Second Edition: Biology, Technology, and Genetics of STR Markers; Elsevier Academic Press: London, UK, 2005.

Butler JM, Shen Y, McCord BR. The Development of reduced size STR Amplicons as Tools for the Analysis of Degraded DNA. J. Forensic Sci. 2003; 48(5): 1054-64.

Chargaff E. Structure and function of nucleic acids as cell constituents. Fed. Proc. 1951; 10: 654-659.

Chung DT. Ph.D. Dissertation. Ohio University, 2004.

de Kok JB, Hendriks JCM, van Solinge WW, Willems HL, Mensink EJ, Swinkels DW. Use of Real-Time Quantitative PCR to Compare DNA Isolation Methods. Clin. Chem. 1998; 44(10): 2201-4.

de Lomas JG, Sunzeri FJ, Busch MP. False-negative results by polymerase chain reaction due to contamination by glove powder. Transfusion 1992; 32(1): 83-85.

Dieffenbach CW, Lowe TM, Dveksler GS. General concepts for PCR primer design. PCR Methods Appl. 1993; 3(3):S30-7.

Demeke T, Jenkins GR. Influence of DNA extraction methods, PCR inhibitors and quantification methods on real-time PCR assay of biotechnology-derived traits. Anal. Bioanal. Chem. 2010; 396:1977-1990.

Dimo-Simonin N, Brandt-Casadevall C. Evaluation and usefulness of reverse dot blot DNA-PolyMarker typing in forensic case work. Forensic Sci. Int. 1996; 81:61-72.

Dobi A, Agoston DV. Submillimolar levels of calcium regulates DNA structure at the dinucleotide repeat (TGyAC)n. Proc. Natl. Acad. Sci. USA. 1998; 95: 5981-5986.

Duncan GT, Balamurugan K, Budowle B, Smerick J, Tracey ML. Microvariation at the human D1S80 locus. Int. J. Legal Med. 1997; 110:150-154. 
Eckhart L, Bach J, Ban J, Tschachler E. Melanin binds reversibly to thermostable DNA polymerase and inhibits its activity. Biochem. Biophys. Res. Commun. 2000; 271: 726-30.

Eilert KD, Foran DR. Polymerase Resistance to Polymerase Chain Reaction Inhibitors in Bone. J. Forensic Sci. 2009; 54(5): 1001-7.

Erlich HA. PCR Technology. Stockton Press: New York. 1989

Frackman S, Ekenberg S, Hoffmann K, Krenke B, Sprecher C, Storts D. Plexor ${ }^{\mathrm{TM}}$ Technology: A New Chemistry for Real-Time PCR. Promega Notes, No. 90, 2005.

Goldar A, Sikorav JL. DNA renaturation at the water-phenol interface. Eur. Phys. J. E. 2004; 14:211-39.

Higuchi R, Fockler C, Dollinger G, Watson R. Kinetic PCR: Real time monitoring of DNA amplification reactions. Biotechnology 1993; 11:1026-1030.

Huang PC. Effect of guanidinium ion on DNA denaturation and renaturation. Biochem. Biophys. Res. Commun. 1968; 33(3):384-90.

Huggett JF, Novak T, Garson JA, Green C, Morris-Jones SD, Miller RF, Zumla A. Differential susceptibility of PCR reactions to inhibitors: an important and unrecognised phenomenon. 2008, 1:70. http://www.biomedcentral.com/1756-0500/1/70

Jeffreys AJ, Wilson V, Thein SL. Hypervariable 'minisatellite' regions in human DNA. Nature 1985; 314, 67 - 73 (a)

Jeffreys AJ, Brookfield JF, Semeonoff R. Positive identification of an immigration testcase using human DNA fingerprints. Nature 1985; 317:818-819. (b)

Katcher HL, Schwartz I. A distinctive property of Tth DNA polymerase: Enzymatic amplification in the presence of phenol. BioTechniques 1994; 16: 84-92.

Kim S, Labbe RG, Ryu S. Inhibitory Effects of Collagen on the PCR for Detection of Clostridium perfringens. Appl. Environ. Microbiol. 2000; 66(3): 1213-5.

Kirby LT. DNA Fingerprinting; Stockton Press: New York, NY, 1990.

Kontanis EJ, Reed FA. Evaluation of Real-Time PCR Amplification Efficiencies to Detect PCR Inhibitors. J. Forensic Sci. 2006; 51(4): 795-804.

Kreader CA. Relief of Amplification Inhibition in PCR with Bovine Serum Albumin or T4 Gene 32 Protein. . Appl. Environ. Microbiol. 1996; 62(3): 1102-1106. 
Krenke, B., Nassif, N., Sprecher, C., Knox, S., Schwandt, M., Storts, D.R. Developmental Validation of a Real-Time PCR Assay for the Simultaneous Quantification of Total Human and Male DNA. For. Sci. Int. Genet. 2008; 3: 14-28.

Lantz PG, Matsson M, Wadströmb T, Rådström P. Removal of PCR inhibitors from human faecal samples through the use of an aqueous two-phase system for sample preparation prior to PCR. J. Microbiol. Meth. 1997; 28(3): 159-67.

LaSalle HE. M.S. Thesis. Florida International University, 2009.

Maher N, Dillon HK, Vermund SH, Unnasch TR. Magnetic Bead Capture Eliminates PCR Inhibitors in Samples Collected from the Airborne Environment, Permitting Detection of Pneumocystis carinii DNA. Appl Environ. Microbiol. 2001; 67(1): 449-452.

Makowski GS, Davis EL, Hopfer SM. Amplification of Guthrie Card DNA: Effects of Guanidine Thiocyanate on binding of Natural Whole Blood PCR Inhibitors. J. Clin. Lab. Anal. 1997; 11: 87-93.

Morrison TM, Weis JJ, Wittwer CT. Quantification of low-copy transcripts by continuous SYBR green I monitoring during amplification. Biotechniques 1998; 24:95462.

Mrevlishvili GM, Svintradze DV. Complex between triple helix of collagen and double helix of DNA in aqueous solution. Int. J. Biol. Macromol. 2005; 35(5): 243-5.

Mullis K, Ferr F, Gibbs, R. Polymerase Chain Reaction. Birkhäuser: Boston, MA, 1994.

Mullis KB. The unusual origin of the polymerase chain reaction. Sci. Am.1990; 56-65.

Nicklas JA, Buel E. Development of an Alu-based, Real-Time PCR Method for Quantitation of Human DNA in Forensic Samples. J. Forensic Sci. 2003; 48(5).

Opel K, Chung D, McCord BR. A Study of PCR Inhibition Mechanisms Using Real Time PCR. J. Forensic Sci. 2010; 55(1): 25-33.

Parson W, Niederstätter H, Lindinger A, Gill P. Y-STR analysis on DNA mixture samples--results of a collaborative project of the ENFSI DNA Working Group. For. Sci. Int. Genet. 2008; 2(3): 238-42.

Powell HA, Gooding CM, Garrett SD, Lund BM, Mckee RA. Proteinase inhibition of the detection of Listeria monocytogenes in milk using the polymerase chain reaction. Lett. Appl. Microbiol. 1994; 18: 59-61.

Promega Corporation. Plexor ${ }^{\circledR H Y}$ System for the Corbett Rotor-Gene 6000 Series Detection System Technical Manual. 2009. (a)

Promega Corporation. PowerPlex®16 HS System Technical Manual. 2009. (b) 
Promega Corporation. PowerPlex®16 System Technical Manual. 2008.

Ramakers C, Ruijtera JM, Depreza RH, Moorman AF. Assumption-free analysis of quantitative real-time polymerase chain reaction (PCR) data. Neurosci Lett. 2003; 339(1): 62-6.

Robertson JM, Walsh-Weller J. An introduction to PCR primer design and optimization of amplification reactions. Methods Mol. Biol. 1998; 98:121-54.

Ririe KM, Rasmussen RP, Wittwer CT. Product differentiation by analysis of DNA melting curves during the polymerase chain reaction. Anal Biochem. 1997; 245(2): 15460.

Ruijter JM, van der Velden S, Ilgun A. LinRegPCR: Analysis of quantitative RT-PCR data [computer program]. Version 11.0. Heart Failure Research Center, Academic Medical Centre: Amsterdam, the Netherlands: 2009.

Saiki RK, Walsh PS, Levenson CH, Erlich HA. Genetic analysis of amplified DNA with immobilized sequence-specific oligonucleotide probes. Proc. Natl. Acad. Sci. USA.1989; 86:6230-6234.

Satoh Y, Takasaka N, Hoshikawa Y, Osaki M, Ohfuji S, Kaibara N, Kurata T, Sairenji T. Pretreatment with Restriction Enzyme or Bovine Serum Albumin for Effective PCR Amplification of Epstein-Barr Virus DNA in DNA Extracted from Paraffin-Embedded Gastric Carcinoma Tissue. J. Clin. Microbiol. 1998; 36 (11): 3423-3425.

Scholz M, Giddings I, Pusch CM. A polymerase chain reaction inhibitor of ancient hard and soft tissue DNA extracts is determined as human collagen type I. Anal. Biochem. 1998; 259(2): 283-6.

Johnson SC, Sherrill CB, Marshall DJ, Moser MJ, Prudent JR. A third base pair for the polymerase chain reaction: Inserting isoC and isoG. Nucleic Acids Res. 2004; 32 (6) 1937-1941.

Seto H, Tomasz A. Early Stages in DNA Binding and Uptake During Genetic Transformation of Pneumococci (divalent cation complexing agents/cell surface sites/nucleolytic splitting). Proc. Natl. Acad. Sci. USA. 1974; 71(4): 1493-1498.

Sullivan KM, Mannucci A, Kimpton CP, Gill P. A rapid and quantitative DNA sex test: fluorescence-based PCR analysis of X-Y homologous gene amelogenin. BioTechniques 1993; 15: 637-41.

Sutlovic D, Gamulin S, Definis-Gojanovic M, Gugic D, Andjelinovic S. Interaction of 
humic acids with human DNA: proposed mechanisms and kinetics. Electrophoresis 2008; 29(7):1467-72.

Tebbe CC, Vahjen W. Interference of humic acids and DNA extracted directly from soil in detection and transformation of recombinant DNA from bacteria and a yeast. Appl. Environ. Microbiol. 1993; 59(8): 2657-65.

Thoss V, Baird MS, Lock MA, Courty PV. Quantifying the phenolic content of freshwaters using simple assays with different underlying reaction mechanisms. $J$. Environ. Monit. 2002; 4(2): 270-5.

Tsai Y, Olson BH. A Rapid Method for Separation of Bacterial DNA from Humic Substances in Sediments for Polymerase Chain Reaction. Appl. Environ. Microbiol. 1992; 58(7): 2292-2295.

Wadowsky RM, Laus S, Libert T, States SJ, Ehrlich GD. Inhibition of PCR-Based Assay for Bordetella pertussis by Using Calcium Alginate Fiber and Aluminum Shaft Components of a Nasopharyngeal Swab. J. Clin. Microbiol. 1994; 32(4): 1054-7.

Wiedbrauk DL, Werner JC, Drevon AM. Inhibition of PCR by Aqueous and Vitreous Fluids. J. Clin. Microbiol. 1995; 33(10): 2643-2646.

Wilhem J, Hahn M, Pingoud A. Influence of DNA target melting behavior on real-time PCR quantification. Clin. Chem. 2000; 46(11):1738-1743.

Wilson I. Inhibition and Facilitation of Nucleic Acid Amplification. Appl. Environ. Microbiol. 1997; 63(10): 3741-3751.

Wyman AR, White R. A highly polymorphic locus in human DNA. Proc. Nati. Acad. Sci. USA 1980; 77(11):6754-6758.

Yang D, Eng B, Waye JS, Dudar JC, Saunders SR. Improved DNA extraction from ancient bones using silica based spin columns. Am J Phys Anthropol 1998; 105:539-43.

Yoshii T, Tamura K, Taniguchi T, Akiyama K, Ishiyama I. Water-soluble eumelanin as a PCR-inhibitor and a simple method for its removal. Nippon Hoigaku Zasshi 1993; 47(323): 329.

Zhou L, Isenberg JS, Cao Z, Roberts DD. Type I collagen is a molecular target for inhibition of angiogenesis by endogenous thrombospondin-1. Oncogene 2006; 25 : 53645 .

Zipper H, Buta C, Lämmle K, Brunner H, Bernhagen J, Vitzthum F. Mechanisms 
underlying the impact of humic acids on DNA quantification by SYBR Green I and consequences for the analysis of soils and aquatic sediments. Nucleic Acids Res. 2003; 31(7): e39. 


\section{APPENDICES}

\section{Appendix A \\ Protocol: Buccal Swab Extraction}

Purpose

To extract and purify human DNA from buccal swab samples

Safety

All laboratory safety procedures will be complied with during this procedure.

Reagents

PCR ddH2O

Stain Extraction Buffer

Dithiothreitol

Proteinase K (600U)

Phenol/Chloroform/Isoamyl Alcohol (25:24:1) (PCIA)

$5 \%$ Bleach solution

ddH2O

Supplies

Wire cutters

Weighing papers or boats.

100-1000 $\mu \mathrm{L}$ pipettor

$10-1000 \mu \mathrm{L}$ barrier pipet tips

$10-100 \mu \mathrm{L}$ pipettor

$10-100 \mu \mathrm{L}$ pipet tips

$0.5-10 \mu \mathrm{L}$ pipettor

$10 \mu \mathrm{L}$ pipet tips

$2 \mathrm{~mL}$ spin basket compatable tubes and spin baskets

Microcon YM-30 spin columns

$15 \mathrm{~mL}$ capped conical bottom tubes

gloves

Kimwipes

Equipment

Temperature-controlled water bath set at 56oC

Sample tube holder

Microcentrifuge

Analytical balance

General

Procedure will be used for extracting and purifying human DNA from buccal swab samples.

Procedure will be used as necessary for research 
Gloves should be worn at all times

\section{Procedure}

1. Preparation of samples

a. Use the wire cutters to cut the end of a buccal swab.

b. Place the cut swab in the bottom of a $2 \mathrm{~mL}$ tube

c. Rinse wire cutter blades with ddH2O, bleach, and again with ddH2O between samples.

Use a new weighing paper for each sample.

2. Preparation of stain extraction buffer (SEB).

Weigh out $6 \mathrm{mg}$ of Dithiolthreitol (DTT) per mL of SEB to be used.

Add DTT to filtered SEB in $15 \mathrm{~mL}$ tube, and mix. May be stored up to two weeks in the refrigerator

3. Add $300 \mu \mathrm{L}$ of SEB to each swab sample and to one reagent blank

4. Add $2 \mu \mathrm{L}$ of Proteinase $\mathrm{K}$ to each sample and to the reagent blank.

5. Make sure caps are secure, and spin tubes down to ensure swab is covered by

the SEB solution.

6. Place tubes in tube holder, and place tube holder across water bath well so that the bottom of the tubes is covered by the water in the water bath

7. Incubate samples at $560 \mathrm{C}$ for 2-4 hours.

8. Remove tubes from holder, wipe dry with Kimwipes, and spin down in microcentrifuge.

9. Remove swab sample from tube and place in spin basket. Place spin basket back in tube, cap, and spin in microcentrifuge for 1 minute at $5000 \mathrm{rpm}$.

10. Remove spin basket from tube and throw away.

11. Add $300 \mu \mathrm{L}$ PCIA to each sample. Mix and spin at $5000 \mathrm{rpm}$ from 3 minutes.

12. Assemble Microcon filters by placing filter cup, blue side up, into $2 \mathrm{~mL}$ tubes.

Label with sample name/number.

13. Remove aqueous (top layer) from sample tube with $100 \mu \mathrm{L}$ pipettor and tips. Transfer to filter cup of Microcon (2-3 transfers). Make sure not to remove any of the organic layer.

14. Cap tubes and spin at $13000 \mathrm{rpm}$ for 12 minutes.

15. Dispose of filtrate. Add $200 \mu \mathrm{L}$ PCR H2O to filter cup, cap tubes, and spin at 13000 rpm for 12 minutes.

16. Prepare collection tubes by removing caps and labeling with sample name/number. 17. Add $60 \mu \mathrm{L}$ PCR H2O directly to filter cup, and invert cup into collection tube. Allow to sit for 3-5 minutes, and spin at $5000 \mathrm{rpm}$ for 2 minutes.

18. Remove filter cup and discard. Cap tubes at store at $4 \mathrm{oC}$ overnight before quantification. 


\section{Appendix B}

RNU2 sequence, GenBank accession number D00269

1 atcgcttctc ggcettttgg ctaagatcaa gtgtagtatc tgttcttatc agtttaatat

61 ctgatacgtc ctctatccga ggacaatata ttaaatggat ttttggagca gggagatgga

121 ataggagctt gctccgtcca ctccacgcat cgacctggta ttgcagtacc tccaggaacg

181 gtgcacc

\section{Appendix C}

Protocol: Alu-based Real-Time PCR Quantitation Method

Purpose

To quantify human DNA using Real Time PCR, Alu primers, and SYBR Green I dye.

Safety

All laboratory safety procedures will be complied with during this procedure. SYBR Green Dye is a mutagen/carcinogen. Appropriate handling procedures should be followed.

\section{Reagents}

SYBR Green I dye

DMSO

PCR ddH2O

10* ABI Buffer I

$\mathrm{MgCl} 2(25 \mathrm{mM})$

dNTPs $(2.5 \mathrm{mM})$

Amplitaq Gold or RampTaq hot start Taq polymerase $(5 \mathrm{U} / \mu \mathrm{L})$

Triton X100 (10\% solution)

Nonacetylated BSA $(20 \mathrm{mg} / \mathrm{mL})$

Alu primers, AluF and Alu82 R for small fragments, AluF and Alu124 for large fragments $(100 \mathrm{pmol} / \mu \mathrm{L})$

Quantiblot Standards (A-2ng, Calibrator $1-0.7 \mathrm{ng}$, Calibrator 2 - $0.1 \mathrm{ng}$ )

9948 Human Male DNA standard

\section{Supplies}

$0.2 \mathrm{~mL}$ flat cap PCR tubes

$2 \mathrm{~mL}$ flat cap microcentrifuge tubes

0.5-20 uL pipet tips

10-100 uL pipet tips

$100-1000 \mathrm{uL}$ pipet tips

$0.5-10 \mathrm{uL}$ pipettor

10-100 uL pipettor

100-1000 uL pipettor

gloves 


\section{Equipment}

0.5-10 uL pipettor

10-100 uL pipettor

100-1000 uL pipettor

Corbett RotorGene 3000 Real Time PCR or Corbett RotorGene 6000 rtPCR

36 sample rotor

\section{General}

Procedure will be used for preparing and quantifying extracted human genomic human DNA samples.

Procedure will be used as necessary for research

Gloves should be worn at all times

\section{Procedure}

1. Preparation of $0.5 \%$ working solution of SYBR Green I (Molecular Probes, Eugene, OR)

a. Take $1 \mu \mathrm{L}$ of $10,000 X$ concentrated SYBR Green I and add $199 \mu \mathrm{L}$ of DMSO. Prepare aliquots for future use.

2. Prepare DNA standards (or use Quantiblot Standard

a. Use 9948 DNA standard, dilute to $1,0.1,0.05 \mathrm{ng} / \mu \mathrm{L}$ for $\mathrm{LCN}$, or

b. Use 9948 as $10 \mathrm{ng} / \mu \mathrm{L}$ and dilute to $1 \mathrm{ng} / \mu \mathrm{L}$ and $0.1 \mathrm{ng} / \mu \mathrm{L}$ for buccal swab samples

3. Prepare DNA samples to be quantified: spin down before opening tubes.

4. Prepare 36 flat-top tubes, label them on the cap. Of the 36, label 2 sets of standards and 1 NTC (no template control).

5. Prepare and vortex Alu Mix for 36 samples:

Mix 542.0 $\mu \mathrm{L}$ PCR H2O, 84.0 $\mu \mathrm{L}$ 10X ABI Buffer I, 67.0 $\mu \mathrm{L}$ dNTPs, $50.0 \mu \mathrm{L} \mathrm{MgC12,} 14$ $\mu \mathrm{L}$ Taq polymerase, $8.4 \mu \mathrm{L}$ Alu Primer 1 (forward), $8.4 \mu \mathrm{L}$ Alu Primer 2 (large) or 60 (small) (reverse), $8.4 \mu \mathrm{L}$ TritonX 10\%, 8.4 $\mu \mathrm{L}$ SYBR green solution, $8.4 \mu \mathrm{L}$ BSA in 2 $\mathrm{mL}$ tube. Spin down before opening tube.

6. Pipet $19 \mu \mathrm{L}$ of Alu Mix into labeled PCR microtubes.

7. Add DNA

8. Add $1 \mu \mathrm{L}$ of standard or DNA sample* to appropriate tube.

9. Add $1 \mu \mathrm{L}$ ddH2O to NTC tube.

10. Vortex and mix.

11. Remove bubbles and spin down.

12. Turn on PC and turn on the Rotor Gene instrument

13. Clean accessible optics with cotton Q-tip and ethanol.

14. Place tubes on the appropriate wells of the carousel and place ring on top. Align carousel in the chamber. Screw in the cap with the red dot on top (3000) or snap ring in place (6000). Close cover.

15. Select Alu program and click "New” (for RG 6000, or SYBRGreen1 for RG3000)

Edit profile (if needed)

Denature $95^{\circ} \mathrm{C} 10$ minutes

Denature $96^{\circ} \mathrm{C} 10$ seconds 
Cycles 45

Cycling $95^{\circ} \mathrm{C} 15 \mathrm{~s}, 55^{\circ} \mathrm{C} 20 \mathrm{~s}, 72^{\circ} \mathrm{C} 20 \mathrm{~s}$ acquiring to

cycling on SYBR Green

Melt: Ramp from $72^{\circ} \mathrm{C}$ to $99^{\circ} \mathrm{C}$

Rising by $1^{\circ} \mathrm{C}$ each step

Wait for 45 seconds on first step, then

Wait for 5 seconds for each step afterwards

Acquire to Melt A on SYBR

16. Calibrate: check "Perform Calibration Before 1st acquisition".

17. Start run, go to correct folder to name an experiment with

"dateNamemethodsamples".

18. During run, fill the sample table: distinguish between DNA samples, no template

control (NTC), and standards. Fill in the given concentrations in the "given

concentration" column for standards and sample names for other sample tubes.

19. When experiment is completed, click Analysis-Quantitation-Show. New windows

will appear and a box in the middle - click Cancel.

Fill:

Slope Correct ON

Eliminate cycles before 5

Threshold default (0.03)

When the box comes up, click OK.

The standard curve, fluorescence threshold cycle $(\mathrm{Ct})$ and concentrations of samples will be calculated. The standard curve should have an efficiency and $r$ value close to 1.00.

You can choose to exclude those standard samples that cause give errors.

If raw data is good but not quantitated, click on the "quantitative settings" and decrease the threshold to $2 \%(1 \%)$.

20. Click "reports" in the upper left of the Quantitation window - Full Report - Send to Word and save.

21. Click Analysis-Melt.

Check if melting curve has two peaks (first is smaller).

* Dilute buccal swab samples 1:10 before quantification. 